$$
\begin{gathered}
\text { UNIVERSIDADE DE SÃO PAULO } \\
\text { FFCLRP - DEPARTAMENTO DE PSICOLOGIA E EDUCAÇÃO } \\
\text { PROGRAMA DE PÓS-GRADUAÇÃO EM PSICOLOGIA }
\end{gathered}
$$

\title{
Desenvolvimento neurocomportamental de bebês prematuros avaliados na fase de 32 a 37 semanas de idade pós-concepcional
}

\section{Paula Stefaneli Ziotti Gabriel}

Dissertação apresentada à Faculdade de Filosofia, Ciências e Letras de Ribeirão Preto da USP, como parte das exigências para a obtenção do título de Mestre em Ciências, Área: Psicologia.

Ribeirão Preto-SP 


\title{
UNIVERSIDADE DE SÃO PAULO \\ FFCLRP - DEPARTAMENTO DE PSICOLOGIA E EDUCAÇÃO \\ PROGRAMA DE PÓS-GRADUAÇÃO EM PSICOLOGIA
}

\section{Desenvolvimento neurocomportamental de bebês prematuros avaliados na fase de 32 a 37 semanas de idade pós-concepcional}

\author{
Paula Stefaneli Ziotti Gabriel
}

Orientadora: Prof ${ }^{a}$. Dr ${ }^{\mathrm{a}}$. Maria Beatriz Martins Linhares

Dissertação apresentada à Faculdade de Filosofia, Ciências e Letras de Ribeirão Preto da USP, como parte das exigências para a obtenção do título de Mestre em Ciências, Área: Psicologia.

Ribeirão Preto-SP 
AUTORIZO A REPRODUÇÃO E DIVULGAÇÃO TOTAL OU PARCIAL DESTE TRABALHO, POR QUALQUER MEIO CONVENCIONAL OU ELETRÔNICO, PARA FINS DE ESTUDO E PESQUISA, DESDE QUE CITADA A FONTE.

FICHA CATALOGRÁFICA

Gabriel, Paula Stefaneli Ziotti

Avaliação Neurocomportamental de bebês prematuros avaliados na fase de 32 a 37 semanas. Ribeirão Preto, 2008.

143. : il. ; $30 \mathrm{~cm}$.

Dissertação, apresentada à Faculdade de Filosofia, Ciências e Letras de Ribeirão Preto / USP - Dep. De Psicologia e Educação.

Orientadora: Linhares, Maria Beatriz Martins.

1. Neurocomportamental. 2. Prematuro.

3. Baixo-peso. 3. Prevenção 
Paula Stefaneli Ziotti Gabriel

Desenvolvimento neurocomportamental de bebês prematuros avaliados na fase de 32 a 37 semanas de idade pós-concepcional.

Dissertação apresentada à Faculdade de Filosofia, Ciências e Letras de Ribeirão Preto da USP, como parte das exigências para a obtenção do título de Mestre em Ciências, Área: Psicologia.

Aprovado em:

Banca Examinadora

Prof. Dr.

Instituição Assinatura

Prof. Dr. Instituição Assinatura

Prof. Dr. Instituição Assinatura 


\section{DEDICATÓRIA}

Aos meus pais e ao meu marido Rodolpho que proporcionaram a realização de um sonho, sempre me apoiando e me incentivando. Agradeço por sempre estarem ao meu lado me iluminando, protegendo e me fazendo enxergar a vida com os olhos da serenidade e doçura. Meu sincero agradecimento porque vocês são exemplo de dedicação e persistência. Acreditaram em minha capacidade e me encorajaram a não desistir dos meus sonhos. 


\section{AGRADECIMENTO ESPECIAL}

A Professora Doutora Maria Beatriz Martins Linhares por ter me aceitado em seu grupo de pesquisa, por sua confiança em meu potencial profissional e de pesquisa, por todo conhecimento passado, pela dedicação, amor, paciência e cuidado de maneira dócil e singular. 


\section{AGRADECIMENTOS}

A Deus por seu amor incondicional e por guiar todos os meus passos em todos os momentos deste estudo.

A minha irmã Andréa que com paciência e amor soube me ajudar e estar ao meu lado durante todo este estudo, me incentivando e apoiando.

A Cibelle por me acolher, pelos momentos que compartilhamos, pela dedicação, respeito e paciência, contribuindo para o meu crescimento pessoal e profissional. Obrigada por acreditar em mim.

Aos meus amigos Camila e Bruno que com amor me ajudaram e estiveram sempre ao meu lado me apoiando em todos os momentos deste estudo. Minha sincera gratidão e eterna amizade.

Pelos meus amigos que estiveram sempre intercedendo e na torcida pelo meu sucesso.

Aos meus avós, Rosa, Elza e Eurípedes, e a minha sogra Madalena que me apoiaram e incentivaram.

A todas as amigas: Luciana C., Valéria, Claudinha, Fabíola, Bia, Vivian, Luciana e Aline que estiveram ao meu lado durante vários momentos. Agradeço a amizade, os ensinamentos, o carinho e o convívio ao longo desta caminhada.

Aos profissionais da saúde que participaram deste estudo e aos pais dos bebês internados no Hospital de Goiânia, os quais permitiram a participação deles no estudo.

A Banca de Qualificação formada pelas professoras Eucia Beatriz e Carolina Funayama que contribuíram com sugestões neste trabalho. 
A todos que, de alguma forma, contribuíram para que este trabalho se tornasse realidade, meus sinceros agradecimentos. 


\section{RESUMO}

GABRIEL, P. S. Z. Desenvolvimento neurocomportamental de bebês prematuros avaliados na fase de 32 a 37 semanas de idade pós-concepcional. 2008. 143f. Dissertação de Mestrado - Faculdade de Filosofia Ciências e Letras de Ribeirão Preto, Universidade de São Paulo, Ribeirão Preto, 2008.

$O$ avanço na qualidade de atendimento intensivo na fase neonatal levou ao aumento dos índices de sobrevivência de bebês prematuros. A grande preocupação, não diz respeito tão somente à sobrevida, mas principalmente à qualidade de vida. $O$ presente estudo teve por objetivo principal caracterizar o desenvolvimento neurocomportamental de bebês nascidos pré-termo antes de atingir o termo de 40 semanas de idade pós-concepcional. Os objetivos específicos foram: a) comparar o desempenho neurocomportamental da amostra de estudo com a amostra original da padronização do teste NAPI; b) comparar os indicadores de desenvolvimento neurocomportamental em grupos diferenciados pelos problemas perinatais; c) comparar os indicadores de desenvolvimento neurocomportamental em grupos diferenciados quanto ao sexo. A amostra foi composta por 202 bebês pré-termo ( $\leq$ 37 semanas de idade gestacional), de ambos os sexos, com baixo peso $(<2500 \mathrm{~g})$, estáveis clinicamente e internados na Unidade de Terapia Intensiva Neonatal ou Berçário de Cuidados Intermediários do Hospital Materno-Infantil da cidade de Goiânia (GO), no período de setembro de 2004 a janeiro de 2006. Foram utilizados os seguintes instrumentos: Avaliação Neurocomportamental do Pré-Termo (NAPI), roteiro de anamnese, prontuário médico e Questionário de Classificação Sócio Econômico. O procedimento de avaliação dos bebês foi filmado. $O$ índice de acordo entre observadores foi de $88 \%$. A análise dos vídeos foi processada para obter a pontuação do desempenho dos bebês, de acordo com o NAPI. Primeiramente, os dados foram submetidos à análise estatística descritiva. As variáveis discretas foram quantificadas em termos de frequência, prevalência ou porcentagem e as variáveis contínuas em termos de média e desvio padrão, mediana, valores mínimo e máximo. Procedeu-se à comparação entre os desempenhos no NAPI obtidos na amostra do estudo e os resultados da amostra do teste, entre meninos e meninas e entre dois grupos (Grupo com problema perinatal - PIG, anóxia, hemorragia e hidrocefalia e Grupo sem problema perinatal). Os resultados mostraram que houve diferença significativa entre os grupos nos domínios do NAPI. A amostra do estudo (AE) apresentou menor tonicidade muscular no sinal de cachecol, menor vigor e movimentação espontânea e maior alerta e orientação do que o grupo de padronização do teste (AT). Além disso, o grupo AE apresentou choro levemente mais fraco e maior quantidade de sono, indicando que os bebês dormiram mais durante a realização do teste, do que o grupo AT. Ao analisar a classificação geral do NAPI, de acordo com o desvio-padrão da amostra de padronização do teste, foi possível notar que a maior parte dos bebês estudados foi classificada na média e cerca de um terço foram classificados como abaixo da média. Verificou-se que não houve diferença estatística significativa entre os desempenho de meninos e meninas. Os resultados do desenvolvimento neurocomportamental dos grupos sem problemas e com problemas perinatais, em comparação à amostra de padronização do teste foram semelhantes em relação ao desempenho nos itens do NAPI. A avaliação forneceu dados sobre a detecção de risco no desenvolvimento de bebês nascidos prematuros, a fim de implementar medidas efetivas de intervenção preventiva para evitar problemas de desenvolvimento no futuro. 
Palavras-chave: desenvolvimento neurocomportamental; prematuro; baixo peso; prevenção. 


\begin{abstract}
GABRIEL, P. S. Z. Neurobehavioral development on premature babies between $32^{\text {nd }}$ to $37^{\text {th }}$ weeks post-conception. 2008. 143f. Dissertation for Master's Degree Faculdade de Filosofia Ciências e Letras de Ribeirão Preto, Universidade de São Paulo, Ribeirão Preto, 2008.
\end{abstract}

The quality improvement on newborn's intensive care leaded to higher levels for premature babies survival rates. The bigger preoccupation doesn't regard simply their survival, but further on, regards quality of life. This study has the main objective to typify the neurobehavioral development on preterm born babies, before the $40^{\text {th }}$ week of post-conceptional age. As specific objectives: a) to compare neurobehavioral performance of this study's sample to the original standard sample of NAPI test; b) to parallel indicators of neurobehavioral development in groups classified according to perinatal problems; c) to compare neurobehavioral development indicators from groups created according the gender. The sample has been composed of 202 preterm infants (gestational age $\leq 37$ weeks), both genders, underweight $(<2500 \mathrm{~g}$ ), clinically stable and on therapy at the Neonatal Intensive Care Unit or Intermediary Care Nursery of the Goiânia's "Hospital Materno-Infantil", for the period of September 2004 to January 2006. The following instruments were applied: Neurobehavioral Assessment for the Preterm Infant (NAPI), guide for anamnesis, medical history and a Questionnaire for Socioeconomical Individuation. The procedure for babies evaluation was filmed. The accordance rate among the beholders has been about $88 \%$. The videos analysis had the purpose of rating babies' performances according to NAPI. Firstly, data were submitted to descriptive statistic analysis. The discret variances were quantified depending on frequency, prevalence or percentage and continuous variances in terms of medium value and standard deviation, median, minimum and maximum values.

Then the comparison of NAPI performances on study's sample and test's standard results, between both genders and two groups (one with perinatal problems - PIG, such as anoxia, hemorrhaging and hydrocephalus and another group without any perinatal problem). Results shown meaningful difference between the groups on NAPI basis. The sample of this study (AE) has shown less muscular tonicity at the scarf sign, less vigor and spontaneuos movements, higher alert and orientation regards test's standard group (AT). Furthermore, the the AE group shown lightly weaker crying and higher quantity of sleeping, what means the newborns slept more during the test, regards AT group. When analyzed NAPI general ratings, according standard deviation on test's sample, it was remarkable that the the most of the newborns on study were rated at medium rating, besides around one third of them under that rate. No meaningful statistic difference was verified between boys and girls ratings. The results of neurobehavioral development on groups with and without perinatal problems, regards the standard of the test were simillar on NAPI. The assessment provided data about risk detection on babies born preterm, with the purpose of putting into effect effective measures for preventive intervention to avoid future development problems.

Keywords: Neurobehavioral development; premature; underweight; prevention. 


\section{LISTA DE TABELAS}

Tabela 1 - Características dos bebês da amostra total e em grupos diferenciados quanto ao sexo. .66

Tabela 2 - Índices de risco clínico neonatal da amostra total e em grupos diferenciados por sexo.

Tabela 3 - Características de evolução clínica dos bebês da amostra total e em grupos diferenciados quanto ao sexo.

Tabela 4 - Procedimentos clínicos a que os bebês foram submetidos e o tempo de internação da amostra total e em grupos diferenciados quanto ao sexo. .70

Tabela 5 - Características das mães dos bebês da amostra total e dos grupos diferenciados quanto ao sexo .72

Tabela 6 - Dados de complicações da gravidez das mães da amostra total e de grupos diferenciados quanto ao sexo.

Tabela 7 - Dados de escolaridade dos pais da amostra total e dos grupos diferenciados quanto ao sexo. .76

Tabela 8 - Dados sócio-demográficos da amostra total e dos grupos diferenciados quanto ao sexo. .78

Tabela 9 - Comparação entre os escores dos itens do NAPI, de acordo com a idade pós-concepcional, da amostra de estudo (AE) e amostra do teste (AT) NAPI - média e desvio padrão.

Tabela 10 - Classificação Geral do NAPI dos bebês de acordo com os desviospadrões (DP) da amostra do teste. .82 
Tabela 11 - Comparação entre os escores dos itens do NAPI, de acordo com a idade pós-concepcional, da amostra dos grupos diferenciados pelos problemas perinatais - média e desvio padrão.

Tabela 12 - Comparação entre os escores dos itens do NAPI, de acordo com a idade pós-concepcional, da amostra de estudo (sem problema) (AE) e amostra de padronização do teste (AT) NAPI - média e desvio padrão. .85

Tabela 13 - Comparação entre os escores dos itens do NAPI, de acordo com a idade pós-concepcional, da amostra de estudo (com problema) (AE) e amostra de padronização do teste (AT) NAPI - média e desvio padrão. 88

Tabela 14 - Escores no NAPI, em grupos diferenciados quanto ao sexo. - média, desvio padrão, mediana, valores mínimos e máximo

Tabela 15 - Classificação geral do NAPI dos bebês de acordo com os desvios padrões da amostra do teste, nos grupos diferenciados por sexo 


\section{SUMÁRIO}

RESUMO

ABSTRACT

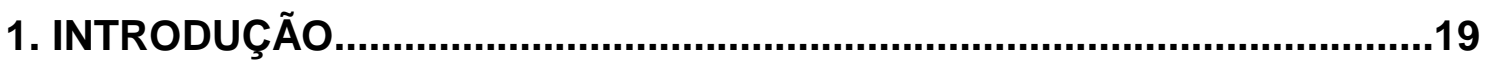

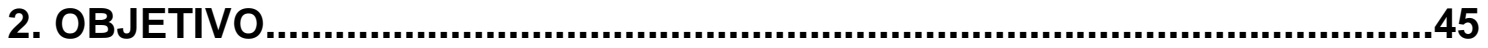

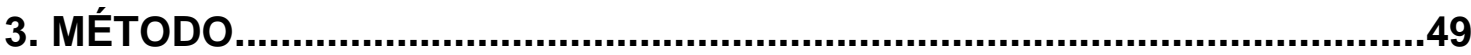

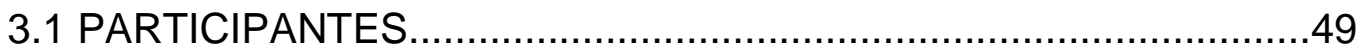

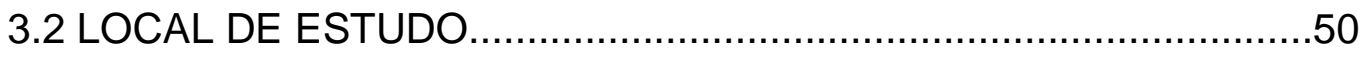

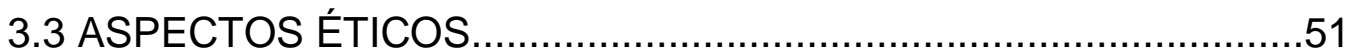

3.4 INSTRUMENTOS E MATERIAIS....................................................

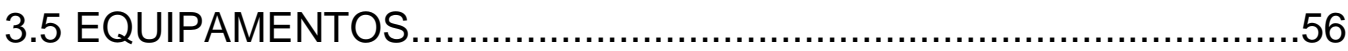

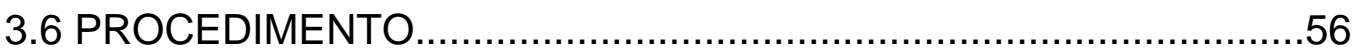

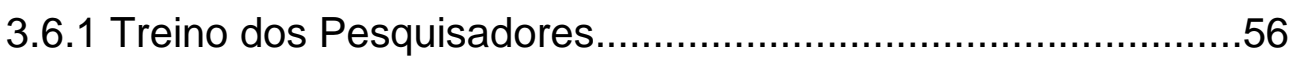

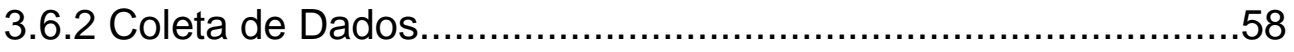

3.6.3 Preparação e Análise dos dados............................................59

4. RESULTADOS

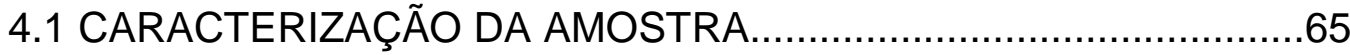

4.2 DESENVOLVIMENTO NEUROCOMPORTAMENTAL DOS BEBÊS DA AMOSTRA TOTAL

4.3 DESENVOLVIMENTO NEUROCOMPORTAMENTAL, EM GRUPOS DIFERENCIADOS PELOS PROBLEMAS PERINATAIS........................82

4.4 DESENVOLVIMENTO NEUROCOMPORTAMENTAL, EM GRUPOS DIFERENCIADOS QUANTO AO SEXO. 90 


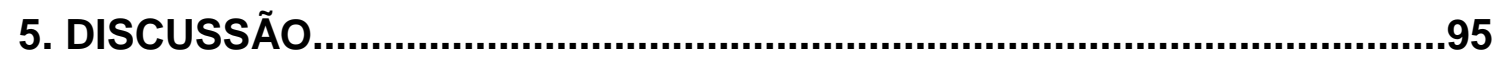

REFERÊNCIAS.......................................................................................117

ANEXOS...............................................................................................131 



\section{INTRODUÇÃO}

O avanço na qualidade de atendimento intensivo na fase neonatal levou ao aumento dos índices de sobrevivência de bebês prematuros. Segundo Linhares et al. (2004), a internação na Unidade de Terapia Intensiva Neonatal, necessária durante as primeiras semanas ou meses de vida, aumenta sobremaneira a quantidade de procedimentos invasivos e dolorosos inevitáveis, com a finalidade de investigação diagnóstica ou de tratamento, a que os neonatos pré-termo são expostos.

Na década de 90, com o advento do surfactante, medicação que visa manter a estabilidade alveolar e proporcionar a melhora da complacência pulmonar e aumento da capacidade residual funcional da oxigenação e da mecânica respiratória, melhorou sobremaneira os índices de sobrevivência de neonatos prétermo de baixo peso ao nascimento (VLBW) e extremamente baixo peso (ELBW). Entretanto, tal sobrevivência se dá à custa de uma internação prolongada em condição de terapia intensiva.

Com a melhora dos cuidados intensivos neonatais, recém-nascidos com 26 semanas de idade gestacional começam a se tornar viáveis para sobreviver, superar as adversidades biológicas e receber alta clínica. Tem-se, portanto, um período de até três meses durante os quais o sistema nervoso dessas crianças terá de se desenvolver sob condições não-fisiológicas e freqüentemente adversas, sujeitos a um risco muito maior de agressões por parte de estímulos visuais, sonoros e táteis. (CARVALHO; MANGIA, 1997; HOEKSTRA et al., 2004) 
O nascimento prematuro pode levar a uma série de fatores de risco associados, constitui-se em uma cadeia de adversidades biológicas simultâneas e sucessivas decorrentes da própria condição de risco neonatal, que operam como uma variável proximal para um complexo de condições de riscos biológicos e psicossociais (LINHARES et al., 2000; AYLWARD, 2002).

A Academia Americana de Pediatria define o recém-nascido pré-termo (RNPT) como sendo aquele que nasce até o último dia da $37^{\text {a }}$ semana de idade gestacional (IG) (37 semanas completas ou 259 dias), semanas estas calculadas a partir do primeiro dia da última menstruação normal. Dessa forma, a criança que nasce durante a $37^{\text {a }}$ semana de IG estaria incluída no conceito de RNPT. Esse conceito difere daquele considerado pela Organização Mundial de Saúde (World Helth Organization - WHO), que define o RNPT como aquele que nasce antes da $37^{\text {a }}$ semana de IG, ou seja, até 36 semanas e 6 dias. Parto pré-termo é o que ocorre antes de 37 semanas de IG. Os RNPT costumam ser agrupados em três categorias, em função da sua IG: RNPT do grupo I, ou pré-termo limítrofes, cuja IG corresponde à 37aㅡ semana (do 1 ao 6 dias); RNPT do grupo II, ou moderadamente pré-termo, cuja IG varia de 31 a 36 semanas completas e RNPT do grupo III, ou extremamente pré-termo, cuja IG varia de 22 a 30 semanas completas. Quando o peso do RN é inferior a 1500g, são denominados de RN de muito baixo peso. (SEGRE, 2002).

A avaliação apenas do peso ao nascimento do recém-nascido passou a levar em conta à relação entre peso ao nascimento e idade gestacional. Em 1967, Battaglia e Lubchenco classificaram os neonatos de acordo com o gráfico de crescimento intra-uterino do Colorado (BATTAGLIA; LUBCHENCO, 1967). Esse gráfico correlaciona a idade gestacional com o peso ao nascer. O pesquisador pesa o recém-nascido, determina a idade gestacional e coloca esse dois parâmetros no 
gráfico. Segundo esta classificação, o recém-nascido pode ser: apropriado para idade gestacional (AIG) o peso está entre o $10^{\circ}$ e $90^{\circ}$ percentil, pequeno para idade gestacional (PIG) cujo peso está fora dessa faixa, e grande para a idade gestacional (GIG) aquele acima de $90^{\circ}$ percentil. O PIG constitui-se em fonte de risco adicional à condição de prematuridade por incluir bebês que têm peso de nascimento abaixo do percentil 10 para bebês da mesma idade gestacional. Após a prematuridade, o retardo no crescimento intra-uterino é a principal causa de morte durante o período neonatal. (KENNER, 2000; SCANLAN et al., 2000)

Segundo Lockwood (2000), os fatores que podem levar ao parto prematuro são os seguintes: infecções maternas, hemorragias que pode resultar na formação de trombina levando ao trabalho de parto prematuro e distensão uterina patológica que pode resultar em ativação do miométrio.

Segundo Geary e Lamont (1997), foram identificados 98 fatores de risco para parto prematuro. Isso torna difícil a aplicação de um sistema de escores para identificar pacientes sob risco. Nesse sentido é preferível estar atento aos principais fatores associados: variáveis sociais e biológicas (idade da mãe, altura materna, peso materno, paridade, nível socioeconômico, fator nutricional, consumo de cigarros), história obstétrica pregressa (abortamento terapêutico ou espontâneo, parto de pré-termo, anomalias uterinas, infecções recorrentes do trato urinário) e complicações da gravidez atual (hemorragia anteparto, doença hipertensiva específica da gravidez, gravidez múltipla, polidrâmnio, malformação fetal, oligoâmnio, cirurgia abdominal, infecção, iatrogenia).

A sobrevida na fase neonatal aumenta na medida em que se eleva a idade gestacional. A grande preocupação, contudo, não diz respeito tão somente à sobrevida, mas principalmente à qualidade de vida. Assim é que a prematuridade 
continua a representar problema grave de saúde pública tanto pelas complicações precoces quanto pelas seqüelas, gerando ônus à saúde pública e as famílias envolvidas (SEGRE, 2002).

À medida que sobrevivem os recém-nascidos com peso ao nascimento e idade gestacional menores, cresce a preocupação dos profissionais que atuam nesse seguimento em longo prazo dessas crianças com a qualidade de vida de seus pequenos pacientes, considerando-se os diferentes aspectos envolvidos, quais sejam o crescimento somático e o desenvolvimento neuropsicomotor. (CAMELO Jr., 2005)

Crianças com idade gestacional entre 34 e 36 semanas - os bebês nascidos pré-termo limítrofe - apresentam risco cinco vezes maior de ir à óbito durante o primeiro ano de vida do que crianças nascidas a termo, mesmo após ajuste para morbidade materna e fatores sociodemográficos (SANTOS et al., 2008).

No Brasil, os últimos dados estatísticos disponíveis do Sistema Único da saúde, referente ao ano base de 2005, apontam que, em um total de 3.35.096 nascidos vivos, 199.018 nasceram pré-termo (6,6\%) e 35.262 nasceram com muito baixo peso (1,2\%). Em Goiânia, os nascidos vivos foram 19.621, referente ao mesmo ano, e os nascimentos prematuros chegam a atingir um índice de 4,4\% (CADERNOS DE INFORMAÇÕES DE SAÚDE, 2007).

Segundo Silveira et al. (2008) houve um aumento da prematuridade no Brasil. Os dados do Sistema de Informações de nascidos vivos não corroboram este aumento, pois mostraram diferenças entre as taxas de prematuridade informados por esse Sistema e as taxas medidas em seu estudo de revisão. Os dados podem estar sub-estimados, de acordo com os autores. Devido ao importante papel da 
prematuridade na mortalidade infantil no Brasil é importante identificar as causas deste aumento e planejar intervenções que diminuam sua ocorrência.

Apesar de os prováveis distúrbios que o bebê prematuro possa ter não se pode estabelecer uma relação direta entre a prematuridade e problemas de desenvolvimento. Isto se deve ao fato de que, mesmo com as adversidades apresentadas ao nascer, o seu desenvolvimento pode ocorrer dentro da normalidade, ou seja, comprometimentos isolados não possuem um efeito significativo e sim a somatória dos fatores das variáveis próprias das crianças, do ambiente e complicações pós-natais (LINHARES et al., 2000).

Segundo Egewarth (2002) a mortalidade perinatal e a incidência de seqüelas neurológicas têm diminuído. Entretanto, as crianças nascidas prematuras parecem estar mais propensas às disfunções cognitivas na escola e a distúrbios de comportamento. É difícil, porém, identificar padrões alterados do desenvolvimento inicial, pois não há concordância sobre o desenvolvimento neurológico normal dos prematuros.

Segundo Linhares et al. (2000) quanto mais precoce for a identificação de fatores que ameaçam o desenvolvimento pleno e sadio da criança, assim como sua aprendizagem acadêmica e adaptação psicossocial, mais eficiente se tornam os cuidados dispensados à criança, a fim de neutralizar riscos e evitar que estes se perpetuem, levando a problemas crônicos de difícil reversão.

Considera-se que diversos fatores de risco presentes na vida de um mesmo indivíduo tendem a se multiplicar, antes que apenas somar. Isto significa a existência de um efeito multiplicador, em que um fator agrava o outro, e assim por diante, formando uma cadeia de eventos negativos sujeito à retro-alimentação. Portanto, tanto as condições de saúde do bebê quanto às condições ambientais e familiares 
da criança podem influenciar de modo significativo e neutralizando ou agravando o desencadeamento de dificuldades no curso de desenvolvimento do prematuro. (RICHARDSON et al., 1992; ANTUNHA, 1994; BRAZELTON, 1994; ROSS et al., 1996)

Os recém-nascidos que sobrevivem as intercorrências perinatais tornam-se propensos a manifestar desvios em seu desenvolvimento, podendo apresentar deficiências neurológicas e sensoriais. (STOLZ, 1998; KELLER et al., 1998; LIMA; GONÇALVES, 2003).

O nascimento prematuro é considerado como um fator de risco para problemas cognitivos (EGEWARTH, 2002; MÉIO et al., 2004; BLOND et al., 2003; MENT et al., 2003; MCGRATH et al., 2000), comportamentais e acadêmicos (PEDROMÔNICO, 2003; LINHARES et al., 2004; MÉIO et al, 2004) e seqüelas para o desenvolvimento motor e linguagem. (HALPERN et al., 2000; EICKMANN, 2002; HACK; FRIEDMAN; FANAROFF, 2000; HACK et al., 2002). Segundo Linhares (2004) a prematuridade associada ao baixo peso ao nascimento são fatores que influenciam diretamente o desenvolvimento e podem aumentar a probabilidade para problemas em diversas áreas e fases evolutivas.

O estudo realizado por Méio, Lopes e Morsch (2003) teve por objetivo descrever o desenvolvimento cognitivo de uma amostra de recém nascidos prematuros de muito baixo peso e verificar possíveis fatores prognósticos para tal desenvolvimento. Concluiu-se que houve maior comprometimento do desenvolvimento cognitivo, nas crianças estudadas, do que o descrito na literatura. Ser pequeno para idade gestacional, ultra-sonografia com transfontanela anormal e sexo masculino foram fatores prognósticos de pior evolução no desenvolvimento. 
Diante da preocupação acerca da qualidade de vida de crianças nascidas prétermo com muito baixo peso ao longo do desenvolvimento, Carvalho, Linhares e Martinez (2001) realizaram um estudo comparando a história de desenvolvimento, aprendizagem e comportamento de 20 crianças na faixa etária de 8 a 10 anos de idade nascidas pré-termo com peso menor de 1500g (grupo MBP) emparelhadas com o grupo de comparação constituídos por 20 crianças a termo. Os resultados indicaram sinais de atraso na aquisição de comportamentos psicomotores iniciais e lateralidade manual no grupo MBP em relação ao grupo de comparação. Na fase escolar a maior parte de crianças de ambos os grupos apresentaram nível intelectual médio e estavam matriculadas no ensino regular. No grupo MBP $20 \%$ das crianças apresentaram dificuldades auditivas, além de apresentarem mais repetências no histórico escolar do que as crianças nascidas a termo.

Ambalavanan et al. (2000) publicaram um estudo realizado com $218 \mathrm{RN}$ com peso entre 501 e $1.000 \mathrm{~g}$ e verificaram, por meio de análise de regressão, que os principais fatores para as seqüelas graves foram o grau de hemorragia preriintraventricular grau II, enterocolite necrosante e raça negra. Para os baixos índices de desenvolvimento mental encontraram o grau de hemorragia periintraventricular, doença pulmonar crônica, gemelaridade e baixa escolaridade materna. Assim como, para os baixos índices de desenvolvimento psicomotor foram grau de hemorragia perintraventricular, leucomalácia periventricular e baixa escolaridade materna. $\mathrm{O}$ peso ao nascimento, isoladamente, não pode predizer a presença de seqüelas maiores, ou índices de desenvolvimento mental ou psicomotor, embora os índices de desenvolvimento psicomotor fossem mais baixos de acordo com a diminuição do peso. 
Segundo Aywarld (2002) nas pesquisas com bebês de risco é necessária uma caracterização precisa do risco neonatal, incluindo dados sobre o período de hospitalização da criança, número de dias de internação, complicações desenvolvidas, para que os resultados sejam comparados com os grupos de outras populações. Em um estudo de revisão, o autor recomenda que se proceda à estratificação de grupos de crianças nascidas baixo peso para fins de comparação entre grupos. Esta estratificação deve ser baseada em fatores pré e perinatais e deve ser utilizada, principalmente, quando existe um grau elevado de dúvida acerca da influência uma variável específica ou de um conjunto de variáveis.

Com base nos estudos dessas adversidades do desenvolvimento do bebê prematuro a avaliação do período neonatal nas primeiras horas de vida, associada com a avaliação de sua evolução clínica até a alta hospitalar, fornece indicadores de prognósticos relevantes do desenvolvimento da criança. Esses indicadores encontram-se devidamente exemplificados em avaliações nas primeiras horas de vida do recém-nascido, como por exemplo, no Índice de Risco Clínico Neonatal para Bebês (Clinical Risk Index for Babies - CRIB) (COCKBURN et al., 1993) e Clinical Risk Index for Babies II (CRIBII) (PARRY; TUCKER; TARNOWMORDI, 2003). Escore para Fisiologia Neonatal Aguda (Score for Neonatal Acute Physiology SNAPII) (GRAY et al., 1992);

O CRIB tem sido amplamente utilizado na avaliação dos riscos de mortalidade e morbidade. O CRIB avalia os parâmetros de peso ao nascimento, idade gestacional, fração de oxigênio, excesso de base na gasometria e má formação congênita. Os critérios devem ser aplicados durante as primeiras 12 horas de vida do bebê e o escore varia de 0 (menor risco) a 23 pontos (maior risco). O CRIB II que avalia o peso ao nascimento e idade gestacional de acordo com o sexo (feminino/ 
masculino), temperatura e excesso de base no sangue. O escore varia de 0 (menor risco) a 27 pontos (maior risco). Alto escore no CRIB (acima de 5 ou 6 pontos) correlaciona-se a altas taxas de mortalidade e morbidade (COCKBURN et al., 1993). Segundo Bordin (2005) as crianças nascidas pré-termo com CRIB maior do que 6 apresentaram mais problemas em comparação com as crianças cujo CRIB era menor do que 6. O escore do CRIB maior do que 4 foi melhor preditor da mortalidade quando comparado com o peso ao nascimento e com a idade gestacional. (BRITO et al., 2003) Segundo Gagliardi et al. (2004) o escore CRIB tem maior poder discriminativo do que o SNAPPE - II.

Apesar de a prematuridade, o baixo peso ao nascimento e anóxia neonatal constituírem-se em riscos para problemas de desenvolvimento, existe uma dificuldade em se detectar nos primeiros quatro meses essas anormalidades, pois este período é caracterizado pela variabilidade do comportamento do bebê, bem como alterações do tônus muscular, atividade postural e reflexa e habilidades funcionais (SOUZA, 1998).

A imaturidade geral do organismo pode levar a disfunção em qualquer órgão ou sistema corporal. Sendo assim, o neonato prematuro corre o risco de sofrer uma ampla faixa de problemas, incluindo síndrome de desconforto respiratório, apnéia, displasia broncopulmonar, persistência do canal arterial, termoregulação ineficaz, hipoglicemia, hemorragia intraventricular, disfunção gastrintestinal, retinopatia, hiperbilirrubinemia e infecção. Desse modo, a ligação entre a mãe e bebê pode ficar comprometida (KENNER, 2000).

A importância do exame neurocomportamental de recém-nascidos é mais do que evidente, pois é por meio dele que se pode determinar a vitalidade, o grau de 
maturidade e as possíveis repercussões precoces ou tardias de patologias dos períodos pré e perinatal, além do pós-natal imediato (DIAMENT et al., 1996).

Com base na literatura consultada sobre instrumentos de avaliações que podem ser usados no desenvolvimento inicial dos bebês, alguns podem ser citados tais como o NIDCAP - Newborn Individualized Developmental Care Assessment Program. (ALS et al., 1984), é um instrumento clínico para crianças na fase de 24 30 semanas de idade pós-concepcional. Envolve cuidados rotineiros do recémnascido e o examinador não precisa manusear a criança para avaliação completa. Não fornece detalhes quantitativos, sendo baseado em observações naturalísticas. O NIDCAP incorpora as idéias de maturação e processamento dinâmico. A porcentagem média de todos os 85 comportamentos é registrada separadamente para cada idade pós-concepcional. (PRESSLER et al., 2001).

O teste APIB - The Assessment of Preterm Infants' Behavior (ALS et al., 1982) é um instrumento de avaliação baseado na Teoria de Desenvolvimento SíncronoAtivo, a qual propõe que a criança e o meio ambiente estão em interação contínua e dinâmica. Apesar de o APIB adaptar uma série de manuseios derivados do NBAS The Neonatal Behavioral Assessment Scale, fornece medidas detalhadas e quantificadas da diferenciação comportamental e sua modulação. No APIB se avalia a organização comportamental do bebê em cinco itens que incluem: o motor, o autonômico, o estado comportamental, a atenção e auto-regulação. A autoregulação da criança e a quantidade de facilitação do examinador, dicas específicas comportamentais e o comportamento reflexo também são avaliados.

O ENNAS - Einstein Neonatal Neurobehavioral Assessment Scale (DAUM et al., 1977), pode ser usado para observar aspectos de organização neurocomportamental de recém-nascidos. É uma escala padronizada que avalia 
movimentos espontâneos e respostas aos estímulos sensoriais. Pode ser aplicado em bebês a termo (37 a 42 semanas de idade pós-concepcional) assim como em bebês pós-termo e pré-termo. É um exame neurológico que enfatiza tônus muscular e padrões de reflexos primitivos, assim como elementos comportamentais, desde orientação de respostas e o estado comportamental. O teste incluem 20 itens e 4 itens resumidos. A ordem de administração dos itens é flexível para otimizar o estado comportamental. A confiabilidade entre observadores foi avaliada como excelente $(r=0,97)$. A confiabilidade teste-reteste apresenta problemas para toda a avaliação neonatal, considerando que os neonatos podem ter desempenho neurocomportamental instável sobre períodos curtos de tempo. (MAJNEMER; SNIDER, 2005)

O GM - Avaliação dos movimentos generalizados (EINSPIELER et al., 2004) foi construída por pesquisadores europeus na década de 70, sendo Prechtl, 0 principal pesquisador. Detecta precocemente anormalidades no desenvolvimento de bebês prematuros e crianças nascidas a termo de risco. $O$ teste consiste na observação dos movimentos espontâneos da criança sem intervenção ou estímulos externo. É realizado por meio de filmagem da criança deitada em supino, acordada e repousando na incubadora ou no leito. A avaliação é realizada a partir do terceiro dia de vida, em três momentos diferentes, entre o período pré-termo e pós-termo até 20 semanas. A classificação do teste é baseada na presença e freqüência, localização e intensidade dos padrões motores de movimentos característicos dos neonatos que são: normal - presença dos movimentos de torção / irregulares; risco - repertório pobre ou caótico de movimentos generalizados; presença de espasmos simultâneos e movimentos irregulares ausentes ou normais. O tempo de aplicação varia de 10 a 50 minutos. A confiabilidade inter-observadores foi entre 92 e 97\%, a sensibilidade 
100\% e a especificidade 96\%. É necessário treinamento para aplicação do teste que tem um custo elevado.

O NAPI - Neurobehavioral Assessment of the Preterm Infant (KORNER et al., 2000) foi criado por um grupo de pesquisadores das áreas de Medicina, Psicologia e Fisioterapia que se destina a avaliar a maturidade e o comportamento do bebê com idade pós-concepcional de 32 a 40 semanas. A avaliação completa envolve 71 itens, incluindo sinais fisiológicos do bebê (coloração, padrão de choro, presença de apnéia, etc.) e avaliação da mudança do estado comportamental ao longo do exame.

É um instrumento muito utilizado em estudos que enfatizam os aspectos adaptativos de bebês pré-termo. Avalia a relativa maturidade de funções em crianças prematuras a partir de 32 semanas de idade até completar o termo (40 semanas de idade pós-concepcional). Os itens do teste avaliam o desenvolvimento motor e força, a amplitude dos movimentos passivos e a capacidade de prestar atenção para estímulos auditivos e visuais.

As respostas da criança ao teste são imediatamente pontuadas após o examinador proceder ao item. Os itens do teste são apresentados numa seqüência invariável que é destinada a reproduzir os tipos de estados comportamentais, o que contribui para eliciar a melhor resposta possível da criança. Essa seqüência invariável de apresentação, juntamente com classificações repetidas do estado comportamental neurológico da criança, permite ao examinador comparar o desempenho do bebê por meio de repetidas administrações ou entre outros bebês. Uma grande parte da avaliação consiste em meramente observar a criança, sem manipulá-la. Por exemplo, estados comportamentais são avaliados em todo o exame, e descrições resumidas de classificações do estado de alerta da criança, 
qualidade do choro, e qualidade do movimento são feitas imediatamente após a conclusão do exame. Finalmente, o examinador completa alguns cálculos, converte o escore da criança em dados padrões e reúne grupos de pontos. A pontuação da criança então pode ser comparada com seus desempenhos anteriores na avaliação NAPI ou com a pontuação de outros bebês.

A Avaliação Neurocomportamental do Bebê Pré-termo foi elaborada em 1977. Este procedimento foi desenvolvido porque nenhum instrumento de avaliação era, até então, válido para acompanhar longitudinalmente 0 desenvolvimento neurocomportamental de crianças prematuras muito novas que participavam de um estudo de intervenção. O único procedimento de avaliação longitudinal da criança prematura que era válido em 1977 era o exame neurológico de Saint-Anne Dargassies (1966) e Amiel Tison (1968). Nenhum destes testes era designado para caracterizar os desempenhos dos bebês em intervalos menores do que duas semanas. Para os propósitos do estudo de intervenção, era necessário desenvolver um procedimento que pudesse revelar diferenças abaixo do desempenho, diferenças que poderiam ser evidentes dentro de um período de duas semanas. (KORNER et al., 1991)

O NAPI foi desenvolvido em três fases que incluíram um estudo piloto, um estudo exploratório, e o estudo de validação. Os grupos que foram formados para os estudos tinham itens de coesão conceitual e validade aparente. Os itens do teste que eram mantidos e agrupados apresentaram boa confiabilidade teste-reteste dia após dia, de seis ou mais repetições, medidos separadamente em áreas distintas de funcionamento; os itens não deveriam ser redundantes entre si, e demonstrar validade desenvolvimental revelando mudanças significativas de função com o passar das idades. Então, itens não confiáveis, redundantes, e inválidos no aspecto 
do desenvolvimento foram excluídos. A versão resultante da avaliação ficou mais resumida do que a versão anterior.

Na segunda fase de desenvolvimento do teste, um grupo independente de 290 crianças prematuras foi estudado durante sete anos. A consistência interna foi demonstrada ser aceitável. Bebês com 34 semanas de idade pós-concepcional foram testados. A correlação de cada item para o escore total foi calculada. Apenas itens que correlacionaram significativamente com o escore do grupo total foi mantido. O objetivo do NAPI era que ele deveria ser capaz de detectar mudanças desenvolvimentais. Em 52 bebês variando de 32 a 40 semanas que foram testados, apenas os escores do grupo que mostrou diferença significativa entre as idades cronológicas foram mantidos.

$\mathrm{Na}$ fase de validação, a validade dos sete domínios foi investigada. As autoras relataram que, na medida em que a idade gestacional aumentava, os escores em todos os domínios exceto o percentual adormecido também aumentavam.

Segundo as autoras do NAPI, esse difere principalmente das outras avaliações neurocomportamentais nos seguintes aspectos: o conceito e desenvolvimento sensato de escolha, ordem e pontuação deste teste são únicos, manobras aversivas como Moro e "alfinetadas" não estão incluídas no exame, e uma técnica especial, passo a passo, é usada para manter o mínimo de estresse da criança. Uma seqüência invariável da apresentação dos itens é usada no exame. Esta seqüência é designada para informar sobre os estados de comportamento que são mais prováveis de obter as melhores respostas da criança pré-termo; caracteriza um sistema de pontuação quantitativa melhor que as usadas em outras avaliações de prematuros; apenas breves e simples cálculos são requisitados para classificar o desempenho da criança. 
O processo avaliativo usado nas duas fases do teste de desenvolvimento resultou em um breve instrumento empírico para se avaliar o desenvolvimento de crianças nascidas prematuras.

Depois que as duas fases de desenvolvimento do teste foram completadas, dados de uma amostra adicional de crianças prematuras foram coletados para incrementar a amostra com base em informações normativas.

De acordo com Korner et al. (2000), para construção do instrumento foram avaliados aproximadamente 990 bebês pré-termo divididos em três grupos. O processo total de avaliação do teste resultou em um instrumento relativamente breve, que consiste de sete dimensões neurocomportamentais representando um espectro significativo conceitual e clinicamente das funções dos bebês pré-termo. Os domínios são os seguintes: Sinal de cachecol, Desenvolvimento motor e de força, Ângulo Poplíteo, Alerta e Orientação, Irritabilidade, Qualidade do choro e Percentual do sono.

Majnemer e Snider (2005) compararam o NAPI - Neurobehavioral Assessment of Preterm Infant com o ENNAS - Einstein Neonatal Neurobehavioral Assessment Scale, sendo encontrada validade concorrente entre os dois instrumentos.

Para testar a validade clínica do procedimento, o Índice Médico Neonatal (NMI) foi desenvolvido, o qual resume em tópicos a trajetória clínica de bebês durante sua estadia no hospital. O NMI foi usado para determinar ou não se o NAPI diferencia o desempenho de bebês que tiveram graves complicações clínicas das crianças que não tiveram complicações clínicas. (KORNER et al., 1994) O NAPI mostrou ser um instrumento sensível para detecção de riscos no desenvolvimento inicial dos bebês nascidos prematuros. Desta forma, o NAPI avança na avaliação de indicadores de padrões de adaptação e estabilidade dos bebês vulneráveis. 
Alguns estudos que utilizaram o NAPI (ARIAGNO et al., 1997; JOHNSTON et al., 2002) demonstraram que a avaliação é sensível para avaliar mudanças neurocomportamentais de bebês nascidos prematuros e avalia itens, tais como o choro e estados de alerta, que constituem sinais indicativos de respostas adaptativas de retraimento ou aproximação. Korner (1996) comparou dois grupos de bebês pré-termo para verificar diferenças individuais de excitabilidade. Os resultados mostraram que dentro de um período de algumas semanas os bebês pré-termo foram altamente consistentes em suas reações e apresentaram diferenças individuais de comportamento altamente confiáveis.

O estudo de Ariagno et al. (1997) utilizou o NAPI, NIDCAP e APIB para avaliação de bebês que receberam tratamento individualizado na UTI Neonatal, determinando se a melhora nos resultados médicos foram associados com a melhora do sono ou resultado neurocomportamental. A medida era realçar o conforto e a estabilidade, além de reduzir o estresse e a agitação da criança. As variáveis eram: posicionamento adequado, diminuição do barulho, diminuição da luz, envolvimentos dos pais. Os resultados mostraram que os bebês passaram mais tempo em estado de alerta e apresentaram características de maior maturidade motora. Ao proceder-se à avaliação neurocomportamental do recém-nascido prematuro, deve-se lembrar que o sistema nervoso deste encontra-se em fase de desenvolvimento diferentemente daquele do recém-nascido a termo.

Brown et al. (1998) utilizaram o NAPI e o NBAS para estudar se o uso de drogas maternas durante a gestação afetam diferentemente bebês nascidos prematuros e a termos. Examinaram se a duração da gestação ameniza os efeitos da exposição pré-natal de drogas (cocaína, álcool ou ambos) e afetam o crescimento físico, neurocomportamental como por exemplo: desenvolvimento 
motor, orientação e irritabilidade, além da reatividade cardiorespiratória para potencializar o evento estressante.

Rakesh Rao et al. (2007) estudaram a medida do Ângulo poplíteo em RN com leucomalácia periventricular. A medida do ângulo poplíteo é um método bem documentado para avaliar a extensibilidade dos membros inferiores. Os autores avaliaram o desenvolvimento neurocomportamental em bebês nascidos prematuros sob ventilação mecânica recebendo analgesia com morfina ou placebo. Demonstraram que o item ângulo poplíteo do NAPI obteve escore significativamente mais alto no grupo morfina comparado com o grupo placebo. No grupo morfina, escores do motor e vigor foram mais baixos nas crianças que receberam analgesia adicional quando comparadas àquelas que não receberam. Em ambos, placebo e morfina, escores do item ângulo poplíteo foram mais baixos nas crianças que receberam analgesia adicional. Os autores concluíram que analgesia com morfina pode resultar em diferenças sutis do desenvolvimento neurocomportamental em bebês nascidos prematuros. O NAPI mostrou ser sensível para discriminar indicadores do desenvolvimento neurocomportamental dos grupos estudados.

No estudo de Kato et al. (2005) o ângulo poplíteo foi medido em 47 RNPT com leucomalácia e comparados com 103 RNPT do grupo controle (sem leucomalácia). O ângulo poplíteo foi medido nos $\mathrm{RN}$ com 1, 4, 8 e 12 meses de idade cronológica corrigida para prematuridade. Eles encontraram que o ângulo poplíteo estreito (s $120^{\circ}$ ) foi observado em $40 \%$ e $37 \%$ das crianças do grupo controle com 1 e 4 meses de idade corrigida, respectivamente. Entretanto, o ângulo poplíteo foi estreito em quase dois terços das crianças do grupo com leucomalácia para qualquer idade corrigida. Análise estatística revelou que o ângulo poplíteo estreito foi mais freqüente no grupo de crianças com leucomalácia periventricular do que nas do grupo controle 
em todas as idades. No grupo de crianças com leucomalácia periventricular, o ângulo poplíteo estreito não foi relativamente freqüente nas crianças com diplegia grave com 1 e 4 meses de idade corrigida. Em contraste, a freqüência do ângulo poplíteo estreito foi significativamente menor nas crianças com suave diplegia do que naquelas com moderada ou grave diplegia em 8 e 12 meses de idade corrigida.

Constantinou et al. (2005) avaliaram o impacto do peso ao nascimento no desenvolvimento de bebês com baixo peso ao nascer (VLBW) antes de receberem a alta hospitalar. Eles acompanharam os bebês aos 12, 18 e 30 meses de idade cronológica corrigida. A média dos escores do item do NAPI alerta e orientação foi significativamente mais baixa nas crianças com paralisia cerebral em relação aos grupos de crianças com extremo baixo peso (ELBW) e VLBW. Além disso, o grupo de crianças com ELBW apresentou escores significativamente mais baixo do que as crianças VLBW nos itens do NAPI alerta e orientação. No item motor, nenhuma diferença significativa foi encontrada entre os dois grupos. As autoras concluíram que o NAPI realizado antes da alta hospitalar fornece informações significativas relacionadas a possíveis atrasos neurocomportamentais.

Lekskulchai e Cole (2000a) relataram que o sinal de cachecol é avaliado ao trazer um braço através do peito da criança até a resistência ser encontrada. É realizada uma estimativa visual do posicionamento do cotovelo em relação à linha média do tronco. O resultado deste estudo revelou que o escore do sinal de cachecol melhorou conforme aumenta a idade da criança. Crianças agrupadas por idade gestacional entre 28 e 31 semanas de idade pós-concepcional apresentaram sinal de cachecol com dificuldade (escore 1), sendo extremamente hipotônicos com 28 semanas, em comparação a crianças com idade pós-concepcional de 40 semanas; neste grupo encontrou-se o escore máximo. Os autores sugeriram que as 
crianças com 40 semanas de idade pós-concepcional têm maior resistência ao movimento passivo do braço, o qual reflete um tônus muscular maior do tronco e membro superior. O tônus muscular muda gradualmente com a idade. Aos 28 a 32 semanas é quando o tônus muscular ativo, significativo, começa a aparecer. Até 37 semanas a manifestação completa do tônus na extremidade superior não é aparente por esse teste. Os autores concluíram que crianças nascidas com idade pósconcepcional menor do que 32 semanas mostraram baixo tônus postural e desenvolvimento motor amplo, quando comparadas com as de idade de 32 a 36 semanas.

Diament et al.(1996) relataram que os movimentos espontâneos voluntários do recém-nascido traduzem a evolução crânio-caudal, de modo que os níveis superiores da atividade nervosa vão exercer inibição sobre os níveis inferiores, que são mais automáticos. Assim, o recém-nascido movimenta mais espontaneamente os membros inferiores do que os superiores. Os movimentos observados nos membros inferiores são de extensão e flexão, geralmente sob forma de pedalagem ou de cruzamento entre eles. A suspensão ventral tem por finalidade verificar o estado tônico da criança, e principalmente da extensão dorsal da cabeça. Classicamente, tal manobra é descrita como Manobra de Landau, porém com respostas não consistentes antes do $4^{0}$ mês (flexão dorsal da cabeça e suspensão do quadril formando concavidade superior da coluna).

Os estados comportamentais têm sido estudados em bebês prematuros. Este comportamento diz respeito, principalmente, ao ciclo vigília/sono, o qual pode alterar várias das respostas às manobras do exame neurológico. Podem ser observados: qualidade de cada estado, variabilidade, estabilidade, transições e estado dominante. Em 1960, Prechtl sistematizou os estados do ciclo vigília/sono do 
recém-nascido: Estado 1 - sono quieto; Estado 2 - sono ativo; Estado 3 sonolência; Estado 4 - alerta inativo; Estado 5 - alerta ativo e Estado 6 - choro (DIAMENT et al, 1996; BRASIL, 2001).

Giganti et al. (2002) estudaram a relação entre bocejar e os estados comportamentais. Os autores encontraram prevalência alta de bocejar com o estado de sonolência; coeficiente significativamente baixo de bocejos no estado sono quieto quando comparado com alerta ativo e sono ativo.

Holditch-Davis et al. (2004) estudaram desenvolvimento dos estados sono e alerta em bebês prematuros. Relataram que sono ativo, largos movimentos corporais e porcentagem de sono não REM durante o sono ativo diminuíram com a idade. Alerta inativo, alerta ativo, sono quieto e respiração regular no sono ativo aumentaram com a idade. A transição do estado sono-alerta aumentou até 40 semanas de idade corrigida e diminuíram depois de 43 semanas de idade corrigida. Expressão facial negativa mostrou um decréscimo com o passar da idade.

Até neste momento, os estudos com bebês nascidos prematuros têm explorado a relação do desenvolvimento neurocomportamental com as variáveis idade gestacional, peso ao nascimento e seqüelas neurológicas nas diversas idades pós-concepcional. Nos estudos sobre desenvolvimento neurocomportamental de bebês prematuros foi pouco explorada a questão da diferença entre sexos dos bebês.

Hintz et al. (2006) estudaram o efeito da variável sexo na exposição a eventos perinatais ou neonatais, explicando que os meninos tem mais desvantagens nos resultados no início da infância em relação às meninas. Encontraram que os meninos mais freqüentemente tiveram resultados adversos, tal como paralisia cerebral moderada a grave. Os principais fatores de risco também foram mais 
comumente encontrados nos meninos do que nas meninas. Concluíram que fatores neonatais, perinatais e da primeira infância conferem similares riscos ou proteção para meninos e meninas, mas os meninos parecem ser mais vulneráveis do que as meninas.

$\mathrm{Na}$ área da reatividade à dor em bebês, o estudo de Guinsburg et al. (2000) foram encontrados diferenças estatisticamente significativas entre meninos e meninas. Nesse estudo foram avaliadas, à beira da incubadora, as respostas de dor por meio da atividade facial e do estado comportamental de 37 meninas e 28 meninos, que tinham entre 25 e 120 horas de vida e com idade gestacional que variava entre 28 e 42 semanas. Os neonatos foram avaliados durante procedimentos de punção capilar. Houve diferença significativa entre meninos e meninas, sendo que as meninas de todas as idades gestacionais exibiram maior atividade facial do que os meninos durante a punção capilar e um minuto após o procedimento de punção.

Na área do comportamento, o estudo de D’Oosterlinck et al. (2006) mostrou que meninos apresentaram mais problemas externalizantes, como distúrbio de hiperatividade do déficit de atenção, desordens de conduta e transtornos invasivos do desenvolvimento, do que as meninas. Estas por sua vez, apresentam desordens oposicionais desafiantes e problemas relacionados ao abuso e negligência.

As diferentes avaliações encontradas nos estudos visam diagnosticar atrasos e ou riscos para problemas de desenvolvimento de crianças nascidas prematuras. Também se tem realizado pesquisas que se utilizam de testes de triagem, a fim de detectar precocemente alterações para o desenvolvimento e assim poder intervir prontamente evitando a cronificação do risco. Além disso, esses estudos revelam 
que as alterações podem ser prevenidas e a intervenção precoce pode evitar o efeito do múltiplo risco.

Muitas crianças prematuras têm um aumento da probabilidade de apresentar alterações significativas em seu desenvolvimento normal e precisarem de intervenção inicial para a estimulação essencial do desenvolvimento. Dependendo da intensidade do risco e do período em que a prematuridade acontece, surgem seqüelas que, futuramente, podem vir a interferir em aspectos do desenvolvimento global das crianças. Contudo, segundo Palácios e Mora (1995), quando ocorre intervenção inicial de qualquer problema com relação à prematuridade, é possível haver uma melhora do prognóstico em relação ao futuro dessas crianças.

Deve-se considerar que o próprio tratamento os quais são submetidos os bebês pré-termo podem acarretar comprometimentos no seu desenvolvimento. A fim de investigar o efeito da prematuridade em crianças com idade gestacional menores de 32 semanas para o desenvolvimento na idade corrigida de 18 e 24 meses, Stoelhorst et al. (2003) realizaram um estudo utilizando os índices de desenvolvimento mental (MDI) e motor (PDI) avaliados pelas Escalas do Desenvolvimento Infantil de Bayley II. As crianças eram procedentes de famílias de nível sócio-econômico baixo. O tratamento pós-natal de corticoterapia com a substância dexametasona foi associado com alto risco para problemas para o desenvolvimento. Os preditores independentes do desenvolvimento atrasado foram displasias broncopulmonares aos 18 meses de idade corrigida, idade materna ao nascimento, baixo peso e sexo aos 24 meses. 0 índice do desenvolvimento motor (PDI) médio das crianças tratadas com dexametasona foi de 16,1 pontos baixos, nas crianças que não receberam tratamento aos 18 meses, e 12,7 pontos mais baixo, na faixa de 24 meses. Aos 18 e 24 meses de idade corrigida, 40\% das crianças 
nascidas prematuras tiveram desenvolvimento mental e motor atrasado. $O$ tratamento com dexametasona pós-natal pode ser considerado um fator de risco para o desenvolvimento psicomotor com atraso.

Nesse contexto verifica-se que além das variáveis biológicas neonatais, os tratamentos necessários subseqüentes podem levar a seqüelas no desenvolvimento. Portanto, a assistência às crianças nascidas prematuramente deve transcender às questões relativas à sobrevivência, fornecendo respostas adequadas de suporte ao desenvolvimento e à qualidade de vida das mesmas.

A intervenção preventiva ou terapêutica é muitas vezes, necessária para quebrar o círculo, vicioso de adversidades ao desenvolvimento, a fim de neutralizar os efeitos de múltiplos riscos e evitar, portanto, a perpetuação dos mesmos na trajetória de desenvolvimento da criança. $\mathrm{Na}$ delicada arquitetura do desenvolvimento do recém-nascido pré-termo deve-se ter em mente que quanto mais precoce for à estimulação essencial e regulada às necessidades do bebê vulnerável, maiores as chances de reverter problemas e minimizar efeitos de seqüelas. (LINHARES, 2000)

A identificação precoce de problemas do desenvolvimento é uma tarefa bastante difícil para o profissional que trabalha com cuidados primários. Devido à grande maleabilidade do desenvolvimento neuropsicomotor da criança, é necessário que a avaliação seja repetida, principalmente durante os primeiros anos de vida, quando o desenvolvimento é mais dinâmico e o impacto dos atrasos é mais importante (HALPERN et al., 2000). Os estudos com delineamento longitudinal são nesse caso úteis para compreensão de recursos e dificuldades do desenvolvimento dos bebês nascidos prematuramente e delineamento de intervenção preventivas ou terapêuticas. 
Como essas crianças podem apresentar alto risco para problemas em diferentes áreas do seu desenvolvimento, elas precisam ser devidamente acompanhadas em uma abordagem de intervenção preventiva em programas de follow-up do desenvolvimento.

Considerando-se as possíveis seqüelas da prematuridade que podem cronicamente acompanhar a criança no seu curso de desenvolvimento, permeando as relações e a integração desta com o ambiente, não se pode prescindir do acompanhamento longitudinal. Com base na necessidade de informações sobre avaliações iniciais, consideram-se promissores estudos sobre avaliação do desenvolvimento inicial do bebê pré-termo nas primeiras semanas de vida.

Até onde se sabe, no Brasil, não existem estudos sistematizados sobre avaliações em bebês antes do termo, em fase inicial de sua vida, que possam fornecer essas primeiras informações. Com essas informações as crianças podem ser acompanhadas e terem uma abordagem preventiva logo no início de seu desenvolvimento. 


\section{OBJETIVO}

O presente estudo ${ }^{1}$ tem por objetivo principal caracterizar o desenvolvimento neurocomportamental de bebês nascidos pré-termo nas primeiras semanas de vida, antes de atingir o termo de 40 semanas de idade pós-concepcional, por meio da avaliação do desenvolvimento, a fim de detectar indicadores de risco para problemas na trajetória de desenvolvimento.

Os objetivos específicos são:

a) Comparar o desempenho neurocomportamental da amostra de estudo com a amostra original da padronização do teste NAPI.

b) Comparar os indicadores de desenvolvimento neurocomportamental em grupos diferenciados pelos problemas perinatais.

c) Comparar os indicadores de desenvolvimento neurocomportamental em grupos diferenciados quanto ao sexo

\footnotetext{
${ }^{1}$ Estudo integrado ao Projeto de Pesquisa de Doutorado intitulado "Estudo Longitudinal de Detecção de Atrasos no Desenvolvimento de bebês pré-termo no Primeiro ano de vida” realizado por Cibelle Kayenne Martins Roberto Formiga, doutoranda do Programa de Pós-graduação em Saúde Mental da Faculdade de Medicina de Ribeirão Preto, sob orientação da Prof ${ }^{a}$. Dr ${ }^{\mathrm{a}}$. Maria Beatriz Martins Linhares.
} 


\section{MÉTODO}

\subsection{Participantes}

A amostra do presente estudo foi constituída por 202 bebês nascidos prétermo ( $\leq 37$ semanas de idade gestacional) e internados na Unidade Neonatal de Médio Risco, caso o bebê recebesse alta desta unidade o mesmo seria avaliado no Berçário de Cuidados Intermediários do Hospital Materno-Infantil da cidade de Goiânia (GO) que era destinado aos bebês que se encontravam clinicamente estáveis e necessitando ganhar peso, no período de setembro de 2004 a janeiro de 2006.

Foram elegíveis para o estudo todos os neonatos nascidos pré-termo, de ambos os sexos e com baixo peso ao nascimento $(<2500 \mathrm{~g})$. No caso de os bebês serem gemelares, eles foram escolhidos aleatoriamente por sorteio.

Os critérios de inclusão foram os seguintes:

- idade pós-concepcional de 32 a 37 semanas

- peso ao nascimento $\leq 2500 \mathrm{~g}$

- estáveis clinicamente, no período da avaliação (respirando espontaneamente em ar ambiente, com ou sem sonda de alimentação)

- ter mais de cinco dias de idade pós-natal, que permitisse a avaliação segundo as normas que constam no Manual NAPI.

Os critérios de exclusão foram os seguintes:

- má formação congênita

- suspeita de doenças genéticas

- sob ventilação assistida 
- hemorragia periventricular graus III e IV

- coma, sedação e septicemia.

Primeiramente, foi realizado um levantamento de dados coletados no livro de registro da Sala de Parto do Hospital que revelaram um total de 268 bebês nascidos pré-termo.

Aplicados os critérios, de 268 recém-nascidos no período da coleta de dados, foram excluídos da amostra 66 bebês pelos seguintes motivos: 19 foram os gemelares excluídos por sorteio; nove dos recém-nascidos apresentavam peso ao nascimento maior do que 2500g; 25 dos recém-nascidos não estavam na fase de 32 a 37 semanas de idade pós-concepcional e quatro recém-nascidos apresentaram má formação congênita (pé-torto). Além disso, nove recém-nascidos tiveram alguma falha ou alteração no momento da filmagem do teste prejudicando a aplicação do teste, sendo, portanto, necessário serem excluídos da amostra.

Portanto, a amostra final do estudo foi composta por 202 neonatos.

\subsection{Local de estudo}

A pesquisa foi realizada na Unidade Neonatal de Médio Risco e/ou Berçário de Cuidados Intermediários do Hospital Materno-Infantil da cidade de Goiânia (GO), sob a coordenação local da doutoranda Cibelle Kayenne Martins Roberto Formiga, discente do curso de Pós-graduação em Saúde Mental da Faculdade de Medicina de Ribeirão Preto. O hospital é uma instituição que se caracteriza como prestadora de um serviço público de referência, é vinculado ao governo estadual e é mantido pelo sistema Único de Saúde. Caracteriza-se por um atendimento de nível terciário no atendimento à mãe e à criança, e atende uma vasta clientela oriunda de outros hospitais da cidade e de outros municípios, por possuir uma UTI Neonatal, UTI 
Pediátrica e atendimento às gestantes de alto risco.

\subsection{Aspectos Éticos}

O estudo foi previsto de acordo com as Diretrizes e Normas Regulamentadoras de Pesquisas Envolvendo Seres Humanos (Resolução 196/1996, do Conselho Nacional de Saúde).

Antes da realização da coleta de dados os pais e/ou responsáveis pelas crianças receberam esclarecimentos sobre o objetivo do estudo, as condições do sigilo de sua identidade a o caráter voluntário para a participação no estudo, podendo desligar-se a qualquer momento durante a execução da pesquisa. Para atender este requisito ético, foi formulado um "Termo de Consentimento Livre e Esclarecido" (ANEXO A), com linguagem compreensível, incluindo informações necessárias para os pais dos bebês a respeito do estudo. O estudo foi submetido e aprovado pelo Comitê de Ética em Pesquisa do Hospital Geral de Goiânia protocolo CEPHA - HGG №. 73/04. (ANEXO B).

\subsection{Instrumentos e Materiais}

a) Avaliação Neurocomportamental do Bebê Pré-Termo (NAPI) Neurobehavioral Assessment of the Preterm Infant (KORNER et al., 2000), o qual foi traduzido para a língua Portuguesa (Brasil) com autorizacão dos autores para fins de pesquisa (FORMIGA; GABRIEL; LINHARES, 2005). Destina-se a avaliar a maturidade e o comportamento do bebê com idade pós-concepcional de 32 a 40 semanas. Os itens do teste avaliam o desenvolvimento motor e força, a amplitude dos movimentos passivos, e a capacidade de atentar para estímulos auditivos e visuais. As respostas da criança ao teste são imediatamente pontuadas após o 
examinador proceder ao item. Os itens do teste são apresentados numa seqüência invariável que é destinada a reproduzir os tipos de estados comportamentais, o que contribui para eliciar a melhor resposta possível da criança. Essa seqüência invariável de apresentação, juntamente com classificações repetidas do estado comportamental neurológico da criança, permite ao examinador comparar o desempenho do bebê por meio de repetidas administrações ou entre outros bebês.

A validade desenvolvimental de sete domínios foi investigada. As autoras relataram que, na medida em que a idade gestacional aumentava, os escores em todos os domínios exceto o percentual adormecido também aumentavam.

A confiabilidade teste-reteste foi avaliada pelos autores. Só os itens que excederam o coeficiente de correlação de Spearman de 0,20 foram considerados. Os itens testados e mantidos variaram de $r=0,41$ a 0,85 . A confiabilidade entre observadores também foi testada em 30 RNPT entre 34 e 35 semanas e a correlação variou de $r=0,67$ a 0,97. A validade aparente e a sensibilidade do NAPI foram obtidas usando o índice de complicações médicas baseado na variação da classificação 1 a 5, NMI- Neonatal Medical Index - O Índice Médico Neonatal (KORNER et al., 1994).

Uma grande parte da avaliação do NAPI consiste em meramente observar a criança, sem manipulá-la. Os estados comportamentais são avaliados em todo o exame e descrições resumidas de classificações do estado de alerta da criança, qualidade do choro, e qualidade do movimento são feitas imediatamente após a finalização do exame.

Os estados comportamentais correspondem ao estado de vigília e sono do bebê no momento da avaliação e permite observar se o bebê encontra-se dormindo, sonolento, acordado e chorando. A classificação varia de 1 a 6 sendo: Estado 1 - 
Sono Tranqüilo (os olhos estão fechados, o rosto está relaxado, a respiração está normal com movimentos pequenos ou ausentes, exceto por ocasião de sustos ou movimentos espasmódicos.); Estado 2 - Sono Ativo ( a pálpebra está fechada na maior parte do tempo, rápidos movimentos dos olhos (REMS) podem ser vistos intermitentemente, tem-se uma aparência vidrada com caretas, sorrisos reflexos e outras expressões da face ocorrem freqüentemente, assim como, pequenas amplitudes de contração. As respirações são irregulares e mais rápidas do que quando o bebê está no sono tranqüilo, várias atividades motoras de lentos movimentos dos membros e ajustes posturais para contorcer todo o corpo.); Estado 3 - Sonolência ( os olhos podem abrir ou fechar intermitentemente, especialmente antes do bebê dormir e podem aparecer fortemente fechados. Durante a sonolência os olhos invariavelmente têm uma aparência entorpecida, vaga e vidrada e o bebê está relativamente inativo. Se o bebê chega a se mover, ele o faz muito lentamente); Estado 4 - Alerta Inativo (os olhos estão usualmente abertos e luminosos, com uma aparência viva e brilhante, o rosto está relaxado (sem caretas) e todos os movimentos do corpo são lentos (falta vigor).); Estado 5 - Alerta ativo (os olhos estão abertos ou fechados. Quando os olhos estão abertos, eles não estão cintilantes nem brilhantes. As caretas de choro podem ser vistas, mas vocalizações estão ausentes, a respiração é irregular com vigorosa e difusa atividade motora freqüentemente envolvendo todo o corpo.); Estado 6 - Choro (os olhos abertos ou fechados, há vocalizações de choro e a atividade motora é vigorosa e difusa.)

A avaliação completa envolve 71 itens, incluindo-se sinais fisiológicos do bebê (coloração, padrão de choro, presença de apnéia, etc.) e avaliação da mudança do estado comportamental ao longo do exame, por meio de sistema de escores. Finalmente, o examinador completa alguns cálculos, converte o escore da criança 
em dados padrões e reúne grupos de pontos. A pontuação da criança então pode ser comparada com seus desempenhos anteriores na avaliação NAPI ou com a pontuação de outros bebês.

Os seguintes materiais e equipamentos foram utilizados na aplicação do NAPI: colchonete, a ficha de registro, um brinquedo vermelho sonoro para os itens de orientação visual e auditivo inanimado, dois suportes de cabeça para manter a cabeça do bebê em linha média, uma manta e uma cadeira para o examinador administras os itens de orientação.

Ao final da avaliação os escores são agrupados em sete categorias neurocomportamentais para a conversão das pontuações em valores de 0 a 100 de acordo com o peso atribuído a cada uma das sete categorias que são: - Sinal de cachecol (avalia o tônus muscular do membro superior bilateralmente), Desenvolvimento Motor e Vigor (consta de seis itens, a saber: recuo de antebraço, suspensão ventral, elevação da cabeça em prono, rastejar espontâneo, potência das atividades do movimento (pernas e braços) são pontuados de nenhum movimento a muito forte e movimentos espontâneos que são pontuados de nenhum a vigorosos), - Ângulo Poplíteo (avalia o tônus muscular do membro inferior bilateralmente), Alerta e Orientação (avalia a responsividade da criança frente a estímulos visual animado (rosto do examinador) e inanimado (brinquedo vermelho) e auditivo animado (voz do examinador) e inanimado (som do brinquedo) e a capacidade em manter-se alerta durante a administração dos quatro itens), - Irritabilidade (podendo ser classificado com os seguintes escores, segundo Korner et al., 1996: zero (bebê nunca chorou durante a avaliação) , 33,3 (bebê apresentou apenas face de choro), 66,7 (bebê chorou raramente) e 100 (bebê chorou freqüentemente) avalia a extensão ou magnitude do choro durante a administração do teste e a freqüência em 
que o bebê esteve no estado comportamental Choro), - Qualidade de choro (podendo ser classificado com os seguintes escores: zero (choro fraco), 50 (choro moderadamente forte) e 100 (choro forte) avalia o vigor do choro do bebê durante a administração do teste), - Percentual adormecido (avalia a freqüência em que o bebê permaneceu no estado comportamental de Sono Quieto, Sono Ativo e Sonolência. A pontuação é feita de acordo com o percentual de ocorrência dentro das 14 oportunidades em que o estado comportamental é avaliado, fazendo uma somatória das ocorrências dos estados (Estado 1, 2 e 3 respectivamente).

De acordo com o instrumento, o estado comportamental do bebê é avaliado em 14 oportunidades com o objetivo de verificar a respostas ao longo da seqüência do manuseio e de suas capacidades sensoriais aos estímulos visuais e sonoros. Destaca-se que para o registro das ocorrências dos estados comportamentais realiza-se uma regra de três para o número das ocorrências, multiplicado por 100 e dividido por 14 oportunidades para a porcentagem. Considera-se: 1 ocorrência = 7,15; 2 ocorrências $=14,3 ; 3$ ocorrências $=21,5 ; 7$ ocorrências $=50 \ldots$ e assim para todos os estados comportamentais.

b) Prontuário médico para obtenção dos seguintes dados: Apgar do $1^{\circ}$ e $5^{\circ}$ minuto, tempo de internação, NMI - O Índice Médico Neonatal / Neonatal Medical Index - (KORNER et al., 1994), CRIB I - Índice de Risco Clínico Neonatal I / Clinical Risk Index for Babies I (THE INTERNACIONAL NEONATAL NETWORK, 1993) e CRIB II - Índice de Risco Clínico Neonatal II / Clinical Risk Index for Babies II (PARRY et al., 2003).

c) Roteiro de Anamnese (FORMIGA, 2009) que incluía dados de identificação do recém-nascido, dados maternos e condições da gestação (planejamento da gravidez, pré-natal, exames realizados), dados do parto (tipo e condições clínicas do 
parto), resumo da história pré e perinatal e dados relacionados às condições clínicas do bebê (ANEXO C).

d) Questionário de Classificação Sócio - Econômico (FORMIGA, 2009) (ANEXO E), os participantes do estudo foram caracterizados de acordo com os dados do Questionário de Classificação Sócio-Econômico.

e) A classificação do nível econômico foi realizada com base no critério de classificação Econômica da Associação Brasileira de Empresas de Pesquisa (ABEP, 2003) (ANEXO D). Este critério considera o poder de compra das pessoas e o grau de instrução do chefe da família, variando de 0 a 34 pontos, classificados em uma escala ordinal decrescente como em Classe A1 (30 a 34 pontos), Classe A2 (25 a 29 pontos), Classe B1 (21 a 24 pontos), Classe B2 (17 a 20 pontos), Classe C (11 a 1 pontos), Classe D (6 a 10 pontos) e Classe E (0 a 5 pontos).

\subsection{Equipamentos}

Para a realização da filmagem, organização e análise dos vídeos para a codificação subseqüente dos escores do NAPI de acordo com o manual, foi utilizada uma câmera filmadora digital "câmera Mini DV Sony-Digital Hanycam- Modelo DCRHC40".

\subsection{Procedimento}

\subsubsection{Treino dos Pesquisadores}

Foi realizado o treino da pesquisadora A (autora deste estudo) e da pesquisadora B (Cibelle Kayenne Martins Roberto Formiga), a fim de capacitação para o desenvolvimento das tarefas de coleta, preparação e análise de dados. 
O treinamento constou da leitura do manual NAPI para aprender sobre o procedimento de aplicação dos itens do teste, julgar os estados comportamentais, pontuar as respostas dos bebês e classificar os desempenhos. A fita do vídeo de treinamento NAPI foi vista repetidas vezes para compreender exatamente como o exame deveria ser realizado. Foi especialmente importante entender a seqüência e proceder ao exame tão bem quanto o padrão, vagarosamente executado passo a passo, manipulando gentilmente a criança, não apenas para minimizar o estresse da criança, mas também para obter respostas sempre dentro da ordem obtida durante a padronização do exame.

A Pesquisadora B treinou 12 alunas de Iniciação Científica do curso de Fisioterapia da Universidade Estadual de Goiás (UEG) para que elas pudessem fazer a aplicação e filmagem do teste nos bebês. A pesquisadora B realizou treinamento e administração da seqüência da avaliação em uma amostra de 20 bebês prematuros previamente selecionados.

A Pesquisadora A realizou o treino da análise dos vídeos desses 20 bebês coletados, pela pesquisadora B. Depois de terminado, foi realizado o treino de mais 20 bebês coletados posteriormente. Foi assegurada a condição "cega" da pesquisadora $B$, a fim de evitar o viés na análise dos dados dos bebês avaliados. Primeiramente, esta só teve acesso aos vídeos. Posteriormente, após finalizar a análise, a Pesquisadora $A$ obteve o banco de dados e as informações sobre os bebês.

Foi realizado um índice de acordo entre as Pesquisadoras $A$ e $B$ quanto às pontuações do desempenho dos bebês no teste NAPI. Houve um treinamento na análise e pontuacão dos videos com discussões sobre os itens concordantes e discordantes. Para a cálulo do Índice de Acordo foi aplicado a seguinte fórmula: 
Acordo/ Acordo + Desacordo X 100. Para obtenção do Índice de Acordo utilizou-se $20 \%$ dos videos. O Índice de Acordo entre observadores independentes e treinados obtido na avaliacão do NAPI foi de $88 \%$.

\subsubsection{Coleta de Dados}

Os bebês elegíveis para o estudo foram identificados junto aos prontuários médicos do hospital com base nos critérios de inclusão exclusão da pesquisa. Em seguida, foi preenchido o Roteiro de Anamnese baseado no prontuário médico. As mães eram localizadas para obtenção da anuência dos pais e a participação no estudo. Foi assinado o Termo de Consentimento Livre e Esclarecido.

Posteriormente, foi realizada a coleta de dados, pela pesquisadora $\mathrm{B}$, por meio de entrevista com as mães para preenchimento dos dados que estavam incompletos no Roteiro de Anamnese, principalmente os dados relacionados ao pré-natal. Nessa mesma ocasião, foi coletado em entrevista com a mãe ou responsável pela criança o Questionário de Classificação Sócio - Econômico. Assim como, utilizou-se o Questionário Sócio-Econômico do ABEP. Esses dados foram direcionados para: escolaridade materna, escolaridade paterna, estado civil dos pais, tipo de residência e número de cômodos, número de pessoas que moram com a criança, renda familiar em número de salários mínimos vigente $\mathrm{R} \$ 300,00$, plano de saúde, dentre outros.

Antes do início da avaliação, a equipe da Unidade era consultada a respeito das condições clínicas do bebê naquele dia e a respeito do horário de alimentação (intervalo dos horários de alimentação eram 45 minutos a uma hora antes da próxima alimentação).

Duas pesquisadoras (Pesquisadora B e uma aluna de Iniciação Científica) entravam na Unidade, no intervalo entre as mamadas dos bebês. Uma das 
pesquisadoras manuseava o bebê, enquanto a outra era responsável pela filmagem da avaliação, orientava a seqüência dos itens e entregava os materiais. Além disso, registrava verbalmente algumas informações importantes que só com a imagem não seriam suficientes, por exemplo: alteração na coloração da pele, o tônus muscular entre outras. As avaliações tiveram uma duração média de 20 minutos, tempo necessário para a aplicação do NAPI sem cansar o bebê.

A avaliação seguiu uma sequência invariável, de acordo com as normas do NAPI, a saber: manobra de cachecol, resistência da perna, rersitência do braço, ângulo poplíteo, suspensão ventral, postura prona, mobilidade de membros superiores e inferiores, e itens de orientação visual e auditiva.

Após a realizacão da avaliacão, o bebê era recolocado gentilmente na incubadora ou entregue para a mãe, caso esta estivesse presente neste momento.

\subsubsection{Preparacão e Análise dos dados}

Após as vídeo-gravações, as avaliações gravadas em fitas mini-DV foram capturadas com auxílio da Placa de captura Firewere IEEE 1394 e do software Pinnacle Studio (versão 10.5) para as edições das imagens de cada bebê e a organização dos arquivos de acordo com códigos. As imagens foram reproduzidas no computador, editadas e armazenadas em DVDs que foram analisadas em computador com drive de DVD. Essas imagens editadas foram armazenadas em DVD para posterior análise dos dados. O desempenho neurocomportamental do bebê foi pontuado de acordo com as normas do NAPI pela pesquisadora A. O NAPI retrata um sistema original de pontuação numérica para avaliar as respostas do bebê aos itens. Assim como, o seu estado comportamental. A pontuação no NAPI 
representa uma progressão na maturidade da resposta dos bebês, podendo variar de 0 a 100.

Foram analisados 202 vídeos contendo uma única sessão em cada, com uma duração média de 20 minutos. Os desempenho neurocomportamental dos bebês foram analisados por examinador a "cego" (Pesquisadora A), em relacão aos dados de caracterização e evolução clínica dos bebês.

$\mathrm{Na}$ análise da Avaliacão Neurocomportamental NAPI foram considerados os dados normativos da amostra padronizada do teste. De acordo com os autores do instrumento, o bebê é considerado atrasado quando a pontuacão obtida nas sete categorias de análise for - 1,0 desvio padrão (DP) abaixo da média.

Em seguida, os dados foram inseridos em uma planílha do Statistical Package for Social Science - SPSS (versão 16.0) para processamento de dados e posterior tratamento estatístico. Os dados foram submetidos à análise estatística descritiva. As variáveis discretas foram quantificadas em termos de frequência, prevalência ou porcentagem e as variáveis numéricas em termos de média, desvio padrão, mediana e valores mínimo e máximo. Procedeu-se à comparação entre os resultados do NAPI obtidos na amostra do estudo e os resultados da amostra original de padronização do teste por meio do programa InStat. A comparação entre as médias foi realizada pelo teste $t$ Student para amostras independentes, com correção no caso das variáveis sem distribuição normal (com diferença significativa entre os desvios-padrão).

$\mathrm{Na}$ análise estatística inferencial, foi realizada a comparacão entre grupos (meninos vs meninas) por meio do teste de Mann-Whitney para duas amostras independentes, para as variáveis numéricas contínuas, e o teste do Qui-Quadrado, para as variáveis categóricas. Foi criado um grupo denominado com problema 
perinatal composto por bebês que nasceram PIG, que tiveram algum episódio de anóxia, hemorragia e hidrocefalia. Procedeu-se à comparação do desempenho no NAPI entre os dois grupos, o grupo com problema perinatal (PIG, anóxia, hemorragia e hidrocefalia) e o grupo sem problema perinatal (os demais da amostra total de estudo), por meio do teste t de Student para duas amostras independentes. Por fim, procedeu-se à comparação entre os escores dos itens do NAPI, de acordo com a idade pós-concepcional, da amostra do grupo sem problema perinatal com amostra original de padronização do teste NAPI, por meio do programa InStat.

O nível de significância adotado no presente estudo para todos os testes foi de $5 \%$. 


\section{Resultados}

Os resultados do presente estudo serão apresentados em quatro sessões. Primeiramente, serão apresentados os dados sobre a caracterização da amostra. Na segunda seção, encontram-se os resultados sobre 0 desenvolvimento neurocomportamental da amostra total. Na terceira sessão, serão apresentados os resultados sobre o desenvolvimento neurocomportamental dos bebês em grupos diferenciados quanto a presença de problemas na fase perinatal. Na última sessão, serão mostrados os resultados da comparação do desenvolvimento neurocomportamental dos bebês em grupos diferenciados por sexo.

4.1 Caracterização da amostra

A Tabela 1 apresenta as características dos bebês da amostra total e em grupos diferenciados quanto ao sexo. 


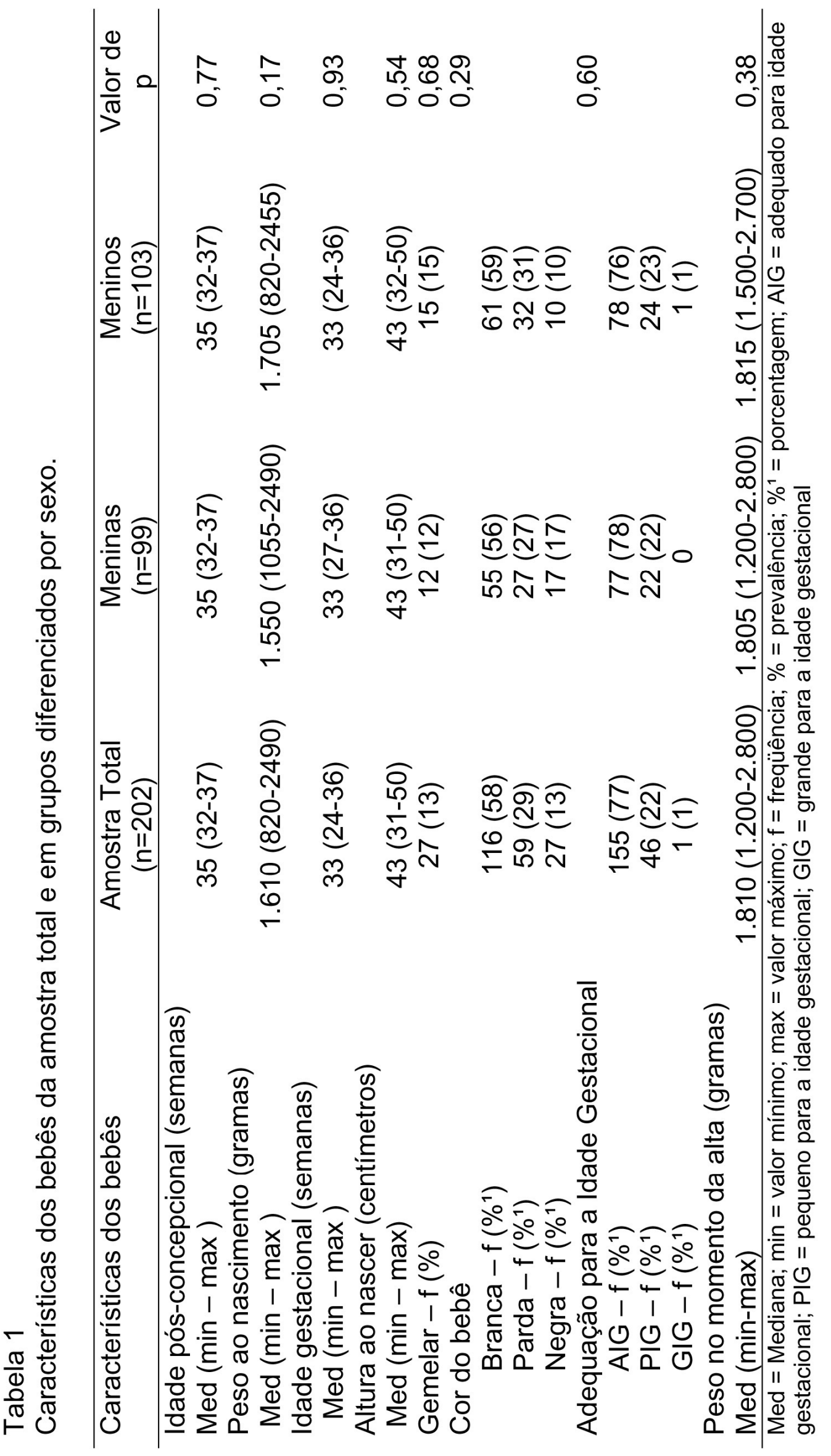


Nota-se na Tabela 1 que os bebês estavam em torno de 35 semanas de idade pós-concepcional, e apresentavam peso ao nascimento de 1.610 gramas. A maior parte da amostra era de bebês nascidos adequados para a idade gestacional e brancos. Dos 202, apenas $13 \%$ eram gemelares. Houve grande variabilidade do peso no momento da alta, apresentando mediana de 1.810 gramas. Houve uma distribuição semelhante entre meninos e meninas na amostra. Observa-se que os grupos de meninas e meninos eram semelhantes quanto às características de idade gestacional, idade pósconcepcional, gemelaridade, adequação para a idade gestacional e peso no momento da alta, o que torna os grupos comparáveis.

A Tabela 2 apresenta os índices neonatais relativas ao Apgar e Índices de risco clínico neonatal CRIB e NMI, da amostra total e em grupos diferenciados quanto ao sexo.

Tabela 2

Índices de risco clínico neonatal da amostra total e em grupos diferenciados por sexo.

\begin{tabular}{|c|c|c|c|c|}
\hline Índices de risco clínico neonatal & $\begin{array}{l}\text { Amostra Total } \\
(\mathrm{n}=202)\end{array}$ & $\begin{array}{c}\text { Meninas } \\
(\mathrm{n}=99)\end{array}$ & $\begin{array}{c}\text { Meninos } \\
(\mathrm{n}=103)\end{array}$ & $\begin{array}{l}\text { Valor } \\
\text { de } p\end{array}$ \\
\hline $\begin{array}{l}\text { Apgar do } 1^{\circ} \text { minuto (escore) } \\
\text { Med (min - max) }\end{array}$ & $7(0-9)$ & $7(0-9)$ & $7(0-9)$ & 0,54 \\
\hline $\begin{array}{l}\text { Apgar do } 5^{\circ} \text { minuto (escore) } \\
\text { Med (min - max ) }\end{array}$ & $8(1-10)$ & $8(2-10)$ & $8(1-10)$ & 0,41 \\
\hline $\begin{array}{l}\text { Índice de risco clínico neonatal } \\
\text { (escore no CRIB-I) } \\
\text { Med (min - max) }\end{array}$ & $0(0-5)$ & $0(0-5)$ & $0(0-4)$ & 0,36 \\
\hline $\begin{array}{l}\text { Índice de risco clínico neonatal } \\
\text { (escore no CRIB-II) } \\
\text { Med (min - max ) }\end{array}$ & $1(0-10)$ & $1(0-7)$ & $1(0-11)$ & 0,31 \\
\hline $\begin{array}{l}\text { Neonatal Medical Index NMI } \\
\text { Med (min - max) }\end{array}$ & $3(1-5)$ & $3(1-5)$ & $3(1-5)$ & 0,08 \\
\hline
\end{tabular}


Observa-se na Tabela 2 que as medianas de Apgar e de Risco Clínico Neonatal foram sugestivos de bom prognóstico dos bebês, considerando-se que as medianas de Apgar foram acima de 8 e o CRIB e NMI abaixo de 5. As meninas e os meninos foram semelhantes quanto aos índices de Apgar e Risco Clínico Neonatal.

Complementando os dados da Tabela 2, verificou-se que $70 \%$ dos bebês choraram ao nascer, tendo uma prevalência de 142 bebês. Houve também uma diferença significativa no item Chorou ao nascer, em que os meninos choraram mais ao nascer (78\%) quando comparados às meninas (63\%).

A Tabela 3 apresenta as características de evolução clínica dos bebês da amostra total e em grupos diferenciados quanto ao sexo. 
Tabela 3

Características de evolução clínica dos bebês da amostra total e em grupos diferenciados quanto ao sexo.

\begin{tabular}{|c|c|c|c|c|}
\hline Características de Evolução Clínica & $\begin{array}{c}\text { Amostra } \\
\text { Total } \\
(n=202)\end{array}$ & $\begin{array}{c}\text { Meninas } \\
(n=99)\end{array}$ & $\begin{array}{c}\text { Meninos } \\
(n=103)\end{array}$ & $\begin{array}{l}\text { Valor } \\
\text { de p }\end{array}$ \\
\hline complicações & & & & \\
\hline Med (min-max) & $3(0-9)$ & $3(0-9)$ & $3(0-9)$ & 0,55 \\
\hline Insufuciência respiratória aguda - f (\%) & $179(89)$ & $85(86)$ & $94(91)$ & 0,27 \\
\hline Icterícia - f (\%) & $145(72)$ & $68(69)$ & $77(75)$ & 0,35 \\
\hline Infecção Neonatal - f (\%) & $135(67)$ & $62(63)$ & $73(71)$ & 0,23 \\
\hline Taquipnéia transitória do $\mathrm{RN}$ - f (\%) & $70(35)$ & 37 (37) & $33(32)$ & 0,46 \\
\hline Anóxia - f (\%) & $24(12)$ & $13(13)$ & $11(11)$ & 0,67 \\
\hline Apnéia - f (\%) & $24(12)$ & $11(11)$ & $13(13)$ & 0,83 \\
\hline Anemia - f (\%) & $16(8)$ & $9(9)$ & $7(7)$ & 0,61 \\
\hline Retardo do crescimento intra-uterino - & $8(4)$ & $4(4)$ & $4(4)$ & 100 \\
\hline Hipoglicemia - f (\%) & $8(4)$ & $3(3)$ & $5(5)$ & 0,72 \\
\hline Tocotraumatismo - $f(\%)$ & $7(4)$ & $2(2)$ & $5(5)$ & 0,45 \\
\hline Refluxo gastro-esofágico - f (\%) & $6(3)$ & $5(5)$ & $1(1)$ & 0,11 \\
\hline Cardiopatia - f (\%) & $5(3)$ & $2(2)$ & $3(3)$ & 1,00 \\
\hline Crise convulsiva $-f(\%)$ & $2(1)$ & $2(2)$ & $0(0)$ & 0,24 \\
\hline Alteração da US transfontanela-f (\%) & & & & 0,06 \\
\hline Leucomalácia Periventricular & $25(12)$ & $7(7)$ & $18(18)$ & \\
\hline HIV grau I ou II & $17(8)$ & $10(10)$ & $7(7)$ & \\
\hline Hidrocefalia & $2(1)$ & 0 & $2(2)$ & \\
\hline Displasia Broncopulmonar - $\mathrm{f}(\%)$ & $1(1)$ & $1(1)$ & 0 & 0,49 \\
\hline Alteração exame visual - f (\%) & $3(2)$ & 0 & $3(2)$ & 0,25 \\
\hline
\end{tabular}

$\mathrm{Na}$ Tabela 3, verifica-se que, em relação às características de evolução clínica, os bebês apresentaram em torno de três complicações, podendo ter bebês sem nenhuma complicação, e bebês com nove complicações. Os bebês apresentaram predominantemente insuficiência respiratória aguda, icterícia e infecção neonatal. Dos 202 bebês, 21\% apresentaram alteração da ultrasonografia transfontanela, sendo que $12 \%$ apresentaram leucomalácia periventricular. Observa-se que os grupos de meninas e meninos foram semelhantes. Verificou-se, no entanto, que houve uma tendência $(p \leq 0,06)$ de 
os meninos apresentarem mais alterações na ultra-sonografia transfontanela do que as meninas.

A Tabela 4 apresenta os procedimentos clínicos a que os bebês foram submetidos e o tempo de internação da amostra total e em grupos diferenciados quanto ao sexo.

Tabela 4

Procedimentos clínicos e tempo de internação hospitalar que os bebês da amostra total e em grupos diferenciados quanto ao sexo.

\begin{tabular}{|c|c|c|c|c|}
\hline Procedimentos clínicos & $\begin{array}{c}\text { Amostra } \\
\text { Total } \\
(n=202)\end{array}$ & $\begin{array}{c}\text { Meninas } \\
(n=99)\end{array}$ & $\begin{array}{c}\text { Meninos } \\
(n=103)\end{array}$ & $\begin{array}{l}\text { Valor } \\
\text { de p }\end{array}$ \\
\hline $\begin{array}{l}\text { № total de medidas clínicas } \\
\text { realizadas Med (min-max) } \\
\text { Ventilação assistida }\end{array}$ & $3(0-8)$ & $3(0-8)$ & $3(0-8)$ & 0,31 \\
\hline $\begin{array}{l}\text { Hood ou Capacete de } \mathrm{O}_{2}-\mathrm{f}(\%) \\
\text { CPAP nasal - } \mathrm{f}(\%) \\
\quad \mathrm{O}_{2} \text { circulante na Incubadora - f (\%) } \\
\text { Ventilação mecânica - f (\%) } \\
\text { Antibioticoterapia - } \mathrm{f}(\%) \\
\text { Fototerapia - } \mathrm{f}(\%) \\
\text { Administração de Surfactante - f (\%) } \\
\text { Corticoterapia - } \mathrm{f}(\%) \\
\text { Transfusão sanguínea - } \mathrm{f}(\%)\end{array}$ & $\begin{array}{c}172(85) \\
118(58) \\
40(20) \\
11(5) \\
144(71) \\
146(72) \\
9(5) \\
4(2) \\
24(12) \\
\end{array}$ & $\begin{aligned} 83(8) \\
55(56) \\
19(19) \\
5(5) \\
67(68) \\
71(72) \\
5(5) \\
1(1) \\
15(15) \\
\end{aligned}$ & $\begin{aligned} & 89(86) \\
& 63(61) \\
& 21(20) \\
& 6(6) \\
& 77(75) \\
& 75(73) \\
& 4(4) \\
& 3(3) \\
& 9(12) \\
&\end{aligned}$ & $\begin{array}{l}0,69 \\
0,48 \\
0,86 \\
1,00 \\
0,28 \\
0,88 \\
0,74 \\
0,62 \\
0,19 \\
\end{array}$ \\
\hline Tempo de internação (em dias) & & & & \\
\hline $\begin{array}{l}\text { Tempo de internação na Unidade } \\
\text { Neonatal de Alto Risco } \\
\text { Med (min-max) } \\
\text { Tempo de internação na Unidade } \\
\text { Neonatal de Médio Risco - } \\
\text { Med (min-max) } \\
\text { Tempo de internação na Enfermaria } \\
\text { Med (min-max) } \\
\text { Tempo total de internação no } \\
\text { Hospital Med (min-max) }\end{array}$ & $\begin{array}{l}8(0-60) \\
8(0-36)\end{array}$ & $\begin{array}{l}8(0-42) \\
7(0-36)\end{array}$ & $7(0-60)$ & 0,35 \\
\hline
\end{tabular}


A Tabela 4 mostra que, em relação aos procedimentos clínicos, $85 \%$ dos bebês usaram o Hood ou Capacete de oxigênio e 58\% usaram CPAP nasal, sendo que apenas $5 \%$ precisaram de ventilação mecânica durante a internação no hospital. Os procedimentos de antibioticoterapia e fototerapia foram os mais freqüentemente utilizados. Quanto à internação, o tempo de internação total no hospital foi de uma mediana de 27 dias, com uma amplitude de variação de 5 a 95 dias.

Observa-se que não houve diferença significativa entre os grupos de meninas e meninos com relação aos procedimentos clínicos necessários durante a internação e o tempo de internação hospitalar.

A Tabela 5 apresenta as características das mães dos bebês da amostra total e dos grupos diferenciados quanto ao sexo. 


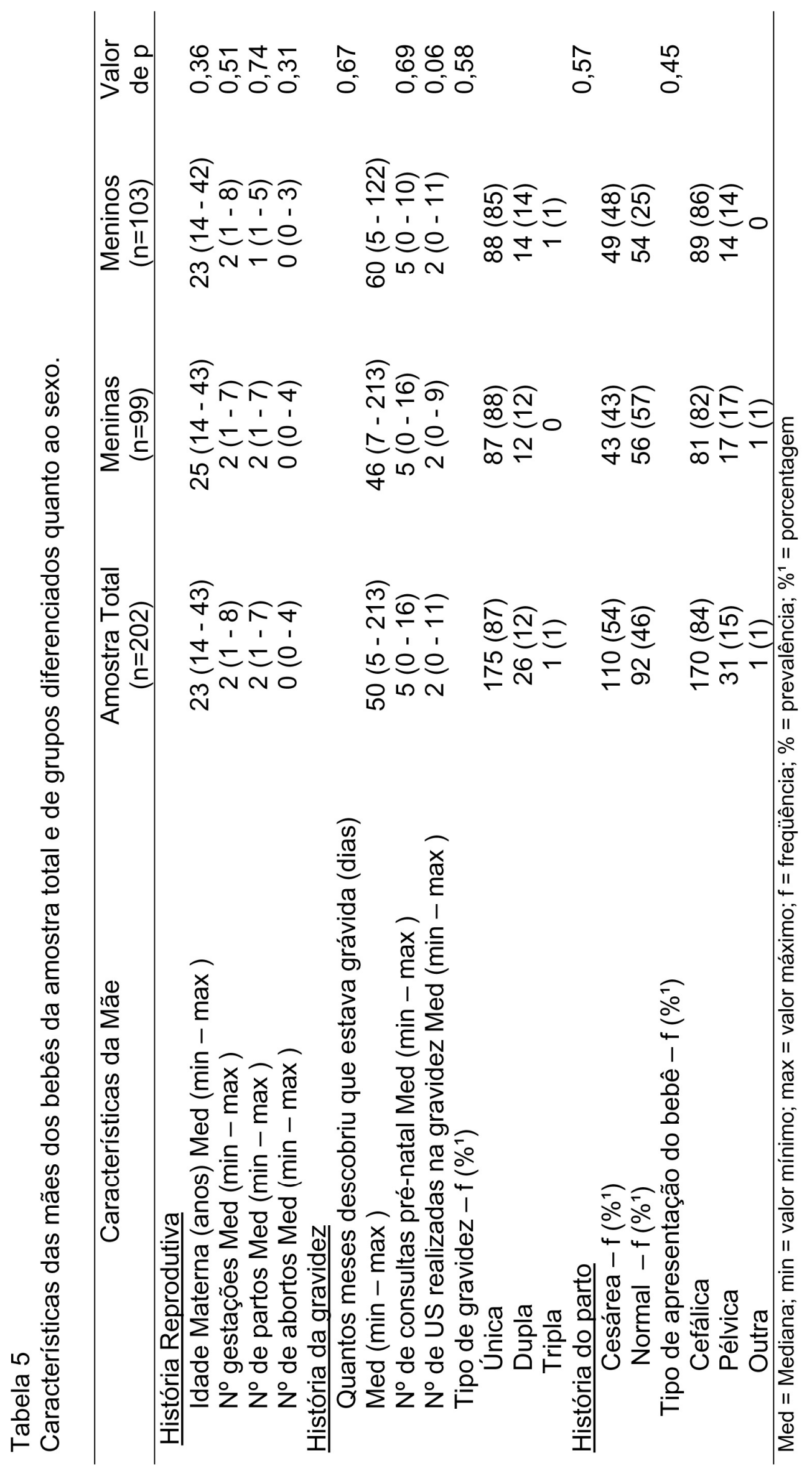


Observa-se na Tabela 5 que as mães dos bebês eram jovens, com uma idade mediana de 23 anos na gravidez, sendo a idade mínima de 14 anos e a máxima de 43 anos. Realizaram cinco consultas pré-natal, em mediana, predominando gravidez única. 54\% dos bebês nasceram de parto cesárea, predominando apresentação cefálica. Observa-se que não houve diferença significativa entre os grupos de meninas e meninos com relação as características maternas.

A Tabela 6 apresenta os dados de complicações da gravidez das mães e aleitamento materno da amostra total e de grupos diferenciados quanto ao sexo. 


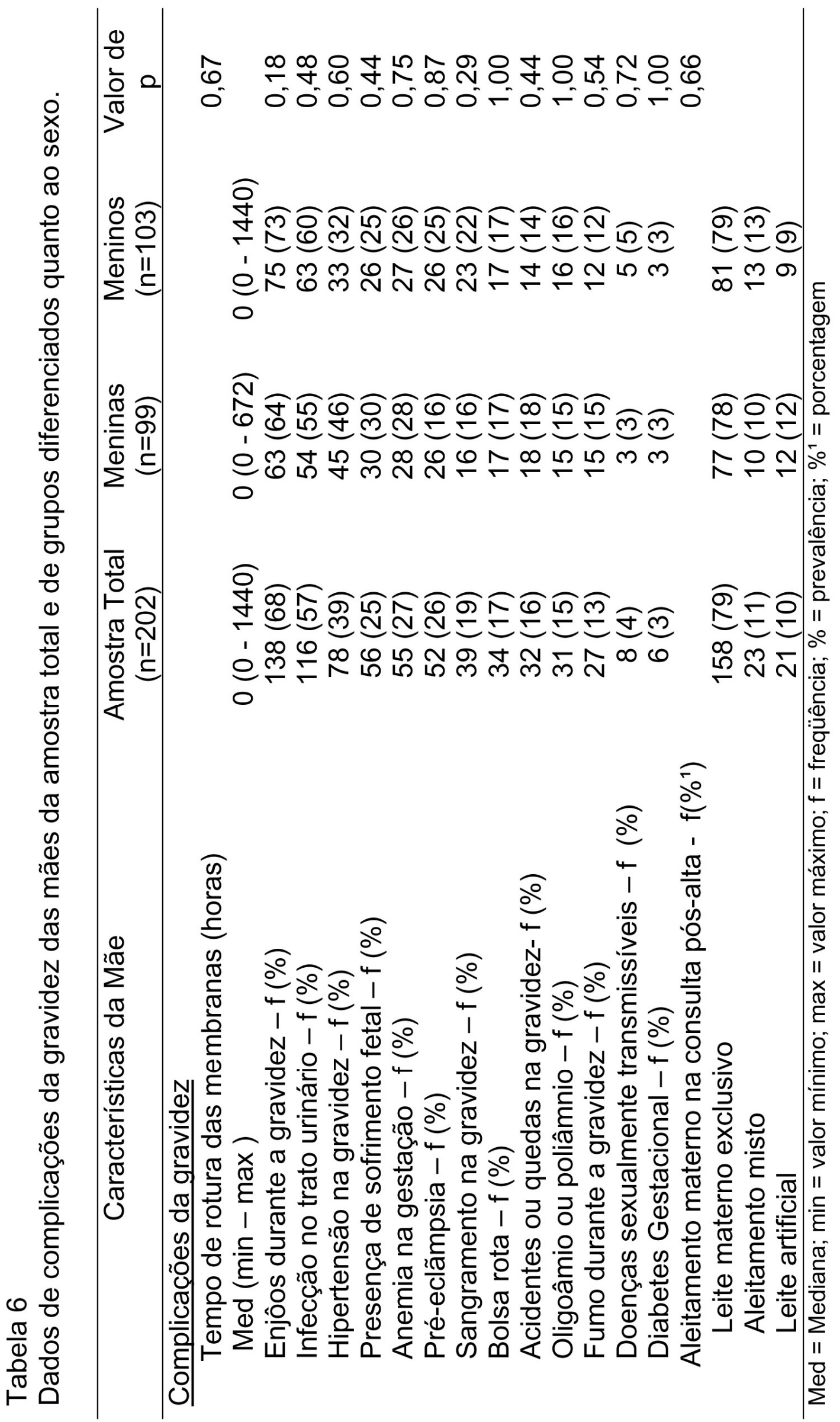


Nota-se na Tabela 6 que as patologias e intercorrências principais que as mães apresentaram foram: enjôos, infecção no trato-urinário e hipertensão na gravidez. Em relação ao aleitamento materno, houve um predomínio da amamentação exclusiva. Não houve diferença significativa entre os grupos de meninas e meninos com relação as características maternas.

A tabela 7 apresenta os dados de escolaridade dos pais da amostra total e dos grupos diferenciados quanto ao sexo. 


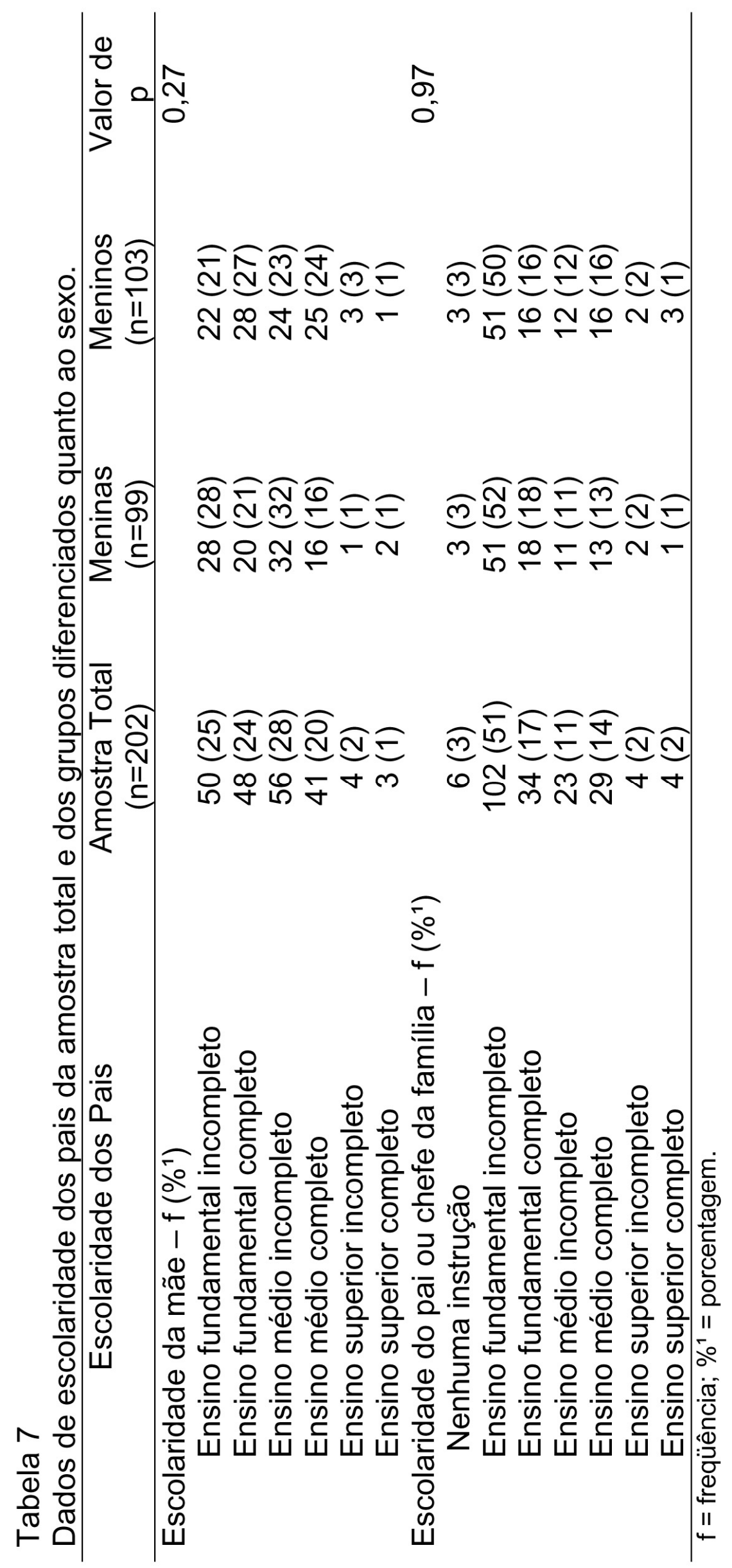


Pode-se observar na Tabela 7 que $49 \%$ as mães estudaram até o ensino fundamental, enquanto $51 \%$ estudaram até o nível médio ou superior. Os pais, por sua vez, estudaram predominantemente até o ensino fundamental (68\%) e $29 \%$ estudaram até o nível médio ou superior.

A Tabela 8 apresenta os dados sócio-demográficos da amostra total e dos grupos diferenciados quanto ao sexo. 


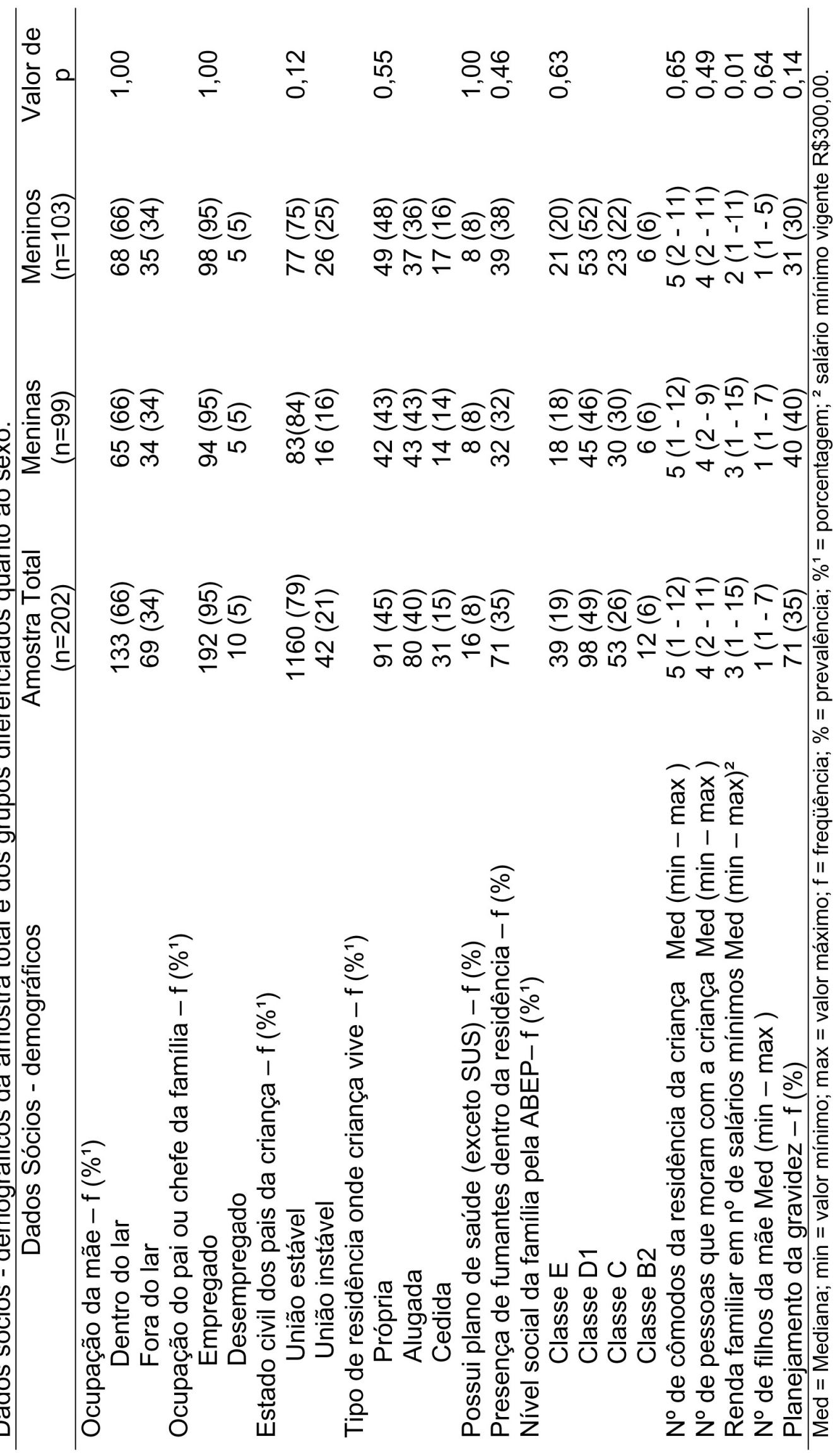


Verificou-se na Tabela 8 que os pais, em sua maioria, estavam empregados e a maioria das mães não estava no mercado de trabalho e permaneciam no lar (66\%). As famílias tinham predominantemente uniões estáveis. O nível social da família avaliado pela ABEP mostrou que na grande maioria das famílias (68\%) foram classificadas como Classe D ou E. Os grupos de meninos e meninas foram comparáveis em relação às variáveis sócioeconômicas, com exceção da renda familiar. Apesar de apresentar uma diferença significativa na renda familiar mensal em números de salários mínimos, essa diferença foi de apenas um salário mínimo. O salário mínimo vigente na época era de $R \$ 300,00$. Verificou-se que em ambos os grupos essa renda mensal foi inferior a $\mathrm{R} \$ 1.000,00$.

4.2. Desenvolvimento neurocomportamental dos bebês da amostra total.

A Tabela 9 apresenta a comparação entre os escores dos itens do NAPI, de acordo com a idade pós-concepcional, da amostra de estudo (AE) e amostra do teste (AT) NAPI - média e desvio padrão. 
Tabela 9

Comparação entre os escores dos itens do NAPI, de acordo com a idade pós-concepcional, da amostra de estudo (AE) e amostra do teste (AT) NAPI - média e desvio padrão

\begin{tabular}{|c|c|c|c|c|c|c|c|}
\hline \multirow[t]{2}{*}{$\begin{array}{c}\text { Itens do } \\
\text { NAPI }\end{array}$} & \multirow{2}{*}{$\begin{array}{l}\text { Idade pós- } \\
\text { concepcional } \\
\text { (semanas) }\end{array}$} & \multicolumn{2}{|c|}{$\begin{array}{l}\text { Amostra de estudo } \\
(A E)\end{array}$} & \multicolumn{2}{|c|}{ Amostra do teste (AT) } & \multirow[t]{2}{*}{$t$} & \multirow[t]{2}{*}{ Valor de $p$} \\
\hline & & Média & $\pm \mathrm{SD}$ & Média & $\pm \mathrm{SD}$ & & \\
\hline Sinal & 32 & 33,3 & 0 & 38,2 & 12,2 & NA & NA \\
\hline de & 33 & 36,5 & 15,8 & 42,2 & 14,7 & 1,90 & 0,06 \\
\hline \multirow[t]{4}{*}{ Cachecol } & 34 & 35,7 & 12,6 & 47,3 & 15,1 & 5,20 & $<0,0001$ \\
\hline & 35 & 39,4 & 13,0 & 51,7 & 16,1 & 5,99 & $<0,0001$ \\
\hline & 36 & 40,5 & 17,8 & 55,9 & 17,8 & 4,74 & $<0,0001$ \\
\hline & 37 & 52,4 & 27,0 & 60,1 & 15,0 & 1,27 & 0,22 \\
\hline Motor & 32 & 33,0 & 12,9 & 47,5 & 12,9 & NA & NA \\
\hline $\mathrm{e}$ & 33 & 35,9 & 13,5 & 51,3 & 14.7 & 5,32 & $<0,0001$ \\
\hline \multirow[t]{4}{*}{ Vigor } & 34 & 41,2 & 16,7 & 57,1 & 14,8 & 6,86 & $<0,0001$ \\
\hline & 35 & 47,8 & 14,5 & 60,0 & 13,0 & 6,09 & $<0,0001$ \\
\hline & 36 & 48,3 & 15,4 & 63,0 & 14,5 & 5,48 & $<0,0001$ \\
\hline & 37 & 51,4 & 14,9 & 67,6 & 10,9 & 4,72 & $<0,0001$ \\
\hline Ângulo & 32 & 22,2 & 19,2 & 21,6 & 22,7 & NA & NA \\
\hline \multirow[t]{5}{*}{ Poplíteo } & 33 & 29,0 & 20,6 & 22,9 & 25,6 & 1,24 & 0,22 \\
\hline & 34 & 35,7 & 25,6 & 32,8 & 29,5 & 0,67 & 0,50 \\
\hline & 35 & 36,3 & 22,5 & 36,8 & 29,2 & 0,13 & 0,90 \\
\hline & 36 & 35,1 & 24,8 & 41,7 & 27,8 & 1,32 & 0,19 \\
\hline & 37 & 42,9 & 18,7 & 43,1 & 32,3 & 0,05 & 0,96 \\
\hline Alerta & 32 & 45,2 & 33,5 & 42,3 & 15,9 & NA & NA \\
\hline e & 33 & 51,8 & 20,3 & 43,0 & 20,5 & 2,15 & 0,03 \\
\hline \multirow[t]{4}{*}{ Orientação } & 34 & 51,2 & 23,3 & 48,6 & 19,9 & 0,81 & 0,42 \\
\hline & 35 & 61,4 & 19,4 & 51,5 & 19,2 & 3,42 & 0,0007 \\
\hline & 36 & 56,4 & 19,8 & 54,0 & 19,4 & 0,66 & 0,51 \\
\hline & 37 & 56,9 & 18,2 & 57,7 & 18,0 & 0,20 & 0,85 \\
\hline \multirow[t]{6}{*}{ Irritabilidade } & 32 & 16,7 & 16,7 & 34,0 & 15,5 & NA & NA \\
\hline & 33 & 28,7 & 21,6 & 33,6 & 19,2 & 1,26 & 0,21 \\
\hline & 34 & 29,4 & 26,6 & 36,6 & 20,6 & 1,87 & 0,07 \\
\hline & 35 & 36,4 & 25,9 & 41,0 & 16,9 & 1,25 & 0,22 \\
\hline & 36 & 39,5 & 25,9 & 41,5 & 20,4 & 0,45 & 0,65 \\
\hline & 37 & 42,8 & 19,9 & 47,2 & 17,9 & 1,00 & 0,32 \\
\hline \multirow[t]{6}{*}{ Choro } & 32 & 0,00 & 0,00 & 41,1 & 25,2 & NA & NA \\
\hline & 33 & 25,8 & 33,8 & 40,9 & 26,8 & 2,32 & 0,03 \\
\hline & 34 & 22,7 & 35,8 & 50,5 & 28,2 & 5,32 & $<0,0001$ \\
\hline & 35 & 39,1 & 43,8 & 54,2 & 28,1 & 2,44 & 0,02 \\
\hline & 36 & 37,8 & 44,7 & 63,4 & 24,2 & 3,37 & 0,002 \\
\hline & 37 & 54,8 & 41,5 & 59,8 & 22,8 & 0,54 & 0,59 \\
\hline Percentual & 32 & 76,2 & 41,2 & 33,6 & 24,3 & NA & NA \\
\hline \multirow[t]{5}{*}{ Adormecido } & 33 & 60,1 & 32,9 & 35,7 & 26,9 & 4,35 & $<0,0001$ \\
\hline & 34 & 58,9 & 33,8 & 31,0 & 28,8 & 6,12 & $<0,0001$ \\
\hline & 35 & 48,0 & 30,7 & 31,0 & 26,8 & 4,08 & $<0,0001$ \\
\hline & 36 & 48,2 & 31,3 & 29,2 & 28,8 & 3,56 & 0,0005 \\
\hline & 37 & 38,7 & 32,8 & 22,5 & 23,7 & 2,15 & 0,04 \\
\hline
\end{tabular}


A Tabela 9 mostra que houve diferença significativa entre os grupos Amostra de estudo (AE) e Amostra do teste (AT) nos seguintes domínios do NAPI: Sinal de Cachecol, Motor e Vigor, Alerta e Orientação, Choro e Percentual Adormecido.

Com relação ao Sinal de Cachecol, o grupo AE apresentou maior dificuldade no tônus muscular na realização da prova em comparação ao grupo AT nas idades pós-concepcional de 34, 35 e 36 semanas.

Quanto ao Motor e Vigor, o grupo AE apresentou menor vigor e movimentação espontânea quando comparados ao grupo AT, em todas as idades pós-concepcionais testadas.

Com relação ao Alerta e Orientação, o grupo AE apresentou maior alerta e orientação aos estímulos em comparação ao grupo AT nas idades pósconcepcionais de 33 e 35 semanas.

Quanto ao Choro, o grupo AE apresentou qualidade de choro levemente mais fraco nas idades de 33, 34, 35 e 36 semanas de idade pós-concepcionais em comparação ao grupo AT, o qual apresentou qualidade de choro moderado.

Com relação ao Percentual Adormecido, o grupo AE permaneceu mais em estado de sono em comparação ao grupo AT, em todas as idades pósconcepcionais testadas.

Não houve diferença significativa entre os grupos nos domínios Ângulo Poplíteo e Irritabilidade. Chama atenção o fato de que apesar de os bebês da amostra de estudo terem apresentado diferença significativa em relação à amostra do teste na qualidade de Choro; porém não houve diferença entre os grupos na quantidade de Choro. 
A Tabela 10 apresenta a Classificação Geral do NAPI dos bebês de acordo com os desvios-padrões (DP) da amostra do teste.

Tabela 10

Classificação Geral do NAPI dos bebês, de acordo com os desvios padrão (DP) da amostra total.

\begin{tabular}{lcc}
\hline Classificação Geral no NAPI & $f$ & $\%$ \\
\hline Abaixo da Média (DP > -1,0) & 63 & 31 \\
Média (DP entre $-0,5$ e 0,5) & 132 & 65 \\
Acima da Média (DP > 1,0) & 7 & 4 \\
\hline
\end{tabular}

$f=$ freqüência; \% = porcentagem

$\mathrm{Na}$ Tabela 10 pode-se notar que os bebês da amostra do presente estudo foram classificados predominantemente na média, apresentando os desvios-padrões entre $-0,5$ e $+0,5$. Cerca de um terço da amostra foi classificada como abaixo da média, considerando-se os desvios-padrão da distribuição da amostra do teste.

4.3. Desenvolvimento Neurocomportamental, em grupos diferenciados pelos problemas perinatais.

A Tabela 11 apresenta a comparação entre os escores dos itens do NAPI, de acordo com a idade pós-concepcional, da amostra dos grupos diferenciados pelos problemas perinatais - média e desvio padrão. 
Tabela 11

Comparação entre os escores dos itens do NAPI, de acordo com a idade pós-concepcional, dos grupos diferenciados quanto aos problemas perinatais - média e desvio padrão.

\begin{tabular}{|c|c|c|c|c|c|c|c|}
\hline \multirow{2}{*}{$\begin{array}{l}\text { Itens do } \\
\text { NAPI }\end{array}$} & \multirow{2}{*}{$\begin{array}{c}\text { Idade pós- } \\
\text { concepcional }\end{array}$} & \multicolumn{2}{|c|}{ Grupo com problema } & \multicolumn{2}{|c|}{ Grupo sem problema } & \multirow[t]{2}{*}{$t$} & \multirow{2}{*}{$\begin{array}{l}\text { Valor } \\
\text { de p }\end{array}$} \\
\hline & & Média & $\pm \mathrm{SD}$ & Média & $\pm S D$ & & \\
\hline \multirow{6}{*}{$\begin{array}{l}\text { Sinal } \\
\text { de } \\
\text { Cachecol }\end{array}$} & 32 & 0 & 0 & 33,3 & 0 & NA & NA \\
\hline & 33 & 29,6 & 11,1 & 39,4 & 16,7 & 1,61 & 0,12 \\
\hline & 34 & 33,3 & 11,1 & 37 & 13,3 & 1,04 & 0,30 \\
\hline & 35 & 40,8 & 14,2 & 37,5 & 11,3 & 0,95 & 0,35 \\
\hline & 36 & 40 & 13,7 & 41,2 & 22,2 & 0,19 & 0,85 \\
\hline & 37 & 53,8 & 29 & 50 & 25,2 & 0,31 & 0,76 \\
\hline \multirow{6}{*}{$\begin{array}{l}\text { Motor } \\
\text { e } \\
\text { Vigor }\end{array}$} & 32 & 0 & 0 & 33 & 12,9 & NA & $\mathrm{NA}$ \\
\hline & 33 & 35,6 & 15,1 & 36 & 13,1 & 0,08 & 0,94 \\
\hline & 34 & 39,9 & 14,2 & 41,8 & 18,1 & 0,4 & 0,69 \\
\hline & 35 & 50,4 & 14,6 & 44,5 & 14 & 1,52 & 0,14 \\
\hline & 36 & 50,3 & 16,1 & 46,1 & 14,6 & 0,82 & 0,42 \\
\hline & 37 & 48,6 & 13,5 & 55,9 & 16,9 & 1,09 & 0,29 \\
\hline \multirow{6}{*}{$\begin{array}{l}\text { Ângulo } \\
\text { Poplíteo }\end{array}$} & 32 & 0 & 0 & 22,2 & 19,2 & NA & NA \\
\hline & 33 & 33,3 & 16,7 & 27,3 & 22,1 & 0,74 & 0,47 \\
\hline & 34 & 36,8 & 27 & 35,2 & 25,1 & 0,23 & 0,82 \\
\hline & 35 & 32,2 & 25,1 & 41,7 & 17,7 & 1,63 & 0,11 \\
\hline & 36 & 30 & 26,3 & 41,2 & 22,2 & 1,39 & 0,17 \\
\hline & 37 & 43,5 & 21 & 41,7 & 15,5 & 0,23 & 0,83 \\
\hline \multirow{5}{*}{$\begin{array}{l}\text { Alerta } \\
\text { e } \\
\text { Orientação }\end{array}$} & 32 & 0 & 0 & 45,2 & 33,5 & NA & NA \\
\hline & 33 & 49,8 & 17,5 & 52,6 & 21,7 & 0,35 & 0,73 \\
\hline & $\begin{array}{l}34 \\
35\end{array}$ & $\begin{array}{l}45,4 \\
65,6\end{array}$ & $\begin{array}{l}23,3 \\
15,9\end{array}$ & $\begin{array}{c}54,2 \\
56\end{array}$ & $\begin{array}{c}23 \\
22,3\end{array}$ & $\begin{array}{l}1,34 \\
1,78\end{array}$ & $\begin{array}{l}0,19 \\
0,08\end{array}$ \\
\hline & 36 & 59,5 & 18,2 & 52,7 & 21,5 & 1,03 & 0,31 \\
\hline & 37 & 55,9 & 21,2 & 58,4 & 13,3 & 0,29 & 0,77 \\
\hline \multirow[t]{6}{*}{ Irritabilidade } & 32 & 0 & 0 & 16,7 & 16,7 & NA & NA \\
\hline & 33 & 40 & 17,5 & 24 & 21,7 & 1,96 & 0,06 \\
\hline & 34 & 27,4 & 26,2 & 30,4 & 27,1 & 0,4 & 0,69 \\
\hline & 35 & 35,6 & 25,9 & 37,5 & 26,3 & 0,27 & 0,79 \\
\hline & 36 & 40,4 & 27,1 & 38,3 & 25,2 & 0,25 & 0,81 \\
\hline & 37 & 41,9 & 18,4 & 44,2 & 23,4 & 0,24 & 0,81 \\
\hline \multirow[t]{6}{*}{ Choro } & 32 & 0 & 0 & 0 & 0 & $\mathrm{NA}$ & NA \\
\hline & 33 & 33,3 & 35,4 & 22,7 & 33,5 & 0,79 & 0,44 \\
\hline & 34 & 15,8 & 29,1 & 26,4 & 38,7 & 1,05 & 0,30 \\
\hline & 35 & 37,1 & 44,7 & 41,7 & 43,4 & 0,38 & 0,71 \\
\hline & 36 & 40 & 44,7 & 35,3 & 46 & 0,31 & 0,75 \\
\hline & 37 & 50 & 45,6 & 62,5 & 35,4 & 0,66 & 0,52 \\
\hline \multirow{6}{*}{$\begin{array}{l}\text { Percentual } \\
\text { Adormecido }\end{array}$} & 32 & 0 & 0 & 76,2 & 41,2 & NA & $\overline{N A}$ \\
\hline & 33 & 69,7 & 34,1 & 56,2 & 32,4 & 1,04 & 0,31 \\
\hline & 34 & 62,9 & 35,5 & 56,8 & 33,1 & 0,64 & 0,52 \\
\hline & 35 & 40,9 & 29,9 & 57,1 & 29,8 & 2,01 & 0,05 \\
\hline & 36 & 42 & 32,7 & 55,5 & 28,9 & 1,33 & 0,19 \\
\hline & 37 & 34,5 & 26,3 & 45,5 & 42,3 & 0,74 & 0,47 \\
\hline
\end{tabular}

Nota: bebês de 32 semanas de idade pós-concepcional: $N=3$ (AS) e $N=0$ (AC); 33 semanas: $N=22$ (AS) e $N=9$ (AC); 34 semanas: $N=36$ (AS) e $N=19(A C)$; 35 semanas: $N=24$ (AS) e $N=31$ (AC); 36 semanas: $N=17$ (AS) e $N=20$ (AC); 37 semanas: $\mathrm{N}=8$ (AS) e $\mathrm{N}=13(\mathrm{AC}) ; \mathrm{NA}=$ não se aplica. 
$\mathrm{Na}$ Tabela 11 pode-se notar que, especificamente, com relação ao Percentual Adormecido, o grupo sem problema permaneceu mais em estado de sono em comparação ao grupo com problema, na idade pós-concepcional de 35 semanas. Houve uma tendência $(p \leq 0,08)$ no item Alerta e Orientação, o grupo com problema, na idade pós-concepcional de 35 semanas, apresentou uma tendência a ter mais alerta do que o grupo sem problema. Houve, também, uma tendência $(p \leq 0,06)$ no item Irritabilidade, o grupo com problema, na idade pós-concepcional de 33 semanas, apresentou uma média maior (40) em comparação ao grupo sem problema, indicando que esse grupo tenderia a ter maior irritabilidade. Nota-se que não houve diferença significativa entre os grupos nos demais domínios.

A Tabela 12 apresenta a comparação entre os escores dos itens do NAPI, de acordo com a idade pós-concepcional, da amostra de estudo (sem problema) (AE) e amostra de padronização do teste (AT) NAPI - média e desvio padrão. 
Tabela 12

Comparação entre os escores dos itens do NAPI, de acordo com a idade pós-concepcional, do grupo sem problema e amostra de padronização do teste NAPI - média e desvio padrão

\begin{tabular}{|c|c|c|c|c|c|c|c|}
\hline \multirow[t]{2}{*}{ Áreas } & \multirow[t]{2}{*}{$\begin{array}{l}\text { Idade pós- } \\
\text { concepcional } \\
\text { (semanas) }\end{array}$} & \multicolumn{2}{|c|}{$\begin{array}{c}\text { Grupo sem } \\
\text { problema }(A E) \\
(n=101)\end{array}$} & \multicolumn{2}{|c|}{ Amostra do teste (AT) } & \multirow[t]{2}{*}{$\mathrm{t}$} & \multirow[t]{2}{*}{ Valor de $p$} \\
\hline & & Média & $\pm S D$ & Média & $\pm \mathrm{SD}$ & & \\
\hline Sinal & 32 & 33,3 & 0,00 & 38,2 & 12,2 & NA & $\mathrm{NA}$ \\
\hline de & 33 & 39,4 & 16,7 & 42,2 & 14,7 & 0,82 & 0,41 \\
\hline \multirow[t]{4}{*}{ Cachecol } & 34 & 37,0 & 13,3 & 47,3 & 15,1 & 3,83 & 0,0002 \\
\hline & 35 & 37,5 & 11,3 & 51,7 & 16,1 & 5,60 & $<0,0001$ \\
\hline & 36 & 41,2 & 22,2 & 55,9 & 17,8 & 3,17 & 0,002 \\
\hline & 37 & 50,0 & 25,2 & 60,1 & 15,0 & 1,12 & 0,30 \\
\hline Motor & 32 & 33,0 & 12,9 & 47,5 & 12,9 & NA & NA \\
\hline e & 33 & 36,0 & 13,1 & 51,3 & 14,7 & 4,57 & $<0,0001$ \\
\hline \multirow[t]{4}{*}{ Vigor } & 34 & 41,8 & 18,1 & 57,1 & 14,8 & 4,78 & $<0,0001$ \\
\hline & 35 & 44,5 & 14,0 & 60,0 & 13,0 & 5,52 & $<0,0001$ \\
\hline & 36 & 46,1 & 14,6 & 63,0 & 14,5 & 4,57 & $<0,0001$ \\
\hline & 37 & 55,9 & 16,9 & 67,6 & 10,9 & 1,93 & 0,09 \\
\hline Ângulo & 32 & 22,2 & 19,2 & 21,6 & 22,7 & NA & NA \\
\hline \multirow{5}{*}{ Poplíteo } & 33 & 27,3 & 22,1 & 22,9 & 25,6 & 0,75 & 0,45 \\
\hline & 34 & 35,2 & 25,1 & 32,8 & 29,5 & 0,45 & 0,65 \\
\hline & 35 & 41,7 & 17,7 & 36,8 & 29,2 & 1,18 & 0,25 \\
\hline & 36 & 41,2 & 22,2 & 41,7 & 27,8 & 0,08 & 0,94 \\
\hline & 37 & 41,7 & 15,5 & 43,1 & 32,3 & 0,23 & 0,82 \\
\hline Alerta & 32 & 45,2 & 33,5 & 42,3 & 15,9 & NA & NA \\
\hline e & 33 & 52,6 & 21,7 & 43,0 & 20,5 & 2,02 & 0,05 \\
\hline \multirow[t]{4}{*}{ Orientação } & 34 & 54,2 & 23,0 & 48,6 & 19,9 & 1,51 & 0,13 \\
\hline & 35 & 56,0 & 22,3 & 51,5 & 19,2 & 1,07 & 0,28 \\
\hline & 36 & 52,7 & 21,5 & 54,0 & 19,4 & 0,25 & 0,80 \\
\hline & 37 & 58,4 & 13,3 & 57,7 & 18,0 & 0,10 & 0,92 \\
\hline \multirow[t]{6}{*}{ Irritabilidade } & 32 & 16,7 & 16,7 & 34,0 & 15,5 & NA & NA \\
\hline & 33 & 24,0 & 21,7 & 33,6 & 19,2 & 2,13 & 0,03 \\
\hline & 34 & 30,4 & 27,1 & 36,6 & 20,6 & 1,30 & 0,20 \\
\hline & 35 & 37,5 & 26,3 & 41,0 & 16,9 & 0,63 & 0,53 \\
\hline & 36 & 38,3 & 25,2 & 41,5 & 20,4 & 0,60 & 0,55 \\
\hline & 37 & 44,2 & 23,4 & 47,2 & 17,9 & 0,45 & 0,66 \\
\hline \multirow[t]{6}{*}{ Choro } & 32 & 0,0 & 0,0 & 41,1 & 25,2 & NA & NA \\
\hline & 33 & 22,7 & 33,5 & 40,9 & 26,8 & 2,83 & 0,005 \\
\hline & 34 & 26,4 & 38,7 & 50,5 & 28,2 & 3,57 & 0,0009 \\
\hline & 35 & 41,7 & 43,4 & 54,2 & 28,1 & 1,38 & 0,18 \\
\hline & 36 & 35,3 & 46,0 & 63,4 & 24,2 & 2,49 & 0,02 \\
\hline & 37 & 62,5 & 35,4 & 59,8 & 22,8 & 0,21 & 0,84 \\
\hline Percentual & 32 & 76,2 & 41,2 & 33,6 & 24,3 & NA & NA \\
\hline \multirow[t]{5}{*}{ Adormecido } & 33 & 56,2 & 32,4 & 35,7 & 26,9 & 3,21 & 0,002 \\
\hline & 34 & 56,8 & 33,1 & 31,0 & 28,8 & 4,82 & $<0,0001$ \\
\hline & 35 & 57,1 & 29,8 & 31,0 & 26,8 & 4,49 & $<0,0001$ \\
\hline & 36 & 55,5 & 28,9 & 29,2 & 28,8 & 3,59 & 0,0004 \\
\hline & 37 & 45,5 & 42,3 & 22,5 & 23,7 & 1,52 & 0,17 \\
\hline
\end{tabular}


A Tabela 12 mostra que houve diferença significativa entre o grupo sem problema e a amostra de padronização do teste nos seguintes domínios: Sinal de cachecol, Motor e vigor, Alerta e Orientação, Irritabilidade, Choro e Percentual adormecido.

Com relação ao Sinal de Cachecol, o grupo sem problema apresentou maior dificuldade no tônus muscular na realização da prova em comparação ao grupo AT nas idades pós-concepcional de 34, 35 e 36 semanas.

Quanto ao Motor e Vigor, o grupo sem problema apresentou menor vigor e movimentação espontânea quando comparados ao grupo AT, nas idades pós-concepcionais de 33, 34, 35 e 36 semanas.

Com relação ao Alerta e Orientação, o grupo sem problema apresentou maior alerta e orientação aos estímulos em comparação ao grupo AT na idade pós-concepcional de 33 semanas.

Quanto a Irritabilidade, o grupo sem problema apresentou maior irritabilidade em comparação a amostra AT na idade pós-concepcional de 33 semanas.

Quanto ao Choro, o grupo sem problema apresentou qualidade de choro levemente mais fraco nas idades de 33, 34 e 36 semanas de idade pósconcepcionais em comparação ao grupo AT, o qual apresentou qualidade de choro moderado.

Com relação ao Percentual Adormecido, o grupo sem problema permaneceu mais em estado de sono em comparação ao grupo AT, nas as idades pós-concepcionais de 33, 34, 35 e 36 semanas. 
A Tabela 13 apresenta a comparação entre os escores dos itens do $\mathrm{NAPI}$, de acordo com a idade pós-concepcional, da amostra de estudo (com problema) (AE) e amostra de padronização do teste (AT) NAPI - média e desvio padrão. 
Tabela 13

Comparação entre os escores dos itens do NAPI, de acordo com a idade pós-concepcional, do grupo com problema e amostra de padronização do teste NAPI - média e desvio padrão

\begin{tabular}{|c|c|c|c|c|c|c|c|}
\hline \multirow[t]{2}{*}{ Áreas } & \multirow[t]{2}{*}{$\begin{array}{l}\text { Idade pós- } \\
\text { concepcional } \\
\text { (semanas) }\end{array}$} & \multicolumn{2}{|c|}{$\begin{array}{c}\text { Grupo com } \\
\text { problema }(A E) \\
(n=92)\end{array}$} & \multicolumn{2}{|c|}{ Amostra do teste (AT) } & \multirow[t]{2}{*}{$\mathrm{t}$} & \multirow[t]{2}{*}{ Valor de $p$} \\
\hline & & Média & $\pm S D$ & Média & $\pm S D$ & & \\
\hline \multirow{6}{*}{$\begin{array}{l}\text { Sinal } \\
\text { de } \\
\text { Cachecol }\end{array}$} & 32 & 0,0 & 0,0 & 38,2 & 12,2 & NA & NA \\
\hline & 33 & 29,6 & 11,1 & 42,2 & 14,7 & 2,52 & 0,01 \\
\hline & 34 & 33,3 & 11,1 & 47,3 & 15,1 & 3,94 & 0,0001 \\
\hline & 35 & 40,8 & 14,2 & 51,7 & 16,1 & 3,57 & 0,0004 \\
\hline & 36 & 40,0 & 13,7 & 55,9 & 17,8 & 3,86 & 0,0002 \\
\hline & 37 & 53,8 & 29,0 & 60,1 & 15,0 & 0,77 & 0,45 \\
\hline \multirow{6}{*}{$\begin{array}{l}\text { Motor } \\
\text { e } \\
\text { Vigor }\end{array}$} & 32 & 0,0 & 0,0 & 47,5 & 12,9 & NA & NA \\
\hline & 33 & 35,6 & 15,1 & 51,3 & 14,7 & 3,09 & 0,002 \\
\hline & 34 & 39,9 & 14,2 & 57,1 & 14,8 & 4,85 & $<0,0001$ \\
\hline & 35 & 50,4 & 14,6 & 60,0 & 13,0 & 3,80 & 0,0002 \\
\hline & 36 & 50,3 & 16,1 & 63,0 & 14,5 & 3,66 & 0,0003 \\
\hline & 37 & 48,6 & 13,5 & 67,6 & 10,9 & 5,74 & $<0,0001$ \\
\hline & 32 & 0,0 & 0,0 & 21,6 & 22,7 & NA & NA \\
\hline \multirow{5}{*}{ Poplíteo } & 33 & 33,3 & 16,7 & 22,9 & 25,6 & 1,20 & 0,23 \\
\hline & 34 & 36,8 & 27,0 & 32,8 & 29,5 & 0,57 & 0,57 \\
\hline & 35 & 32,2 & 25,1 & 36,8 & 29,2 & 0,83 & 0,41 \\
\hline & 36 & 30,0 & 26,3 & 41,7 & 27,8 & 1,79 & 0,07 \\
\hline & 37 & 43,5 & 21,0 & 43,1 & 32,3 & 0,07 & 0,94 \\
\hline \multirow{6}{*}{$\begin{array}{l}\text { Alerta } \\
\text { e } \\
\text { Orientação }\end{array}$} & 32 & 0,0 & 0,0 & 42,3 & 15,9 & NA & NA \\
\hline & 33 & 49,8 & 17,5 & 43,0 & 20,5 & 0,97 & 0,33 \\
\hline & 34 & 45,4 & 23,3 & 48,6 & 19,9 & 0,65 & 0,51 \\
\hline & 35 & 65,6 & 15,9 & 51,5 & 19,2 & 3,90 & 0,0001 \\
\hline & 36 & 59,5 & 18,2 & 54,0 & 19,4 & 1,19 & 0,23 \\
\hline & 37 & 55,9 & 21,2 & 57,7 & 18,0 & 0,33 & 0,74 \\
\hline \multirow[t]{6}{*}{ Irritabilidade } & 32 & 0,0 & 0,0 & 34,0 & 15,5 & NA & NA \\
\hline & 33 & 40,0 & 17,5 & 33,6 & 19,2 & 0,98 & 0,33 \\
\hline & 34 & 27,4 & 26,2 & 36,6 & 20,6 & 1,81 & 0,07 \\
\hline & 35 & 35,6 & 25,9 & 41,0 & 16,9 & 1,13 & 0,26 \\
\hline & 36 & 40,4 & 27,1 & 41,5 & 20,4 & 0,17 & 0,87 \\
\hline & 37 & 41,9 & 18,4 & 47,2 & 17,9 & 0,99 & 0,32 \\
\hline \multirow[t]{6}{*}{ Choro } & 32 & 0,0 & 0,0 & 41,1 & 25,2 & NA & NA \\
\hline & 33 & 33,3 & 35,4 & 40,9 & 26,8 & 0,80 & 0,42 \\
\hline & 34 & 15,8 & 29,1 & 50,5 & 28,2 & 5,11 & $<0,0001$ \\
\hline & 35 & 37,1 & 44,7 & 54,2 & 28,1 & 2,08 & 0,05 \\
\hline & 36 & 40,0 & 44,7 & 63,4 & 24,2 & 2,30 & 0,03 \\
\hline & 37 & 50,0 & 45,6 & 59,8 & 22,8 & 0,76 & 0,46 \\
\hline Percentual & 32 & 0,0 & 0,0 & 33,6 & 24,3 & NA & NA \\
\hline \multirow[t]{5}{*}{ Adormecido } & 33 & 69,7 & 34,1 & 35,7 & 26,9 & 3,61 & 0,0004 \\
\hline & 34 & 62,9 & 35,5 & 31,0 & 28,8 & 4,53 & $<0,0001$ \\
\hline & 35 & 40,9 & 29,9 & 31,0 & 26,8 & 1,89 & 0,06 \\
\hline & 36 & 42,0 & 32,7 & 29,2 & 28,8 & 1,84 & 0,07 \\
\hline & 37 & 34,5 & 26,3 & 22,5 & 23,7 & 1,69 & 0,09 \\
\hline
\end{tabular}

Nota: bebês de 32 semanas de idade pós-concepcional: $N=0$ (AE) e $N=51$ (AT); 33 semanas: $N=9$ (AE) e $\mathrm{N}=131$ (AT); 34 semanas: $\mathrm{N}=19$ (AE) e $\mathrm{N}=200$ (AT); 35 semanas: $\mathrm{N}=31$ (AE) e $\mathrm{N}=224$ (AT); 36 semanas: $\mathrm{N}=20$ (AE) e $\mathrm{N}=161$ (AT); 37 semanas: $N=13(\mathrm{AE})$ e $\mathrm{N}=99$ (AT) ; $\mathrm{NA}=$ não se aplica. 
A Tabela 13 mostra que houve diferença significativa entre o grupo com problema e a amostra de padronização do teste nos seguintes domínios: Sinal de cachecol, Motor e vigor, Alerta e Orientação, Choro e Percentual adormecido. Houve tendência a ter diferenças entre os grupos nos itens Ângulo poplíteo $(p \leq 0,07)$ e Irritabilidade $(p \leq 0,07)$.

Com relação ao Sinal de Cachecol, o grupo com problema apresentou maior dificuldade no tônus muscular na realização da prova em comparação ao grupo AT nas idades pós-concepcional de 33,34, 35 e 36 semanas.

Quanto ao Motor e Vigor, o grupo com problema apresentou menor vigor e movimentação espontânea quando comparados ao grupo AT, em todas as idades pós-concepcionais testadas.

Em relação ao Ângulo poplíteo, o grupo com problema apresentou uma tendência a ter menor tônus muscular e, conseqüentemente, menor ângulo avaliado, em comparação a amostra AT na idade pós-concepcional de 36 semanas.

Com relação ao Alerta e Orientação, o grupo com problema apresentou maior alerta e orientação aos estímulos em comparação ao grupo AT na idade pós-concepcional de 35 semanas.

Quanto a Irritabilidade, o grupo com problema apresentou uma tendência a ter maior irritabilidade em comparação a amostra AT na idade pósconcepcional de 34 semanas.

Quanto ao Choro, o grupo com problema apresentou qualidade de choro levemente mais fraco nas idades de 34, 35 e 36 semanas de idade pósconcepcionais em comparação ao grupo AT, o qual apresentou qualidade de choro moderado. 
Com relação ao Percentual Adormecido, o grupo com problema permaneceu mais em estado de sono em comparação ao grupo AT, nas as idades pós-concepcionais de 33, 34 e 35.

Houve uma tendência a permanecer mais em estado de sono nas idades de 35,36 e 37 semanas de idade pós-concepcional.

Os resultados do desenvolvimento neurocomportamental dos grupos sem problemas perinatais e com problemas perinatais, em comparação a amostra de padronização do teste foram semelhantes em relação ao desempenho nos itens do NAPI. As diferenças encontradas foram nas idades pós-concepcionais avaliadas.

4.4 Desenvolvimento neurocomportamental, em grupos diferenciados quanto ao sexo.

A Tabela 14 apresenta os escores no NAPI, em grupos diferenciados quanto ao sexo. - média, desvio padrão, mediana, valores mínimos e máximo. 


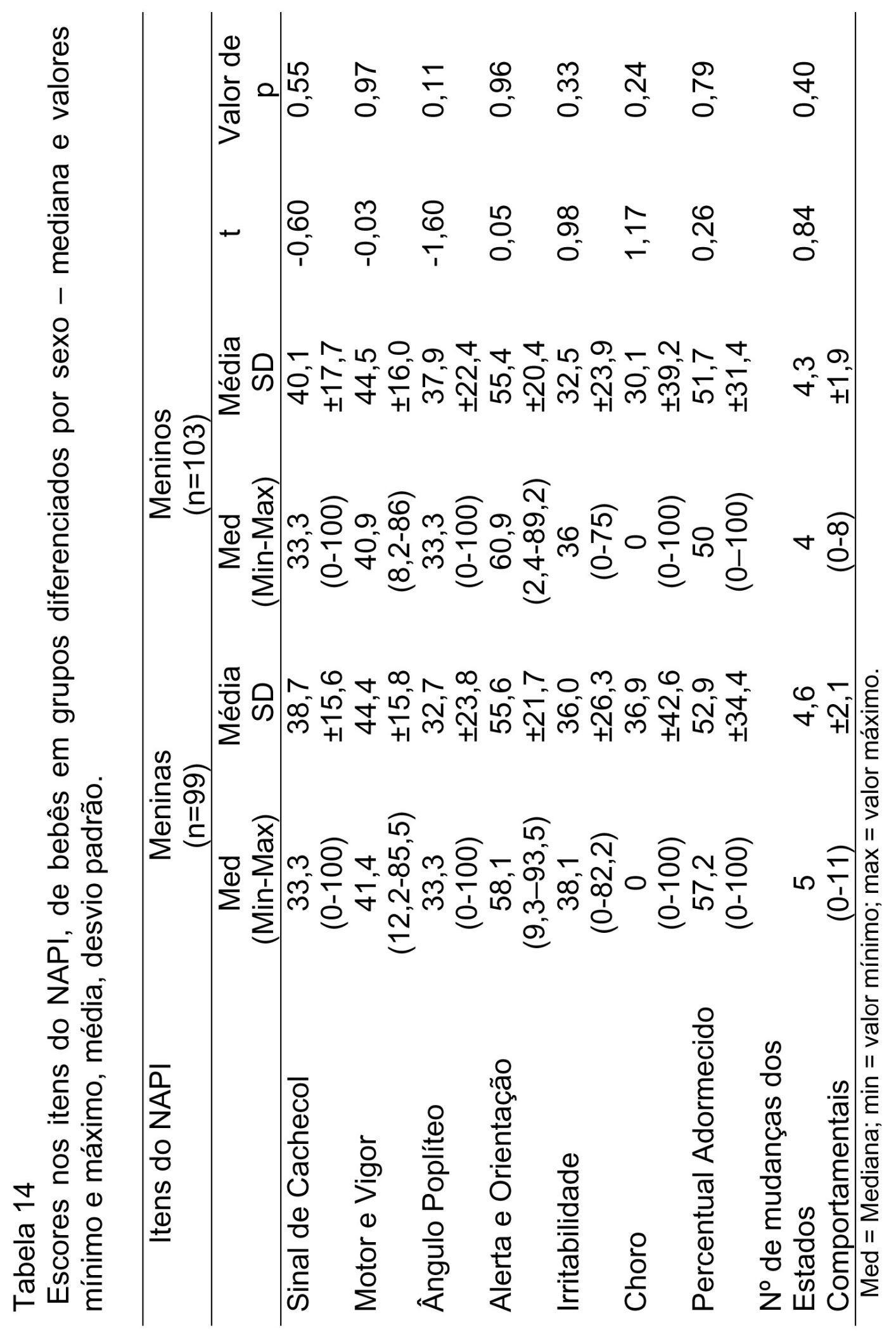


$\mathrm{Na}$ Tabela 14, verifica-se que as meninas e os meninos apresentaram padrões semelhantes de desenvolvimento neurocomportamental nos itens do NAPI. Não houve diferença estatística significativa entre os grupos diferenciados por sexo no desempenho no NAPI.

A Tabela 15 apresenta a classificação geral do NAPI dos bebês de acordo com os desvios padrões da amostra do teste, nos grupos diferenciados por sexo.

Tabela 15

Classificação Geral do NAPI dos bebês, de acordo com os desvios padrões, nos grupos de diferenciados por sexo.

\begin{tabular}{|c|c|c|c|c|c|}
\hline \multirow[t]{2}{*}{ Classificação Geral no NAPI } & \multicolumn{2}{|c|}{$\begin{array}{c}\text { Meninas } \\
(\mathrm{n}=99)\end{array}$} & \multicolumn{2}{|c|}{$\begin{array}{c}\text { Meninos } \\
(n=103)\end{array}$} & \multirow[t]{2}{*}{$\begin{array}{l}\text { Valor } \\
\text { de } p\end{array}$} \\
\hline & $f$ & $\%$ & $f$ & $\%$ & \\
\hline Abaixo da Média (DP $>-1,0)$ & 30 & 30 & 33 & 32 & 0,14 \\
\hline Média (DP entre $-0,5$ e 0,5 ) & 63 & 64 & 69 & 67 & \\
\hline Acima da Média (DP > 1,0) & 6 & 6 & 1 & 1 & \\
\hline
\end{tabular}

$\mathrm{Na}$ Tabela 12, observa-se que não houve diferença significativa entre os grupos diferenciados por sexo na classificação Geral do NAPI, de acordo com os desvios padrões. Nota-se que tanto um grupo quanto no outro houve uma predominância de classificação na média (67\%) e cerca de 30\% apresentaram escores abaixo da média. 
DISCUSSÃO 


\section{Discussão}

A amostra estudada caracteriza-se por um grupo de bebês nascidos prétermo, em torno de 33 semanas de idade gestacional e 35 semanas de idade pósconcepcional. A maior parte da amostra era de bebês nascidos adequados para a idade gestacional, com distribuição semelhante entre meninas e meninos.

Trata-se de bebês prematuros com risco biológico presente, o que aumenta a chance de problemas no desenvolvimento. Os índices de risco clínico neonatal foram sugestivos de bom prognóstico, considerando-se as medianas do Apgar do $5^{\circ}$ minuto igual a oito, o CRIB II igual a 1 e o NMI igual a três.

Os bebês foram submetidos a tratamentos e procedimentos durante a hospitalização, com maior incidência para o Hood ou Capacete de $\mathrm{O}_{2}(85 \%)$, Antibioticoterapia $(71 \%)$ e fototerapia $(72 \%)$.

Constatou-se, também, que as mães eram jovens e realizaram as consultas pré-natais com uma mediana de cinco consultas. $54 \%$ dos bebês nasceram de parto cesárea. Em relação ao aleitamento materno, houve um predomínio de amamentação exclusiva (79\%).

Portanto, além de os bebês estudados constituírem um grupo de risco biológico devido a prematuridade, há os fatores associados, tais como eles pertencerem, em sua maioria, a famílias de baixa escolaridade dos pais, os pais estudaram predominantemente até o ensino fundamental (68\%) e o nível social da família ter sido classificado pela ABEP como classe D (49\%) ou E (19\%).

Segundo Halpern (2000) as crianças nascidas com peso ao nascimento inferior a $2.000 \mathrm{~g}$ e as crianças nascidas prematuras apresentam maior incidência de apresentarem atraso no desenvolvimento neuropsicomotor. 
O presente estudo teve por objetivo geral avaliar o desenvolvimento neurocomportamental de bebês nascidos pré-termo nas primeiras semanas de vida, antes de atingir o termo de 40 semanas de idade pós-concepcional, por meio da avaliação do desenvolvimento, a fim de detectar indicadores de risco para problemas na trajetória de desenvolvimento.

Para responder a esse objetivo foram comparados os escores dos itens do NAPI, de acordo com a idade pós-concepcional, da amostra de estudo e os escores da amostra de padronização do teste NAPI. Verificou-se que houve diferença estatisticamente significativa entre as duas amostras nos seguintes domínios do NAPI: Sinal de Cachecol, Motor e Vigor, Alerta e Orientação, Choro e Percentual Adormecido.

Com relação ao Sinal de Cachecol, a amostra de estudo apresentou menor tônus muscular na realização da prova em comparação a amostra de padronização do teste nas idades pós-concepcional de 34, 35 e 36 semanas. Nossos resultados de diminuição do tônus muscular foram similares aos encontrados no estudo de Lekskulchai e Cole (2000a) que concluíram que crianças com idade pósconcepcional menor do que 32 semanas mostraram baixo tônus postural e desenvolvimento motor amplo, quando comparadas com as idades de 32 a 36 semanas. Demonstraram que o tônus muscular muda gradualmente com a idade, melhora conforme aumenta a idade da criança. Até completarem 37 semanas de idade pós-concepcional, a manifestação do tônus na extremidade superior não é aparente. Os autores sugeriram que as crianças com 40 semanas de idade pósconcepcional têm maior resistência ao movimento passivo do braço, o qual reflete um tônus muscular maior no tronco e membros superiores. Os bebês do nosso estudo estavam nessa faixa de idade pós-concepcional. 
Em outro estudo, dos mesmos autores Lekskulchai e Cole (2000b), encontraram que a medida de sinal de cachecol no pré-termo de 36 semanas de idade pós-concepcional tem correlação positiva significativa com o desempenho motor avaliado, deduzindo-se que crianças com altos valores para sinal de cachecol têm melhor desempenho motor na avaliação em idade futura, e o inverso também é verdadeiro. No nosso estudo os bebês que apresentaram menores escores para o Sinal de Cachecol estavam com idade pós-concepcional menor de 36 semanas.

No estudo de Ohgi et al. (2008), verificaram que os movimentos espontâneos dos membros superiores de crianças nascidas prematuras têm características de dinâmica não-linear. Revelaram que a orientação do processo de desenvolvimento motor é de auto-organização, os quais reflete na interação dos sistemas, desde o sistema nervosos central, a percepção sensorial, o sistema músculoesquelético e o ambiente.

No item Motor e Vigor, por sua vez, a amostra de estudo em todas as idades pós-concepcionais testadas apresentou menor vigor e menor movimentação espontânea do que a amostra de padronização do teste. Esse item abrange seis diferentes medidas que são: recuo do antebraço, suspensão ventral, elevação da cabeça em prono, rastejar espontâneo, potência das atividades do movimento e movimentos espontâneos.

A maturação do sistema motor de neonatos não é linear e pode apresentar variações individuais dentro do padrão de normalidade. Os resultados de Darrah et al. (1998) sugerem que incertezas quanto à predição do desenvolvimento motor estão mais relacionadas à inadequação das escalas de mensuração do que à natureza (variações normais) do desenvolvimento motor. Concordamos com esses autores, pois as escalas de mensuração ou os testes de avaliação são muito 
diferentes entre si. Cada um deles avalia o aspecto motor das crianças abrangendo itens diferentes. Isso dificulta a comparação entre os estudos, pois há uma diversidade de itens para determinar atrasos ou normalidade no desenvolvimento motor global.

Por exemplo, no estudo de Chaudhari e Deo (2006) foi utilizada a Avaliação Neurodesenvovimental Amiel-Tison em bebês nascidos a termo ( $>37$ semanas de idade gestacional e peso ao nascimento $>2.500 \mathrm{~g}$ ), em que o aspecto motor foi avaliado por reflexos primitivos, controle da cabeça, sentar, tônus muscular passivo e ativo, assim como, medidas do ângulo poplíteo e ângulo adutor do quadril com goniômetro. Em estudos que utilizaram a Escala Motora Infantil de Alberta (MANACERO; NUNES, 2008, VAN HAASTER et al., 2006) a avaliação do aspecto motor é realizada a partir de observação livre da criança em quatro posturas: supino, prono, sentado e de pé. O teste avalia a permanência na postura, a atitude antigravitacional e a capacidade da criança em realizar transições entre as posturas de forma independente.

No nosso estudo e em estudos que utilizaram o NAPI (CONSTANTINOU et al., 2005, ARIAGNO et al., 1997) o aspecto motor é avaliado por seis diferentes medidas que são: recuo do antebraço, suspensão ventral, elevação da cabeça em prono, rastejar espontâneo, potência das atividades do movimento e movimentos espontâneos.

Os resultados do estudo de Manacero e Nunes (2008) corroboram os achados de Darrah et al. (1998), ou seja, que a média do desenvolvimento motor é progressiva e o peso ao nascimento não interfere na progressão desse desenvolvimento. Os autores avaliaram o desempenho motor de prematuros com idade gestacional entre 32 e 34 semanas, dividindo-os em dois grupos de acordo 
com o peso ao nascimento. Um grupo de bebês com peso ao nascimento $<1.750 \mathrm{~g}$, e outro grupo de peso ao nascimento $\geq 1.750 \mathrm{~g}$, durante os primeiros meses de vida utilizando a AIMS (Escala Motora Infantil de Alberta). Verificaram que o desenvolvimento da habilidade motora ao longo do período de observação, não diferiu entre esses grupos. No nosso estudo os bebês apresentaram uma mediana de $1610 \mathrm{~g}$ de peso ao nascimento, sendo o peso mínimo de $820 \mathrm{~g}$ e o máximo de $2490 \mathrm{~g}$.

A maioria dos estudos compara bebês nascidos prematuros com bebês nascidos a termo. Isso pode ser uma limitação na comparação dos nossos resultados com os resultados na literatura, pois a nossa comparação foi feita entre bebês nascidos prematuros. Além disso, a nossa amostra os bebês são brasileiros e na amostra de padronização do teste NAPI os bebês são americanos.

A grande parte dos estudos encontra diferenças significativas entre as amostras de bebês nascidos prematuros e os bebês nascidos a termo no desempenho motor. O estudo Van Haaster et al. (2006) comparou bebês nascidos prematuros com idade gestacional $\leq 32$ semanas com a amostra de bebês a termo da padronização do teste AIMS. Posteriormente, compararam com amostras de bebês prematuros de vários estudos publicados. Identificaram diferenças significativas no desenvolvimento motor amplo inicial de bebês nascidos prematuros comparados com os a termo, mesmo após a correção da idade pela prematuridade. Apresentam diferentes padrões no desenvolvimento motor inicial. A média nos escores dos bebês nascidos prematuros foram significativamente mais baixos em comparação aos bebês nascidos a termo. Na comparação entre os bebês nascidos prematuros do estudo com os da literatura, os bebês do estudo apresentaram a média dos escores significativamente mais baixos nas idades corrigidas de 6, 7, 9 e 
10 meses. Esses resultados foram semelhantes aos nossos resultados que compararam os bebês nascidos prematuros brasileiros e os bebês prematuros americanos que apresentaram diferentes padrões no desenvolvimento motor inicial.

No estudo de Chaudhari e Deo (2006) demonstraram que o tônus passivo é avaliado mais precisamente do que o tônus ativo porque é independente da resistência. A avaliação do tônus passivo é essencial para o planejamento de uma terapia de intervenção. Os autores encontraram que a avaliação feita aos três meses de idade corrigida seria bom preditor para resultados em avaliações aos 12 meses de idade corrigida. Concluíram que o tônus muscular para extremidades inferiores foi maior nos bebês com peso ao nascimento $<2.000 \mathrm{~g}$ para quatro meses de idade corrigida. Em nosso estudo, o tônus muscular foi avaliado em três momentos específicos: no Sinal de Cachecol (membro superior), no item Motor e Vigor em que o tônus muscular foi avaliado juntamente com o recuo de antebraço e no item Ângulo Poplíteo (membro inferior). No item Ângulo Poplíteo não houve nenhuma diferença significativa entre a nossa amostra de estudo e a amostra de padronização do teste. Além disso, os nossos bebês foram avaliados nas idades pós-concepcional de 32 a 37 semanas e tinham o peso ao nascimento $<2.500 \mathrm{~g}$, apresentando tônus muscular nos membros inferiores dentro do esperado pela literatura.

O estudo de Mercuri et al. (2003) verificou que as crianças nascidas prematuras exibem debilidade na musculatura flexora em itens medidos de resposta ativa ou reflexa. Essas crianças tinham mais posturas extensoras e menor controle de cabeça quando comparadas com as crianças nascidas a termo e saudáveis. Sendo esta uma possível hipótese para o menor vigor encontrado em nosso estudo, pois o item controle de cabeça está incluso nessa avaliação. 
No estudo de Cameron e Maehe (2006) não acharam diferenças significativas na área motora entre as crianças nascidas prematuras $(<32$ semanas de idade gestacional e peso ao nascimento $<1.500 \mathrm{~g}$ ) e as de termo. Verificaram que a freqüência de distribuição dos quatro itens avaliados: atraso da cabeça / cabeça alinhada ao corpo quando puxada para sentar / controle de cabeça / flexão de quadril. A maioria das crianças tem pobre atraso de cabeça e pobre controle da cabeça, moderada resposta na cabeça alinhada ao corpo quando puxada para sentar e boa variação na flexão de quadril antigravitacional na posição prono. Este padrão supõe uma distribuição caudocefálica do tônus muscular para os dois grupos de crianças. Em nosso estudo foi avaliado a elevação da cabeça em prono no item Motor e Vigor, observou-se, também, essa distribuição caudocefálica do tônus muscular.

Em estudo de Eliakim et al. (2002) estudaram três casos de bebês nascidos prematuros VLBW com patologia no SNC para determinar a densidade óssea dos membros inferiores. Os bebês foram avaliados por medidas feitas no osso Tibial. Acharam uma redução unilateral de movimentos espontâneos da perna em prematuros VLBW com patologia no SNC. Mostraram o importante papel da atividade física para o desenvolvimento e mineralização óssea, até mesmo no período neonatal. O tipo de atividade física que a criança prematura usualmente faz é a movimentação espontânea antigravitacional (movimento de flexão e extensão das pernas). Esses resultados sugeriram que essa movimentação pode aumentar a força óssea. Apesar de a comparação feita nesse estudo ser em crianças com patologia, esses resultados vai ao encontro com os nossos resultados, pois comprovam que mesmo apresentando escores menores na comparação da amostra 
de estudo com a amostra de padronização do teste, os nosso bebês apresentaram uma movimentação espontânea presente.

Nos estudos de Seme-Ciglenecki (2003) e Ohgi et al. (2008) que compararam crianças nascidas prematuras com e sem patologia neurológica, usaram para a avaliação motora o teste GM - Avaliação dos movimentos generalizados. Em ambos os estudos, a avaliação só ocorreu quando as crianças estivessem no estado comportamental 4 (alerta inativo) ou no estado de alerta. Esses resultados não podem ser comparados com o nosso estudo, pois no nosso, a avaliação ocorreu no estado comportamental em que as crianças estivessem, sem que essa variável fosse manipulada.

As diferenças apresentadas em nosso estudo no item motor corroboram com outros estudos que afirmam que os fatores biológicos possivelmente influenciam o desenvolvimento motor nos bebês nascidos prematuros. Esses fatores são a insuficiência no crescimento pós-natal (peso, altura e circunferência da cabeça). A maturação cerebral (especialmente o cerebelo). (MARLOW, 2004). O pequeno tamanho do músculo, a pobre proporção de fibras musculares, a redução intramuscular com alta concentração de fosfato e a hipoatividade física que pode causar menor desempenho anaeróbico dos prematuros em comparação aos bebês nascidos a termo. (BARTLETT; FANNING, 2003) Assim como, a coordenação intermuscular inferior, a pobre força muscular, o pobre poder de regulação muscular e inadequado controle postural podem afetar a qualidade dos movimentos e resultar em atrasos nas atividades antigravitacionais, particularmente em prematuros. (KELLER et al., 2000)

Com relação à Alerta e Orientação, a amostra de estudo apresentou maior alerta e orientação aos estímulos nas idades pós-concepcionais de 33 e 35 semanas 
em comparação com a amostra de padronização do teste. Nosso resultado não é semelhante com os resultados de outros autores que relatam que problemas visuais e auditivos são associados ao nascimento prematuro. Problemas visuais graves ocorrem em 1-3\% de crianças com peso ao nascimento abaixo de $1000 \mathrm{~g}$ e $2-6 \%$ nas crianças com idade gestacional abaixo de 27 semanas. (SOMMER et al., 2007; MARRET et al., 2007)

No estudo de Constantinou et al. (2005) avaliaram o impacto do peso ao nascimento no desenvolvimento de bebês nascidos prematuros $(<32$ semanas de idade gestacional) com baixo peso ao nascer antes de receberem a alta hospitalar. Eles acompanharam os bebês aos 12, 18 e 30 meses de idade cronológica corrigida e compararam os resultados. Foram divididos em dois grupos: ELBW (peso ao nascimento < 1.000g) e VLBW (peso ao nascimento entre 1.000 a 1500g). Foram avaliados com o NAPI aos 36 semanas de idade pós-concepcional. Depois foram avaliados pelo BINS (Bayley Infant Neurodevelopmental Screener) aos 12 meses de idade corrigida e pelo Bayley Scales of Infant Debelopment com 18 e 30 meses de idade corrigida. Foi observado que algumas crianças apresentaram paralisia cerebral em ambos os grupos. Quando estas foram retiradas da análise dos grupos e comparadas com cada grupo VLBW e ELBW observaram que a média dos escores do item do NAPI alerta e orientação foi significativamente mais baixa nas crianças com paralisia cerebral em relação aos grupos de crianças com ELBW e VLBW. Além disso, o grupo de crianças com ELBW apresentou escores significativamente mais baixo do que as crianças VLBW nos itens do NAPI alerta e orientação. No item motor e vigor, nenhuma diferença significativa foi encontrada entre os grupos ELBW e VLBW. As autoras concluíram que o NAPI realizado antes da alta hospitalar fornece informações significativas relacionadas a possíveis atrasos 
neurocomportamentais. Os autores utilizaram o mesmo teste, mas os resultados foram diferentes. Uma hipótese seria a diferença do peso ao nascimento da amostra desse estudo com o nosso estudo e por esse estudo apresentar em sua composição crianças com paralisia cerebral.

Nosso estudo vai ao encontro ao estudo de Ariagno et al. (1997) que utilizou o NAPI, NIDCAP e APIB para avaliação de bebês que receberam tratamento individualizado na UTI Neonatal, determinando se a melhora nos resultados médicos foram associados com a melhora do sono ou resultado neurocomportamental. A medida era realçar o conforto e a estabilidade, além de reduzir o estresse e a agitação da criança. As variáveis eram: posicionamento adequado, diminuição do barulho, diminuição da luz, envolvimentos dos pais. Os resultados mostraram que os bebês passaram mais tempo em estado de alerta e apresentaram características de maior maturidade motora.

Segundo Allen (2008) em seu estudo de revisão, a maioria das crianças nascidas prematuras tem mais prevalência para paralisia cerebral e/ou problemas cognitivos, e o risco é maior com o decréscimo da idade gestacional. O risco adicional é mais observado nos problemas de atenção, linguagem, habilidade perceptual-visual e na função motora fina.

Quanto ao Choro, a amostra de estudo apresentou qualidade de choro levemente mais fraco nas idades de 33, 34, 35 e 36 semanas de idade pósconcepcionais em comparação a amostra de padronização do teste que apresentou qualidade de choro moderado. No estudo de Rothganger H. (2003) no qual relata que a freqüência fundamental da acústica do choro aumenta para as idades de 0 a 12 meses de idade corrigida, esse aumento tem sido interpretado com aumento no controle da produção do choro com o crescimento da criança. No estudo de Rautava 
et al. (2006), os resultados foram diferentes, encontraram que o valor da freqüência fundamental mínima do choro foi alto nos prematuros quando comparados com grupo controle de bebês nascidos a termo, embora eles fossem jovens na idade corrigida no tempo analisado. O efeito da prematuridade na freqüência fundamental mínima permaneceu após ser ajustada a idade corrigida. Concluíram que alguns efeitos do nascimento prematuro na qualidade do choro podem constantemente ser vistas para a idade de um ano e meio. É visto que as diferenças na qualidade de choro em bebês VLBW comparados com bebês a termo são próprias da prematuridade, não somente a algum evento de injúria cerebral, mas também a outras características do paciente.

A metodologia dos estudos são diferentes, pois, em sua maioria, os estudos avaliam item específicos do choro, como por exemplo a freqüência. No nosso estudo, o item choro é avaliado pela observação do choro (choro fraco, choro moderadamente forte e choro forte). Nenhuma medida específica como intensidade, freqüência ou altura do choro é utilizada. Isso pode representar uma limitação do nosso estudo.

Uma possível hipótese para essa diferença na qualidade de choro no nosso estudo (choro levemente mais fraco) em comparação com a amostra de padronização do teste (choro moderado), pode ser que os nossos bebês permaneceram grande parte do tempo em estado de sono.

No estudo de Ohgi et al. (2006) que analisaram a relação entre o desempenho comportamental e o choro em prematuros e baixo peso ao nascer (entre 1.001 a $2.500 \mathrm{~g}$ ), comparando um grupo de bebês com alto nível de choro, com outro grupo de bebês com baixo nível de choro. Relataram que os baixos escores do grupo com alto nível indicaram pobre controle comportamental e foram 
considerados irritáveis. Além disso, encontraram que as crianças desse grupo tinham dificuldades de auto-regulação e concluíram que as crianças desse grupo podem ter baixo limiar de estimulação e sendo propensos a estimulação demasiada. Esses resultados são opostos aos nossos resultados porque os nossos bebês choraram menos e não eram irritáveis. O item Irritabilidade avalia a quantidade de choro.

Uma hipótese para essa diferença nos resultados da literatura com os nossos achados é que as crianças do estudo de Ohgi et al. (2006), foram divididas nos grupos: alto nível de choro e baixo nível de choro, baseado em um diário que registrava os períodos de choro, sono e alimentação feito pelas mães. A metodologia utilizada por ser diferente, torna-se difícil qualquer relação entre os resultados.

Com relação ao Percentual Adormecido, a amostra de estudo em todas as idades pós-concepcionais testadas apresentou maior sono indicando que os bebês desse estudo dormiram mais durante a realização do teste. Esses resultados foram semelhantes aos encontrados no estudo de Iglowstein et al. (2006) que concluíram que o comportamento do sono não difere entre prematuros e a crianças nascidas a termo, do nascimento até completarem dez anos de idade, indicando que a prematuridade ou as experiências na Unidade de Terapia Intensiva não afetam significativamente o sono no primeiro ano de vida. Nossos resultados foram similares ao estudo de Holditch-Davis et al (2004) que relataram que largos movimentos corporais e porcentagem de sono não REM durante o sono ativo diminuíram com a idade e que alerta inativo, alerta ativo, sono quieto e respiração regular no sono ativo aumentaram com a idade. 
Pode-se relacionar o fato de as crianças desse estudo dormirem mais durante a realização do teste e o fato dos itens Sinal de Cachecol e Motor e Vigor terem escores mais baixos, porque o sono pode levar a hipotonia. Além disso, pode-se levantar a hipótese da diferença nos ambientes hospitalares em que os bebês das amostras foram internados. O ambiente hospitalar em que os bebês do nosso estudo estavam no momento da avaliação, propiciou um ambiente menos estressante ao ambiente quando comparados ao grupo da amostra padronizada do teste.

Segundo Barradas et al. (2006) os prematuros não apresentam maturidade neurológica ou alguma vantagem do posicionamento prolongado no ambiente intrauterino que possa auxiliar no desenvolvimento da flexão dos membros, fazendo com que esses bebês apresentem uma hipotonia.

Apesar de os bebês do nosso estudo terem dormido mais em comparação a amostra de padronização do teste, eles estiveram mais vezes em estado de alerta e melhor orientação aos estímulos visuais e auditivos (animados e inanimados).

Em todos esses itens do NAPI (Sinal de cachecol, Motor e Vigor, Alerta e Orientação, Choro e Percentual adormecido) que apresentaram diferença significativa nos resultados da amostra de estudo com a amostra de padronização do teste, tem-se que levar em conta que a comparação foi feita com amostras diferente, pois a da amostra de padronização do teste as crianças são americanos e as nossas brasileiras. Essa diferença cultural, assim como, a diferença no tipo de hospital que prestaram os cuidados aos bebês e os dados sociodemográficos, podem ter exercido alguma influência.

Segundo Linhares et al (2004), tanto as condições de saúde do bebê, quanto as condições ambientais e familiares podem interferir, neutralizando ou 
potencializando, o desencadeamento de dificuldades para o desenvolvimento de bebês nascidos prematuros e de muito baixo peso.

No nosso estudo, não houve diferença significativa entre a amostra de estudo e a amostra de padronização do teste nos itens Ângulo Poplíteo e Irritabilidade. Especificamente, no caso do item Ângulo poplíteo, não houve diferenças significativas entre a amostra de estudo comparada a amostra de padronização do teste, pois como os autores do estudo de Rakesh Rao et al. (2007) relataram que a medida do ângulo poplíteo é um método bem documentado para avaliar a extensibilidade dos membros inferiores. Em ambas as amostras de estudo e de padronização do teste essa medida foi semelhante ao esperado para os bebês nascidos prematuros segundo a literatura.

Chama atenção o fato de que apesar de os bebês terem apresentado diferença significativa entre a amostra de estudo e a amostra de padronização do teste na qualidade de choro, não houve diferença entre a amostra de estudo e a amostra de padronização do teste na quantidade de choro que é avaliada por meio do item Irritabilidade. Mais uma vez, podemos levantar a hipótese de o ambiente ter sido menos estressante para os bebês.

Ao analisar a classificação geral do NAPI, de acordo com os desvios padrão, foi possível notar que os bebês do nosso estudo foram classificados na Média, de acordo com os desvios-padrão. Cerca de um terço, foram classificados como abaixo da média.

Os dados encontrados no presente estudo foram próximos aos índices de riscos ou atraso (30\%) encontrados em outros estudos, tais como o de Nobre (2005) que observou um índice de risco ou atraso nas áreas: axial espontâneo não comunicativo, que envolve a atividade de ficar em pé quando seguro pela cintura e 
rolar, observou $29 \%$ de risco ou atraso. Na área apendicular estimulado não comunicativo, que envolve atividade de balançar brinquedo sonoro, o índice de risco ou atraso foi da ordem de 30\%. A área apendicular espontâneo não comunicativo, que envolve ter preensão palmar simples, perceber e explorar objeto com a boca e em prono alcançar objeto, também apresentou índice de risco ou atraso de $31 \%$.

Linhares et al. (2003) desenvolveram pesquisa por meio da Escala EDCC (Escala de Desenvolvimento do Comportamento da Criança), com intuito de avaliar o desenvolvimento no primeiro ano de vida de bebês pré-termo de muito baixo peso. Entre os resultados, destaca-se índice de risco ou atraso inferior a $20 \%$ nas áreas preparatórias para andar e sentar. Aos 11 meses de idade cronológica corrigida houve índice de risco em torno de $30 \%$ para comportamento motor amplo e comportamento verbal.

Para responder ao terceiro objetivo proposto por este estudo, e verificar se a amostra total de estudo estaria influenciada por apresentar em sua composição os bebês nascidos pequenos para a idade gestacional (PIG), terem tido algum evento de anóxia, hemorragia e hidrocefalia. Excluímos da amostra total esses bebês (grupo com problema) e comparamos com o grupo sem problema. Houve um padrão semelhante nas diferenças significativas apresentadas nos itens avaliados. $O$ item Motor e Vigor, e o Sinal de Cachecol foram os itens onde as diferenças foram apresentadas na maioria das idades pós-concepcionais testadas. Esses resultados demonstraram que o grupo que foi excluído não interferiu no desempenho neurocomportamental da amostra total e confirmou o fato de que a prematuridade pode afetar especificamente à área motora. 
Manacero e Nunes (2008) corroboram os achados desse estudo, ou seja, que a média do desenvolvimento motor é progressiva e o peso ao nascimento não interfere na progressão desse desenvolvimento.

A influência do peso ao nascimento no desempenho motor de recémnascidos, na ausência de distúrbios neurológicos, tem sido discutida na literatura com resultados conflitantes, principalmente no que se refere a prematuros. Isso ocorre pelo fato de muitos estudos de prognóstico terem sido baseados no peso ao nascimento e não levarem em consideração a adequação deste peso à idade gestacional. É importante diferenciar situações transitórias e fisiológicas que ocorrem no prematuro durante o primeiro ano de vida com algum possível atraso no seu desenvolvimento. (DA SILVA; NUNES, 2005)

No estudo de Ramos et al (2000) relataram que os recém-nascidos prematuros e PIG, parecem apresentar maior incidência de seqüelas neurológicas do que a população em geral de prematuros e do que os recém-nascidos de termo e PIG, mas provavelmente menor que a dos recém-nascidos prematuros e AIG. A incidência de seqüelas neurológicas graves nos recém-nascidos prematuros parecem predominar nos AIG, uma vez que os PIG têm menor freqüência de complicações respiratórias e hemorragias intracranianas. Alguns autores, entretanto, não confirmam tais achados. No estudo de Barros et al. (2008) que compararam o neurocomportamento de recém-nascidos a termo PIG e AIG, concluíram que os PIG mostraram menor qualidade de movimento, mais excitabilidade e mais sinais de estresse, em associação com o sexo do neonato e com variáveis relacionadas ao parto.

Para atingir o quarto objetivo proposto do presente estudo foi comparado os indicadores do desenvolvimento em grupos de bebês diferenciados quanto ao sexo. 
Verificou-se que não houve diferença significativa entre os meninos e meninas quanto ao desenvolvimento neurocomportamental avaliado pelo NAPI. Os nossos resultados foram diferentes aos encontrados na literatura em que vários autores relataram diferenças entre o sexo. Boatella-Costa et al. (2007) demonstraram em seu estudo que as meninas nascidas a termo mostraram melhor orientação a face do examinador e direcionaram os olhos para a voz humana quando comparados aos meninos nascidos a termo. Demonstraram, também, que os meninos tiveram altos escores no item de irritabilidade. Esta medida, em geral, os meninos mostram menos irritabilidade que as meninas na escala The Brazelton. As meninas obtiveram melhores resultados na auto-regulacão quando comparados aos meninos. No estudo de Hintz et al. (2006) verificaram que o efeito da variável sexo na exposição a eventos perinatais ou neonatais, explicando que os meninos tem mais desvantagens nos resultados no início da infância em relação às meninas. Encontraram que os meninos mais freqüentemente tiveram resultados adversos como moderada a grave paralisia cerebral. Os maiores fatores de risco também foram mais comumente encontrados nos meninos. Concluíram que fatores neonatais, perinatais e da primeira infância conferem similares riscos ou proteção para meninos e meninas, mas os meninos parecem ter inerentemente maior risco. Variáveis biológicas não medidas provavelmente contribuem para que os meninos prematuros tenham desvantagens nos resultados neurodesenvolvimentais em comparação às meninas.

Uma possível explicação para não ter ocorrido diferenças significativas entre as meninas e os meninos é o fato de ter ocorrido uma distribuição semelhante entre eles, quanto as suas características. Outra hipótese seria que em nosso estudo, o sexo pode atuar como uma variável organísmica biológica sem ter as representações e influências do conceito gênero. Pode-se notar que nessa fase 
inicial do desenvolvimento, a variável organísmica biológica não assumiu ainda um papel diferenciador. Aspectos como cultura e interferência hormonal, por exemplo, pode não ter ainda influência sobre esta questão de sexo no bebê.

Cabe-se ressaltar que este estudo foi realizado em um contexto de hospitalmaternidade na cidade de Goiânia (GO), que é uma instituição que se caracteriza como prestadora de um serviço público (SUS) de referência no atendimento à mãe e à criança, e atende uma vasta clientela oriunda de outros hospitais da cidade e de outros municípios, por possuir uma UTI Neonatal e atendimento as gestantes de alto risco.

Levando-se em conta as características do presente estudo, tais como as características da amostra, os dados sociodemográficos, o tipo de hospital e o estado em que foi realizada a pesquisa. Deve-se tomar cuidado na generalização dos dados da presente pesquisa, que deve ser feita para amostras de bebês com características semelhantes.

A escassez de instrumentos nacionais padronizados nessa fase inicial do desenvolvimento ressalta a importância de estudos em nosso país para verificar a adequação e validação de instrumentos para os parâmetros locais.

Os achados do presente estudo permitem confirmar que a avaliação neurocomportamental do NAPI pode ser realizada com crianças brasileiras e esta fornece dados importantes para detecções de possíveis atrasos no desenvolvimento de bebês nascidos prematuros. Estes achados demonstram que nas pesquisas nacionais, essa avaliação neurocomportamental é pioneira por ser realizada em bebês prematuros. Santos et al (2008), em uma revisão bibliográfica, conclui a importância dos testes de triagem para acelerar o início da intervenção precoce e facilitar o desenvolvimento futuro das crianças. 
Segundo Kleine et al. (2007) programas de follow up deveriam identificar os problemas na idade inicial e providenciar terapias de intervenção quando necessário. A avaliação neurocomportamental utilizada nesse estudo mostrou-se ser eficiente para a detecção inicial de possíveis problemas.

Destaca-se nas pesquisas nacionais que os instrumentos que estão sendo utilizados em maior escala são o teste de DENVER II e o AIMS, mas estes não são aplicados nessa mesma faixa de idade pós-concepcional, e sim em idades corrigidas na primeira infância.

Estudos futuros podem avançar no estabelecimento de padrões utilizando o NAPI em crianças brasileiras e testar sua validade preditiva.

Sugere-se como desdobramento prático a implementação de avaliações neurocomportamentais em bebês prematuros na fase de 32 a 40 semanas de idade pós-concepcional, como rotina de exames em hospitais, a fim de avaliar os indicadores de risco o mais cedo possível. Desta forma pode-se fornecer subsídios para implementar medidas efetivas de intervenção preventiva para evitar problemas futuros de desenvolvimento. 


\section{REFERÊNCIAS BIBLIOGRÁFICAS ${ }^{2}$}

ABEP - Associação Brasileira de Empresas de Pesquisa - 2003. Disponível: http://www.abep.org; abep@abep.org. Dados com base no levantamento SócioEconômico - 2000 - IBOPE.

ALLEN, M.C. Neurodevelopmental outcomes of preterm infants. Current Opinion Neurology. 21:123-128.2008

ALS, H.; LESTER, B. M.; TRONICK, Z. e BRAZELTON, B. Toward a research instrument for the assessment of preterm infant's behavior (APIB). Em; $H$. $E$. Fitzgerald; B.M. Lester e M. W. Yogman (Orgs) Theory and Research in Behavioral Pediatrics New York: Plenum Press. 1982. (pp.35 - 63).

ALS, H; GIBES, R. Neonatal Individualizede Developmental care and Assessment Program. Boston. The Children's Hospital and Brigham and Women's Hospital. 1984.

AMBALAVANAN, N.; NELSON, KG; ALEXANDRE G.; JOHNSON, SE.; CARLO, WA. Prediction of neurologic morbidity in extremely low birth weigth infants. Journal of Perinatology 2000; 20:496-503.

AMERICAN ACADEMY OF PEDIATRICS. The American College of Obstetricians and Gunecologists. Guidelines for perinatal care. $4^{\text {th }}$ ed. Elk Gove Village, IL: American Academy of Pediatrics; 1997. p.313.

ANTUNHA, E.L.G. A avaliação neuropsicológica na infância (0 a 6 anos). Em:V.B.de Oliveira e N.A.Bossa (orgs). Avaliação Psicopedagógica da criança de 0 a 6 anos. Petrópolis: Vozes. 1994. (pp. $89-122$ )

2 Elaborada de acordo com a Associação Brasileira de Normas Técnicas. NBR 6023: informação e documentação: referências: elaboração. Rio de Janeiro, 2002 
ARIAGNO, R.L; THOMAN, E.B.; BOEDDIKER, M.A.; KUGENER, B.; CONSTANTINOU, J.C.; MIRMIRAN, M. e BALDWIN, R.B. Developmental care does not alter sleep and development of premature infants. Pediatrics, 100, 1997. 6, 1-7.

AYLWARD, G.P. Methodological issues in outcomes studies of at-risk infants. Journal of Pediatric Psychology, 2002, 27, 1, 37-45.

BARRADAS, J.; FONSECA, A.; GUIMARÃES, C.L.N.; LIMA, G.M.S. A relação entre posicionamento do prematuro no Método Mãe-Canguru e desenvolvimento neuropsicomotor precoce. Jornal de Pediatria. 2006; 82(6):475-80

BARROS, M.C.M.; GUINSBURG, R.; MITSUHIRO, S.S.; CHALEM, E.; LARANJEIRA, R. Neurocomportamento de recém-nascidos a termo, pequenos para a idade gestacional, filhos de mães adolescentes. Jornal de Pediatria. 2008;84(3):217-223.

BARTLETT, D.J.; FANNING, J.E. Use of the Alberta Infant Motor Scale to characterize the motor development of infants born preterm at eight months corrected age. Physical and Occupational Therapy Pediatrics. 2003; 23:31-45

BARTOCCI, M.; BERGQVIST, L.L.; LAGERCRANTZ, H.; ANAND, K.J.S. Pain actives cortical areas in the preterm newborn brain. Pain. 122 (2006), 109-117

BATTAGLIA, F.C.; LUBCHENCO, L.O. A pratical classification of newborn infants by weight and gestacional age. Journal of Pediatrics. 71: 159-163, 1967.

BLOND, M.H.; CASTELLO-HERBRETEAU, B.; AYAN, E.; LECUYER, A.I.; FRADET, A.; PALAT, F. Devenir Medical, cognitive et affectif à L'âge de quatre ans de prematures indennes de handicap severe. Etude prospective descas-témoins. Archives Pediatrics. 2003; 10:117-25

BOATELLE-COSTA, E.; COSTAS-MORAGAS, C.; BOTET-MUSSONS, F.; FORNIELES-DEU, A.; DE CÁCERES ZURITA, M.L. Behavioral gender differences in the neonatal period according to the Brazelton scale. Early Human Development, 2007, 83, 91-97

BORDIN, M.B.M. Desenvolvimento psicológico na fase escolar de crianças exprematuras, diferenciadas quanto ao risco clínico neonatal. Tese (Doutorado). Faculdade de Filosofia, Ciências e Letras de Ribeirão Preto. Universidade de São Paulo. Ribeirão Preto. 2005 
BRANDT, I. Patterns of early neurological development. In. F. Falkner \& J.M. Tanner (Eds). Human growth - neurobiology and nutrition (vol 3, pp. 243-304) New York: Plenum.

BRASIL. Ministério da Saúde. Atenção humanizada ao recém-nascido de baixo peso: método mãe-canguru. Manual Técnico. Secretaria de Políticas de Saúde, Área da Saúde da Criança. Brasília, 2001.

BRAZELTON, T.B. Momentos decisivos do desenvolvimento infantil. (J.L. Camargo, Trad.) 1994. São Paulo: Martins Fontes (Trabalho original publicado em 1992).

BERNSTEIN, OS. Confronting preterm delivery in the $21^{\text {st }}$ century: from molecular intervention to community action. Conference report. New York, November 10-11, 2000. www.medscape.com Medscape Women's Health 5(6), 2000.

BRITO, A.; MATSUDO, T; GONZALEZ, M.R., CARVALHO, A.B.R.C.; FERRARI, L.S.L.. Escore CRIB, peso ao nascer e idade gestacional. Ver. Saúde Pública, 2003; 37(5): 597-602.

BROWN, J.V.; COLES, C.D.; SEXSON, W.R.; DEMI, A.S. Maternal Drug use during pregnancy: Are preterm and full-term infants affected differently? Developmental Psychology. 1998. vol.34. n33. 540-554

CADERNOS DE INFORMAÇÕES DE SAÚDE, 2007

CAMELO JR., J.S. Recém-nascidos de muito baixo peso e estado nutricional: certezas e incertezas. Jornal de Pediatria. 2005. 81 (1):5-6

CAMERON, E.C.; MAEHLE, V.M. Comparison os active motor items in infants born preterm and infants born full term. Pediatric Physical Therapy. 2006; 197-203

CARVALHO, W. B.e MANGIA, C. M. F. Efeitos na função pulmonar após utilização de surfactante pulmonar exógeno na Síndrome do desconforto respiratório agudo na criança. Revista Associação Médica Brasileira, 43, 1997, 2, 145-150.

CARVALHO, A. E. V.; LINHARES, M. B. M. e MARTINEZ, F. E. História de desenvolvimento e comportamento de crianças prematuras e de baixo peso (< 1500g). Psicologia: Reflexão e Crítica. 2001 
CHAUDHARI, S.; DEO, B. Neurodevelpmental Assessments in the first year with emphasis on evolution of tone. Indian Pediatrics. 2006; 43: 527-534

COCKBURN, F.; COOKE, R.W.I.; GAMSU, H.R.; GREENOUGH, A.; HOPKINS, A.; MCINTOSH, N.; OGSTONT, S.A.; PARRYT, G.J.; SILVERMAN, M.; SHAW, J.C.L.; TARNOW-MORDIT, W.O. e WILKINSON, A.R. The CRIB (Clinical Index for Babies) score: a tool for assessing initial neontal risk and comparing performance of neontal care units. Lancet, 1993. 342, 193-198.

CONSTANTINOU, J.C.; ADAMSON-MACEDO, E.N.; MIRMIRAN, M.; ARIAGNO, R.L.; FLEISHER, B.E. Neurobehavioral Assessment Predicts Differential Outcome Betwwen VLBW and ELBW preterm infants. Journal of Perinatology 2005, 25:788793.

CREASY, RK; IAMS, JD.; JOHNSON, FF. Prevention of preterm birth. Clinical Obstetrics Gynecology 1988; 31:599-615.

CREASY, RK.; MERKATZ, IR. Prevention of preterm birth: CLINICAL OPINION. Obstetetrics Gynecology 1990; 76 (1 Suppl):2S-4S.

DA SILVA, E.S; NUNES, M.L. The influence of gestacional age and birth weight in the clinical assessment of the muscle tone of healthy term and preterm newborns. Arquivos de Neuropsiquiatria. 2005; 63:956-62

DARRAH, J.; PIPER, M.; WATT, M.J. Assessment of gross motor skills of at-risk infnts: predictive validity of the Alberta Infant Motor Scale. Devlopmental Medical Child Neurology. 1998;40:485-91

DAUM, C.; GRELLONG, B.; KURTZBERG, D. Et al. The Albert Einstein Neonatal Neurobehavioral Scale, unpublished manual. 1977

DIAMENT, A. J. \& GHERPELLI, J.L.D.. Exame Neurológico do recém-nascido. In: VazFAC (coord.). Problemas neurológicos do recém-nascido. Monografias Médicas. Série "Pediatria". Volume 24, Sarvier, S. Paulo, 1985, p.29.

DIAMENT, A. J. et al. Neurologia Infantil (coord). 3o ed. São Paulo: Editora Atheneu, 1996.

D'OOSTERLINCK, F.; BROEKAERT, E.; DE WILDE, J.; GOETHALS, I. Characteristics and profile of boys and girls with emotional and behavioural disorders 
in Flanders mental health institutes: a quantitative study. Child: Care, Health \& Development, 2006, 32, 2, 213-224.

EGEWARTH, C.; PIRES, F.D.A.; GUARDIOLA, A. Avaliação da idade gestacional de recém-nascidos pré-termo através do exame neurológico e das escalas neonatais e obstétrica. Arquivos de Neuropsiquiatria. 2002; 60(3-B):755-759

EICKMANN, S.H.; DE LIRA, P.I.C; LIMA, M.C. Desenvolvimento mental e motor aos 24 meses de crianças nascidas a termo com baixo peso. Arquivos de Neuropsiquiatria. 2002; 60(3-B)

EINSPIELER, C.; PRECHTL H.F.; BOS A.R.; FERRARI, F.; CIONI, G. Prechtl's method on the qualitative assessment of general movements in preterm, term and young infants. Cambridge: Cambridge University Press, 2004.

ELIAKIM, A.; NEMET, D.; FRIEDLAND, O.; DOLFIN, T.; REGEV, R.H. Spontaneous activity in premature infants affects bone strength. Journal of Perinatology. 2002; 22:650-652

FRAGA, D.A.; LINHARES, M.B.M.; CARVALHO, A.E.V.; MARTINEZ, F.E. Desenvolvimento de bebês prematuros relacionados a variáveis neonatais e maternas. Psicologia em estudo. 2008; 13(2)

FONSECA, ESVB. Estudo da monitorização nas contrações uterinas em gestantes de risco para o parto prematuro espontâneo. Dissertação apresentada na Faculdade de Medicina da USP para obtenção do título de Mestre em Medicina. São Paulo, 1998.

FORMIGA, C.K.M.R.; GABRIEL, P.S.Z.; LINHARES, M.B.M. (2005). Avaliação Neurocomportamental do Bebê Pré-termo, tradução do Manual Neurobehavioral Assessment of Preterm Infant (não publicada).

FORMIGA, C.K.M.R. (2009). Detecção de Risco para Problemas no Desenvolvimento de Bebês Nascido Pré-termo no Primeiro Ano. Tese de Doutorado, Programa de Pós-graduação em Saúde Mental, Faculdade de Medicina de Ribeirão Preto, Universidade de São Paulo.

GAGLIARDI, L.; CAVAZZA, A.; BRUNELLI, A.; BATTAGLIOLI, M.; MERAZZI, D.; TANDOI, F.; CELLA, D.; PEROTTI, G.F.; PELTI, M.; STUCCHI, I.; FRISONE, F.; AVANZINI, A; BELLER, R. Assessing mortality risk in very low birth weight infants.: a 
comparasions of CRIB, CRIB II and SNAPPE-II. Archives of disease in Childhood. 2004;89:419-422

GEARY, M.; LAMONT, RF. Prediction of preterm birth. In: Elder MG, Lamont RF, Romero R. Preterm Labor. New York: Churchill Livingstone Inc; 1997. p. 51-63.

GIGANTI, F.; HAYES, M.J.; AKILESH, M.R.; SALZARULO, P. Yawning and Behavioral States in premature infants. Wiley Periodicals 2002, 289-296.

GUINSBURG et al. Differences in pain expression between male and female newborn infants. Pain, 2000, 85: 127-133.

GOLDBERG, S.; VITTO, B.D. Parenting children born preterm. Em: M.H.Bornstein, Handbook of parenting-children and parenting. New Jersey: Lawrence Erbaum Associates. 1995. (pp. $209-231$ )

GRAY, J.E.; RICHARDSON, D.K.; MCCORMICK, M.C.; et al. Neonatal acute physiology (SNAP) and risk of IHV. Pediatric Research. 1992;31:249A

GRUNAU RVE, WHITFIELD MF, PETRIE JH \& FRYER EL. Early pain experience, child and family factors, as precursors of somatization: a prospective study of extremely premature and fullterm children. Pain, 1994, 56, 353-359.

HACK, M.;FLANNERY, D.J.; SCHLUCHTER, M.; CARTAR, L.; BORAWSKI, E.; KLEIN, N. Outcomes in young adulthood for very-low-birth-weight infants. New England Journal of Medicine. 2002, 346:149-157

HACK, M.; FRIEDMAN, H.; FANAROFF, AA. Outcomes of extremely low birth weigth infants. Pediatrics, 1996; 98:931-7.

HACK, M.; FANAROFF, AA. Outcomes of children of extremely low birth weigth and gestational age in the 1990s. Seminars Neonatology, 2000; 5:89-106.

HALPERN, R.; GIUGLIANI, E. R. J.; VICTORA, C. G.; BARROS, F. C. e HORTA, B. $\mathrm{L}$. Fatores de risco para suspeita de atraso no desenvolvimento neuropsicomotor aos 12 meses de vida. Jornal de Pediatria. 76, 2000, 6, 421-428. 
HINTZ, S.R.; KENRICK, D.E.; VOHR, B.R.; POOLE, W.K.; HIGGINS, R.D. Gender differences in neurodevelopmental outcomes among extremely preterm, extremelylow-birthweigth infants. Acta Pediatrica 2006; 95:1239-1248.

HOEKSTRA, R.E.; FERRARA, T.B.; COUSER, R.J.; PAYNE, N.R.; CONNETT, J.E.; Survival and long-term neurodevelopmental outcome of extremely premature infants born at 23-26 weeks gestacional age at a tertiary center. Pediatrics. 2004; 113:1-6

HOLDITCH-DAVIS, D.; SCHER, M.; SCHWARTZ, T.; HUDSON-BARR, D. Sleeping and waking state development in preterm infants. Early Development 2004, 80:4364.

IGLOWSTEIN, I.; HAJNAI, B. L.; MOLINARI, L.; LARGO, R.H.; JENNI, O.G. Sleep behaviour in preterm children from birth to age 10 years: a longitudinal study. Acta Paediatrica, 95:12, 1691-1693. 2006.

JOHNSTON, C.C.; FILION, F.; SNIDER, L.; MAJNEMER, A.; LIMPEROPOULOS, C.; WALKER, C.D.; VEILLEUX, A.; PELAUSA, E.; CAKE, H.; STONE, S.; SHERRARD, A. e BOYER, K. Routine sucrose analgesia during the first week of life in neonates younger than 31 weeks' postconceptional age. Pediatrics, 2002, 110, 3, 523-528.

KATO, T.; OKUMURA, A.; HAYAKAWA, F.; ITOMI, K.; KUNO, K.; WATANABE, K. Popliteal Angle in Preterm Infants with Periventricular Leukomalacea. Pediatric Neurology. 2005, Vol 32, no 2.

KELLER, H.; BAR-OR, O.; KRIEMLER, S.; AYUB, B.V.; SAIGAL, S. Anaerobic performance in 5-to-7-yr-olg children of low birthweight. Medical \& Sciences in Sports \& Exercise. 2000; 32:278-83

KENNER, C. Enfermagem Neonatal. Reichmann \& Affonso Editores. 2000, 2a ed.

KLEINE, M.J.K; DEN OUDEN, A.L.; KOLLÉ, L.A.A.; NIJHUIS-VAN DER SANDEN, M.W.G.; SONDAAR, M.; VAN KESSEL-FEDDEMA, B.J.M.; KNUIJT, S.; VAN BAAR, A.L.; ILSEN, A.; et al. Development and evaluation of a follow up assessment of preterm infants at 5 years of age. Archives of Disease in Childhood. 2003;88:870875

KORNER, A. F. Reliable individual differences in preterm infant's excitation management. Child Development, 1996, 67, 1793-1805. 
KORNER, A. F.; BROWN, J.V.; THOM, V. A. e CONSTANTINOU, J.C. The neurobehavioral assessment of the preterm infant. 2000. Manual revised. $2^{\text {nd }}$. Edition.

KORNER, A.F; STEVENSON, D.K.; FORREST, T.; CONSTANTINOU, J.; DIMICELI, S. e BROWN, B.R. Jr. Preterm medical complications differentially affect neurobehavioral functions: results from a new neonatal medical index. Infant Behavior and Development, 1994, 17, 37-43.

KORNER, A.F; CONSTANTINOU, J.; DIMICELI, S. e BROWN, B.R. Jr. Establishing the Reliability and Developmental validity of a Neurobehavioral Assessment for Preterm Infants: A methodological Process. Child Development. 1991; 62:12001208

LEKSKULCHAI, R; COLE, J. Scarf Ratio: A Method of measuring the scarf sign in preterm born infants. Australian Journal of Phisiotherapy, 2000, vol 46: 85-90.

LEKSKULCHAI, R; COLE, J. The relationship between the Scarf Ratio and subsequent Motor performance in infants born preterm. Pediatric Physical Therapy. 2000;12:150-157

LINHARES, M.B.M.; CARVALHO, A.E.V.; BORDIN, M.M.; CHIMELLO, J.T.; MARTINEZ, F.E. e JORGE, S.M. Prematuridade e muito baixo peso como fatores de risco ao desenvolvimento da criança. Paidéia, FFCLRP-USP, Ribeirão Preto, 2000, jan/jul, 60-69.

LINHARES, M.B.M. Estresse, resiliência e cuidados no desenvolvimento de neonatos de alto risco. Temas em Educação Especial. Avanços recentes. MENDES, E. G.; ALMEIDA, M. A.; WILLIAMS, L. C. A. (org). 2004, Cap. 14, 315324.

LINHARES, M.B.M., CARVALHO, A.E.V., PADOVANI, F.H.P., BORDIN, M.B.M., MARTINS, I.M.B. e MARTINEZ, F.E. A compreensão do fator de risco da prematuridade sob a ótica desenvolvimental. In: Marturano, E.M., Linhares, M.B.M., Loureiro, S.R. (Orgs.). Vulnerabilidade e Proteção. Indicadores na trajetória de desenvolvimento do escolar. São Paulo: Fapesp/Casa do Psicólogo, 2004, 11-38.

LOCKWOOD, CJ. Comento n: prediction of pregnancy loss. Lancet, 2000; 355:1326-9. 
MAJNEMER, A.; SNIDER, L. A comparison of Developmental Assessments of the Newborn and Yong Infant. Mental Retardation and Developmental Disabilities Research Reviews, 2005, 11:68-73.

MANACERO, S.; NUNES, M.L. Evaluation of motor performance of preterm newborns during the first months of life using the Alberta Infant Motor Scale (AIMS). Journal of Pediatrics. 2008;84(1):53-59.

MARLOW, N. Neurocognitive outcome after very preterm birth. Archives of Disease in Childhood Fetal Neonatal. 2004;89:F224-8

MARRET, S.; ANCEL, P.Y.; MARPEAU, L.. Neonatal and 5-year outcomes after birth at 30-34 weeks of gestation. Obstetrics Gynecology. 2007;110:72-80

MCGRATH, M.M.; SUELIVAN, M.C.; LESTER, B.M.; OH, N. Longitudinal neurologic follow-up in neonatal intensive care until survivous. Pediatrics. 2000;106(6):13971405

MEIO, M. D. B. B.; LOPES, C. S. e MORSCH, D. S. Fatores prognósticos para o desenvolvimento cognitivo de prematuros de muito baixo peso. Revista Saúde Pública. 2003, 37, 3, 311-318.

MÉIO, M.D.B.B.; LOPES, C.S.; MORSCH, D.S.; MONTEIRO, A.P.G.; ROCHA, S.B.; BORGES, R.A.; REIS, A.B. Desenvolvimento cognitivo de crianças prematuras de muito baixo peso na idade pré-escolar. Jornal de Pediatria. 2004;80:495-502

MENT, L.R.; VOHR, B.; ALLAN, W.; KATZ, K.H.; SCHNEIDER, K.G.; WESTERVELD, M. Change in cognitive function over time in very low-birth-weight infants. JAMA. 2003;289:705-11

MERCURI, E.; GUZZETTA, A.; LAROCHE, S. Et al. Neurologic examination of preterm infants at term age: comparison with term infants. Journal of Pediatrics. 2003;142:647-655

MORRISON, JJ.; RENNIE, JM. Clinical, scientific and ethical aspects of fetal and neonatal care at extremely preterms periods of gestation. Brazil Journal Obstetrics Gynecology, 1997; 104:1231-50. 
MOURADIAN, L. E.; HEIDELISE ALS. e COSTER, W. J. (2000). Neurobehavioral Functioning of Healthy Preterm Infants of Varying Gestacional Ages. Developmental and Behavioral Pediatrics. 21, 6.

NOBRE, F.D.A. Indicadores do desenvolvimento de crianças nascidas pré-termo de muito baixo peso nos dois primeiros anos de vida. Dissertação de Mestrado. Faculdade de Filosofia, Ciências e Letras de Ribeirão Preto. Ribeirão Preto. 2005

O'BRIEN, M.; SOLYDAY, E. e MCCLUSKEY-FAWCETT, K. Prematurity and The Neonatal Intensive Care Unit. In; ROBERTS, M. C. (Org). Handbook of Pediatric Psychology. New York: Guilford Press, 1995, 463-478.

OHGI, S.; GIMA, H.; ARIYAMA, T. Neonatal behavioural profile and crying in premature infants at term age. Acta Paediatrica. 2006;95:1375-1380

OHGI, S; MORITA, S.; LOO, K.K.; MIZUIKE, C. Time series analysis of spontaneous upper-extremity movements of premature infants with brain injuries. Physical therapy. 2008;88(9):1022-1033

PEDROMÔNICO, M. R. Problemas de desenvolvimento das crianças: prevenção e intervenção. Temas sobre desenvolvimento. 12, suplemento especial. 2003.

PERSSINOTO, J. Atuação fonoaudiológica com os bebês prematuros: Acompanhamento do desenvolvimento. In. Andrade CRF. (ED) Fonoaudiologia em berçário normal e de risco. São Paulo: Lovise, 1996, 129-148.

PETROU, S.; SACH, T. e DAVIDSON, L. The long-term costs of preterm birth and low birth weight: results of a systematic review. Child: Care Health and Development, 2001, 27 (2), 97-115.

PRESSLER,J. L.; HELM, J. M.; HEPWORTH, J. T. e WELLS, N. L. Behaviors of very Preterm Neonates as Documented Using NIDCAP observations. Neonatal Network. 2001, 20, 8.

RAKESH RAO, M.D.; SAMPERS, J.S.; KRONSBERG, S.S.; BROWN, J.V.; ANAND, K.J.S. Neurobehavior of Preterm Infants at 36 weeks posconception as a function of Morfine Analgesia. American Journal of Perinatology 2007, 24:511-518. 
RAMOS, J.L.A.; VAZ, F.A.C.; CALIL, V.M.L.T. O recém nascido pequeno para o idade gestacional. Pediatria Moderna. Vol. XXXVI, edicão especial, 153-164, 2000.

RAUTAVA, L.; LEMPINEN, A.; OJALA, S.; PARKKOLA, R.; RIKALAINEN, H.; LAPINLEIMU, H.; HAATAJA, L.; LEHTONEM, L. Acoustic quality of cry in very-lowbirth-weigth infants at the age of $11 \frac{1}{2}$ years. Early Human Development. 2007; 83: 5-12.

RICHARDSON, D. K.; GRAY, J. E.; Mc CORNICK, M.C.; WORKMAN, K. e GOLDMAN, D. A. Neonatal Therapeutic Intervention Scaring System: A Therapybased severity of illness index. Pediatrics, 1992, 90 (4), 561-567.

ROSS, G.; LIPPER, E. e AULD, P. A. M. Cognitive abilities and early precursors of learning disabilities in very low birthweigth children with normal intelligences and normal neurological status. Internacional Journal of Behavioral Development, 1996, 19(3), 533-547.

ROTHGANGER, $\mathrm{H}$. Analysis of the sounds of the child in the first year of age and a comparison to the language. Early Human Development. 2003; 75:55-69.

SAINT-ANNE DARGASSIES, S. Neurological maturation of the premature infant of 28 to 41 week's gestacional age. In. F. Falkner (Ed). Human Development (pp. 306325). Philadelphia \& London: Saunders.

SANTOS, R.S.; ARAÚJO, A.P.Q.C.; PORTO, M.A.S. Diagnóstico precoce de anormalidades no desenvolvimento em prematuros: instrumentos de avaliação. Jornal de Pediatria. 2008; 84 (4): 289-299.

SCANLAN, C.L.; WILKINS, R.L.; STOLLER, J.K. Fundamentos da Terapia Respiratória de Egan. Editora Manole. 7ª̣ed. 2000; 43:1039-1040

SEGRE, CAM. Informações perinatais. Relatório de atividades. HIAE, 1999.

SEGRE, CAM. Perinatologia Fundamentos e prática. Sarvier, 2002; p:226-251.

SEME-CIGLENECKI, P. Predictive value of Assessment of General Movements for Neurological Development of high-risk preterm infants: Comparative study. Clinical Sciences. 2003;44(6):721-727 
SILVEIRA, M.F.; SANTOS, I.S.; BARROS, A.J.D.; MATIJASEVICH, A.; BARROS, F.C.; VICTORA, C.G. Aumento da prematuridade no Brasil: revisão de estudos de base populacional. Revista de Saúde Pública. 2008;42(5):957-64

SOMMER, C.; URLESBERGER, B.; MAURER-FELLBAUM, U. et al. Neurodevelopmental outcomes at 2 years in 23 to 26 weeks old gestation infants. Klinische Pãdiatrie. 2007;219:23-29

STOELHORST, G. M. S. J.; RIJKEN, M.; MARTENS, S. E.; ZWIETEN, P. H. T.; FEENSTRA, J.; e SWEET, A. Y. Classificação do recém-nascido de baixo peso. Em: Klaus, M. H. e Fanaroff, A. (Eds). Alto risco em Neonatologia 1982, (63-88) (L. E. Vaz Miranda, Trad.). Rio de Janeiro: Interamericana (Trabalho original publicado em 1979).

STRUBBLEFIED, P. Causes and prevention of premature birth: na overview. Preterm birth: causes, prevention and management, 2 nd. Ed. New York: McGraw Hill; 1993. p. 3-40.

STOLZ, JW. Hearing loss in neonatal intensive care unit graduates. In: Cloherty JP, Stark AR (eds). Manual of neonatal care. 4 ed. Philadelphia: Lippincott-Raven; 1998. p.648-9.

USHER, R. Extreme prematury In: Avery GB. Neonatology Pathophysiology and Management of the Newborn. 3/ed. Philadelphia: JB Lippincott Company; 1987. p. 264.

VAN HAASTERT, I.C.; DE VRIES, L.S.; HELDERS, P.J.M.; JONGMANS, M.J. Early gross motor development of preterm infants according to the Alberta Infant Motor Scale. Journal of Pediatric. 2006;149:617-22

WOLKE, D. Enviromental neonatology. Archives of Disease in Childhood, 1987, $62,987-988$.

WORLD HEALTH ORGANIZATION.Recommended definitions, terminology, and format for statical tables related to the perinatal period and use of a new certificate for cause of perinatal deaths. Modifications recommended by FIGO as amended October 14, 1976. Acta Obstetrics Gynecology Scandinavic 1977; 56:247. 


\section{ANEXO A}

\section{TERMO DE CONSENTIMENTO LIVRE E ESCLARECIDO}

(Consentimento Pós-informação para Pesquisa com Seres Humanos)

Consentimento formal de participação no estudo intitulado "Estudo Longitudinal de Detecção Precoce de Problemas no Desenvolvimento Inicial de Bebês Pré-termo".

Responsável: Ms. Cibelle Kayenne Martins Roberto Formiga

$\mathrm{Eu}$, portador(a) do $R G n^{\circ}$ residente na cidade de

telefone responsável pelo (a) menor autorizo a participação

de meu(minha) filho(a) na pesquisa ““"Estudo Longitudinal de Detecção Precoce de Problemas no Desenvolvimento Inicial de Bebês Pré-termo" conduzida pela fisioterapeuta Cibelle Kayenne Martins Roberto Formiga.

\section{Objetivo do estudo:}

A referida pesquisa têm como objetivos: Realizar uma avaliação global do desenvolvimento das crianças nos aspectos de socialização, cognição, linguagem, autocuidados e motricidade; e levantar os fatores de riscos que possam estar influenciando o processo de desenvolvimento.

\section{Explicação do procedimento:}

Estou ciente de que antes da avaliação serei submetida a um questionário acerca dos meus dados e do (da) meu (minha) filho (a). A avaliação com meu(minha) filho(a) será realizada mensalmente pela equipe de fisioterapia até que sejam completados 12 meses de idade da criança. Estou informada de que a criança será observada em relação aos seus comportamentos motores e alguns testes serão feitos para avaliar se o bebê está se desenvolvendo ou apresenta algum tipo de atraso. Concordo que as avaliações poderão ser filmadas e /ou fotografadas e que estarei presente na sala de avaliação durante todos os procedimentos com o (a) meu (minha) filho (filha). 


\section{Benefícios previstos:}

Os resultados deste estudo poderão ajudar na prática de profissionais que trabalham na com bebês em Unidades de Terapia Intensiva Neonatais, estimulando um programa de prevenção de déficits no desenvolvimento neuropsicomotor e/ou promovendo uma intervenção nas que apresentarem algum atraso. Entendo que é importante acompanhar o desenvolvimento motor da criança prematura, pois como é uma criança muito frágil pode vir a apresentar algum tipo de atraso no seu desenvolvimento.

\section{Potenciais riscos e incômodos:}

Fui informado de que o experimento não trará nenhum risco para a saúde de meu (minha) filho (a) e que a identidade dele (a) ou minha não serão reveladas. Fui informado que os possíveis riscos da pesquisa estão relacionados ao cansaço físico da criança em realizar os itens propostos pela pesquisadora, ao fato da criança chorar durante a avaliação como forma de manifestar a sua não participação no projeto de pesquisa e/ou alterações de sinais vitais, tais como temperatura corporal, freqüência respiratória, freqüência cardíaca e coloração da pele. Caso a criança apresente alguns destes sinais e sintomas o pesquisador deverá interromper o procedimento de avaliação e tomar as providências necessárias para os cuidados que garantam a integridade física e mental da criança. Havendo a necessidade de interromper a avaliação, fui informado que o pesquisador deverá remarcar outro encontro para complementar os dados.

Considerando os possíveis riscos supracitados, verifica-se que o risco se justifique pela importância do benefício esperado com os resultados do trabalho. Além disso, estou informada de que a pesquisadora assume a responsabilidade de dar assistência integral às complicações e danos decorrentes dos riscos previstos.

\section{Seguro saúde ou de vida:}

Eu entendo que não existe nenhum tipo de seguro de saúde ou de vida que possa vir a me beneficiar em função de minha participação neste estudo.

\section{Liberdade de participação:}

A minha participação neste estudo é voluntária. É meu direito interromper a participação de meu (minha) filho(a) a qualquer momento sem que isto incorra em qualquer penalidade ou prejuízo. Também entendo que as pesquisadoras têm o direito de excluir do estudo o(a) meu(minha) filho(a) a qualquer momento. 


\section{Sigilo de identidade:}

A responsável por este estudo me explicou das necessidades da pesquisa e se prontificaram a responder todas as questões sobre a avaliação. Eu estou de acordo com a participação de meu (minha) filho(a) no estudo de livre e espontânea vontade e entendo a relevância dele. Julgo que é meu direito manter uma cópia deste consentimento.

Compreendo e concordo que as informações divulgadas e/ou publicadas, ressaltandose a garantia de que a identidade de meu filho(a) e de minha família, serão preservadas e mantidas sob sigilo.

Para questões relacionadas a este estudo entre em contato com:

Cibelle Kayenne Martins Roberto Formiga

(62) 261-8127 (residência)

(62) $9996-5123$ (celular) de. de 


\title{
ANEXO B
}

\section{HOSPITAL GERAL DE GOIÂNIA CEPHA}

Comitê de Ética em Pesquisa

Humana e Animal

Goiånia, 05 de julho de 2004.

\section{PROTOCOLO CEPHA-HGG NN 73/04}

Investigador Responsável: Cibelle Kayene Martins Roberto Formiga

Título: "Programa de Follow-up do desenvolvimento do bebé de risco".

\begin{abstract}
CARTA DE APROVAÇĀO
Informamos que o Comits de Etica em Pesquisa Humana - Animal CEPHA-HGG, analisou e aprovou o protocolo de pesquisa $n^{\circ}$.73/04, bem como o Termo de Consentimento Livre e Esclarecido, - estes foram considerados em acordo com os
\end{abstract} principios éticos vigentes.

Lembramos ao investigador a necessidade de enviar um relatório ao CEPHA. HGG ao término da pesquisa.

Atenciosamente,

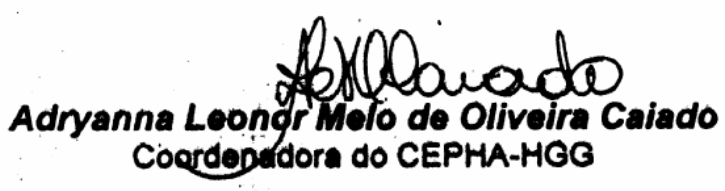

Hoopltal Coral de Collinia - Dr. Nberto Raeel

Av. Anhanguera n'6479 - et. Oente Coilinia - $\infty$ - Cep.: 74043-011

Tone: (62) 221-6116 - PNX: (62) 221-6012 


\section{ANEXO C}

\section{ROTEIRO DE ANAMNESE}

Data da avaliação:

$\mathrm{N}^{\circ}$ de registro:

\section{DADOS GERAIS DO RECÉM-NASCIDO}

Nome:

Idade:

Data de Nascimento: Sexo:

Cor:

Nome da Mãe:

Idade: Endereço:

Telefone:

\section{DADOS MATERNOS - CONDIÇÕES DE GESTAÇÃO}

Gestações: Paridade:

Aborto:

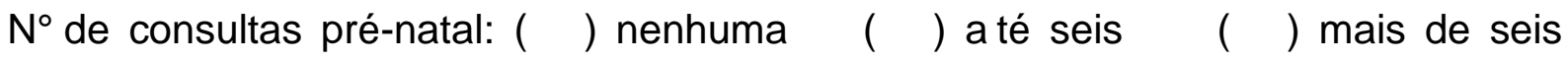
Local:

Doenças Maternas Pré-existentes:

Complicações durante a gestação: $($ ) nenhuma ( ) sangramentos ( ) infecções

( ) hipertensão arterial ( ) diabetes ( ) bolsa rota ( ) anemia ( ) outras: 
O bebê foi planejado? ( ) não ( ) sim

Quantos meses de gestação você estava quando soube que estava grávida?

Tabagismo: ( ) não ( ) sim Há quanto tempo?

Enjoou? ( ) não ( ) sim . Quanto tempo?

Vomitou? ( ) não ( ) sim . Quanto tempo?

Fez exames de radiografia? ( ) não ( ) sim Que tipo?

Fez ultra-som? ( ) não ( ) sim Em que mês (es)?

Teve acidentes durante a gravidez? ( ) não ( ) sim Quando?

A gravidez foi tranqüila? ( ) sim ( ) não O que aconteceu?

\section{DADOS DO PARTO}

Tempo de rotura das membranas: Sinais de sofrimento fetal? ( ) sim ( ) não

Tipo de gestação: ( ) única ( ) dupla ( ) tríplice $\quad($ ) mais de três Tipo de Parto: ( ) Normal - apresentação ( ) Induzido ( ) Cesárea ( ) 


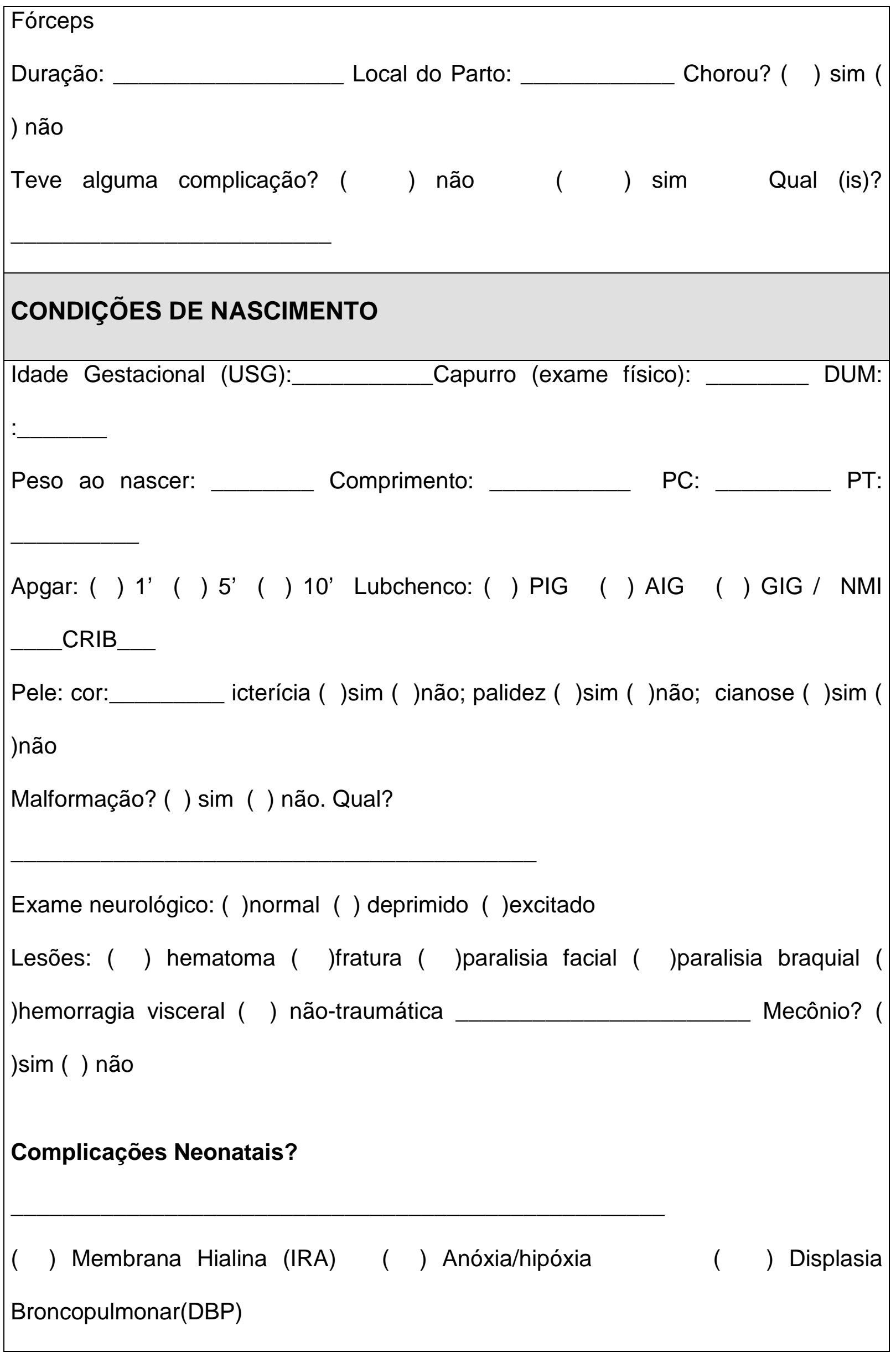




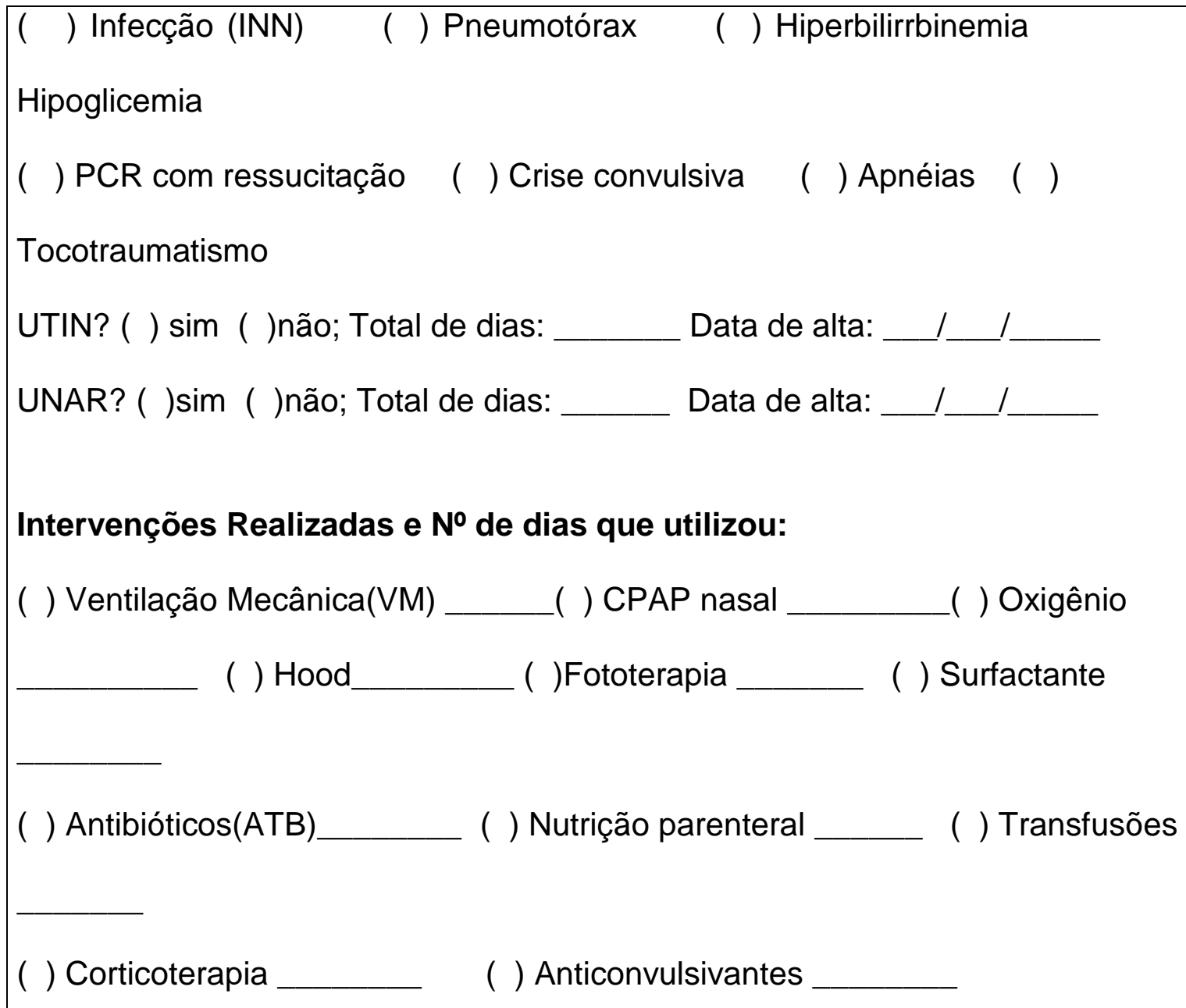

Alimentação na UTIN ou UNAR e № de dias que utilizou:

( ) sonda ( ) seringa ( ) copinho ( ) seio materno

Permanência no Berçário? ( ) não （ ) sim. Quantos dias?

Data de alta hospitalar: Condições de alta hospitalar:

USG transfontanela: Data: Resultados: 
Observações 


\section{ANEXO D}

Protocolo do Questionário ABEP (Associação Brasileira de Empresas de Pesquisa)

Nome:

Data:

Nome da Mãe:

Código:

Dados de Classificação

1. Quem é o chefe da família na sua casa?

2. Grau de instrução do chefe da família

\begin{tabular}{|l|c|}
\hline Analfabeto / Primário incompleto & 0 \\
\hline Primário completo / Ginasial incompleto & 1 \\
\hline Ginasial completo / Colegial incompleto & 2 \\
\hline Colegial completo / Superior incompleto & 3 \\
\hline Superior completo & 5 \\
\hline
\end{tabular}

3. Posse de itens

\begin{tabular}{|l|c|c|c|c|c|}
\hline \multirow{2}{*}{ Itens } & \multicolumn{5}{|c|}{ Quantidade de itens } \\
\cline { 2 - 6 } & 0 & 1 & 2 & 3 & 4 ou + \\
\hline Televisão em cores & 0 & 2 & 3 & 4 & 5 \\
\hline Rádio & 0 & 1 & 2 & 3 & 4 \\
\hline Banheiro & 0 & 2 & 3 & 4 & 4 \\
\hline Automóvel & 0 & 2 & 4 & 5 & 5 \\
\hline
\end{tabular}




\begin{tabular}{|l|c|c|c|c|c|}
\hline Empregada mensalista & 0 & 2 & 4 & 4 & 4 \\
\hline Aspirador de pó & 0 & 1 & 1 & 1 & 1 \\
\hline Máquina de lavar & 0 & 1 & 1 & 1 & 1 \\
\hline Videocassete e/ou DVD & 0 & 2 & 2 & 2 & 2 \\
\hline Geladeira & 0 & 2 & 2 & 2 & 2 \\
\hline Freezer (aparelho independente & 0 & 1 & 1 & 1 & 1 \\
ou parte da geladeira duplex) & & & & & \\
\hline
\end{tabular}

Total de pontos:

4. Classes econômicas -

\begin{tabular}{|c|c|}
\hline Classe & Pontos \\
\hline A1 & $30-34$ \\
\hline A2 & $25-29$ \\
\hline B1 & $21-24$ \\
\hline B2 & $17-20$ \\
\hline C & $11-16$ \\
\hline D & $6-10$ \\
\hline E & $0-5$ \\
\hline
\end{tabular}




\section{ANEXO E}

\section{Questionário Sócio-econômico}

Nome da Mãe/Pai:

Idade:

Data de Nascimento:

Cor:

Profissão:

Número de Filhos: ( ) nascidos vivos. Idades:

( ) nascidos mortos ( ) abortos

Responsáveis pela criança: ( ) pais ( ) só pai ( ) só mãe ( ) pais adotivos ( ) outros

Qual seu nível de escolaridade?

\begin{tabular}{|c|c|}
\hline $\begin{array}{l}\text { (__ nenhuma instrução } \\
\text { (__ ensino fundamental incompleto } \\
\text { (__ ensino fundamental completo } \\
\text { (__ ensino médio incompleto }\end{array}$ & $\begin{array}{l}\text { (__ ensino médio completo } \\
\left(\_ \text {) ensino superior incompleto }\right. \\
\left(\_ \text {) ensino superior completo }\right. \\
\left(\_ \text {) pós-graduação }\right.\end{array}$ \\
\hline
\end{tabular}

\begin{tabular}{|c|c|}
\hline Qual seu estado civil? & Onde reside atualmente? \\
$\left(\_\right.$) solteira & $\left(\_\right.$Goiânia \\
$\left(\_\right.$(_ Casada & Cidade interior (Goiás) \\
$\left(\_\right.$) Viúva & $\left(\_\right.$Capital de outros Estados \\
$\left(\_\right.$) Interior de outros Estados \\
\hline
\end{tabular}

Qual o tipo de residência de sua família?

\begin{tabular}{|c|c|}
\hline $\begin{array}{l}\text { (_ }) \text { Própria } \\
\left(\_ \text {Alugada }\right.\end{array}$ & \begin{tabular}{|l}
$\left(\_\right)$Cedida \\
$\left(\_\right.$) Outros
\end{tabular} \\
\hline $\begin{array}{l}\text { Tipo de construção: ( )casa d } \\
\text { Tipo de piso: ( )cimento ( } \\
\text { Número de cômodos na casa: } \\
\text { Beneficiamento: ( )água, luz } \\
\text { Equipamentos em casa: ( )re } \\
\text { ( )som ( )liquidificador ( ) } \\
\text { ( )ar condicionado ( )telefone } \\
\text { Que meio de transporte você }\end{array}$ & $\begin{array}{l}\text { ( )casa de madeira ( )edifício } \\
\text { ( )taco ( )Outro } \\
\text { quartos: } \\
\text { água e luz ( )luz ( ) } \mathrm{N}^{\circ} \text { de banheiros } \\
\text { )fogão ( )máquina de lavar ( )TV } \\
\text { o de passar ( )ventilador } \\
\text { ( )outro. }\end{array}$ \\
\hline $\begin{array}{l}\text { (__ carro próprio } \\
\text { (__ carro da família } \\
\left(\_ \text {) coletivo }\right.\end{array}$ & $\begin{array}{l}\text { (__ }) \text { moto } \\
\text { (__ outros meios }\end{array}$ \\
\hline
\end{tabular}

Quantas pessoas contribuem para obtenção de renda da sua família?

\begin{tabular}{|l|l|l|}
\hline $\begin{array}{l}\left(\_\right) \text {uma } \\
\left(\_\right) \text {duas }\end{array}$ & $\begin{array}{l}\left(\_\right) \text {três a quatro } \\
\left(\_\right) \text {cinco a seis }\end{array}$ & $\left(\_\right.$mais de seis \\
\hline
\end{tabular}

Quantas pessoas vivem da renda mensal de seu grupo familiar?

\begin{tabular}{|l|l|l|}
\hline$\left(\_\right)$uma & $\begin{array}{l}\left(\_\right) \text {três a quatro } \\
\left(\_\right. \\
\left(\_\right) \text {cinco a seis }\end{array}$ & $\left({ }_{-}\right)$acima de sete \\
\hline
\end{tabular}

Qual o seu salário?

\begin{tabular}{|c|c|c|}
\hline $\begin{array}{l}\text { (__ nenhum } \\
\left(\_ \text {) }<\text { salário mínimo }\right.\end{array}$ & $\begin{array}{l}\text { (__ um salário mínimo } \\
\text { (__ 2-3 salários mínimos }\end{array}$ & $\begin{array}{l}\text { (__ 4-6 salários mínimos } \\
\text { (__ 7-9 salários mínimos } \\
\left(\_ \text {__ } 10 \mathrm{ou}+\text { salários }\right. \\
\text { mínimos }\end{array}$ \\
\hline
\end{tabular}

Qual a renda mensal de seu grupo familiar?

\begin{tabular}{|c|c|c|}
\hline (__ 1 salário mín & (__ 4-5 salários mínimos & 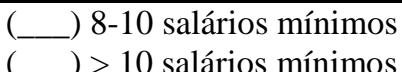 \\
\hline
\end{tabular}

Qual é a sua participação na vida econômica familiar?

( $\quad$ não trabalho

(__ trabalho, mas recebo ajuda financeira da família ou de outras pessoas.

(__ trabalho para meu próprio sustento

(__ t trabalho, sou responsável pelo meu sustento e contribuo parcialmente para o sustento da família

(__ ) trabalho e sou o principal responsável pelo sustento da família.

Assistência à saúde: Plano de saúde ( )não ( ) sim. Qual?

Qual o meio de comunicação que você mais utiliza para se manter informado?

\begin{tabular}{|c|c|c|}
\hline $\begin{array}{l}\text { (__ jornal falado (TV) } \\
\text { (__ jornal falado (rádio) }\end{array}$ & $\begin{array}{l}\text { (__ Internet } \\
\text { (_ Revistas }\end{array}$ & (__ outras fontes \\
\hline
\end{tabular}


Há fumantes na Casa? ( )não ( ) sim Quem?

Presença de animais domésticos? ( )não ( )sim. Qual? 